\title{
Allocation of resources and support: novice and experienced French as a Second Language (FSL) teachers in Ontario
}

by

Megan Elizabeth Ouellette

A thesis submitted to the Faculty of Graduate and Postdoctoral Affairs in partial fulfillment of the requirements for the degree of

Master of Arts

in

Applied Linguistics and Discourse Studies

Carleton University

Ottawa, Ontario

(C) 2020, Megan Elizabeth Ouellette 


\begin{abstract}
At the inception of the Canadian French as a Second Language (FSL) program, researchers primarily examined students' success (e.g. Cummins, 1998; Tardiff, 1990). However, there has been increasing focus on FSL teacher perspectives (e.g. Arnott, 2017; Salvatori, 2009). This qualitative study used a narrative inquiry method and semi-structured interviews to investigate six novice and experienced (i.e., based on years of experience) FSL teacher participants' accounts of the allocation of resources and support for their FSL teaching. Narrative inquiry allowed for a richly detailed understanding of the teachers' accounts of their practice. Results suggest that the novice teacher participants received more resources and support than the experienced teachers, based on the assumption that they were more willing to learn new teaching practices and in greater need. Ironically, this study suggests that the experienced teachers were very willing to adopt new strategies, and their need for resources and support was equally great.
\end{abstract}




\section{Acknowledgements}

Throughout writing this thesis, I have received a tremendous amount of support and assistance.

I would first like to pay special regard to my supervisor, Professor Janna Fox, whose expertise was invaluable in formulating my methodology. Your helpful feedback not only sharpened my writing, but also my thinking, which brought my work to a higher level. It is tremendously appreciated that your great advice for my study proved monumental in the success of this study.

I would like to express my deep gratitude to those in my cohort, who were incredibly supportive. They acted as a useful sounding board to further develop certain aspects of my thesis.

I wish to acknowledge the support and love from my family, my partner, Chris; and, my mother, Laura. They kept me going and this work would not have been possible. I wish to dedicate my work to my late grandmother, Faye, who was unable to pursue her goal of becoming a teacher herself, but she instilled the importance of education and teachers' value.

I would like to recognize the invaluable assistance that everyone provided to my study. 


\section{Table of Contents}

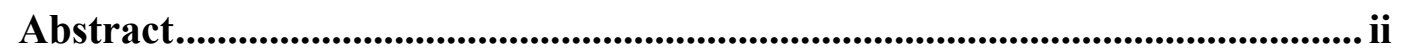

Acknowledgements ............................................................................................. iii

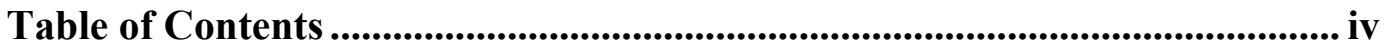

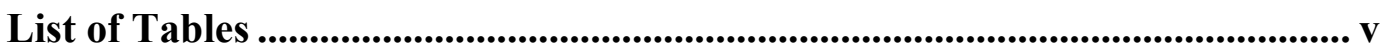

List of Illustrations....................................................................................... vi

List of Appendices........................................................................................................ vii

Chapter 1: Introduction ................................................................................................. 1

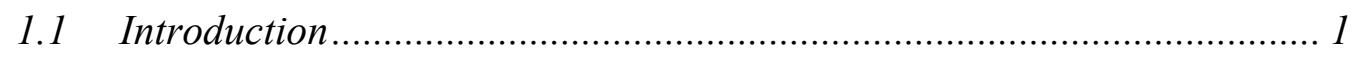

1.1.1 Description of the FSL Program ............................................... 3

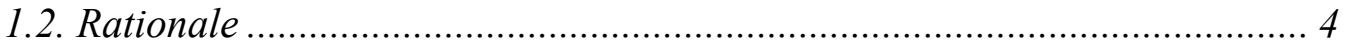

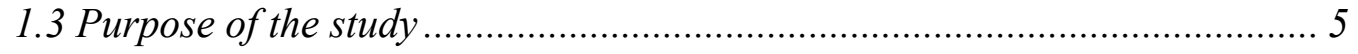

1.3.1 Research questions ..................................................................... 5

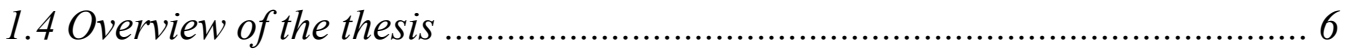

Chapter 2: Literature Review ................................................................... 7

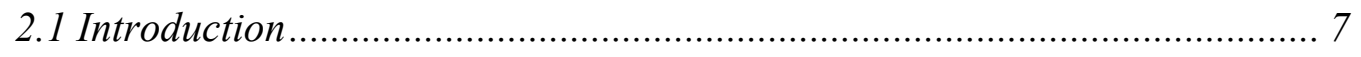

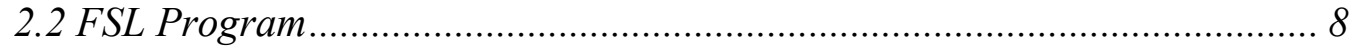

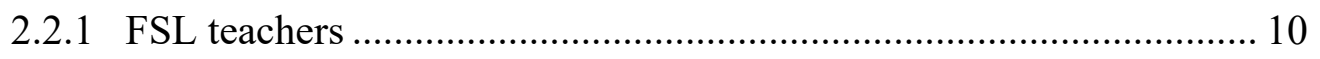




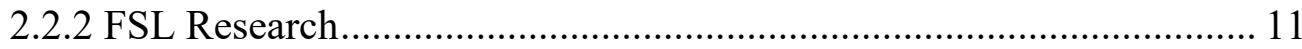

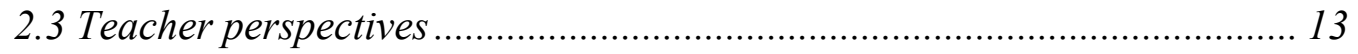

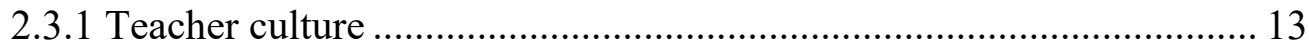

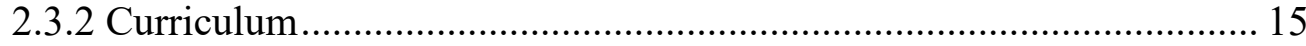

2.3.3. Teacher professional development versus professional learning ........ 17

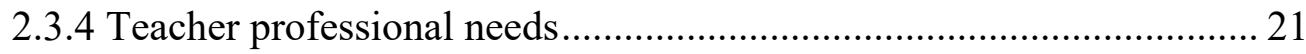

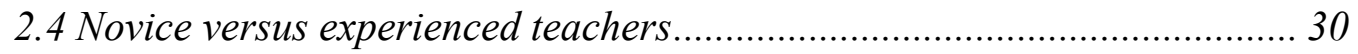

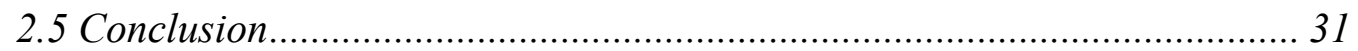

Chapter 3: Methodology...................................................................................... 32

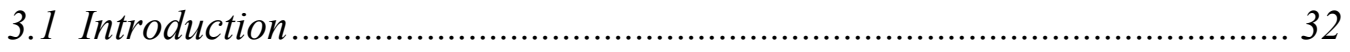

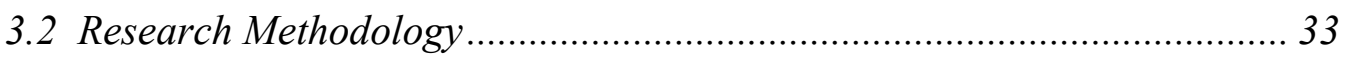

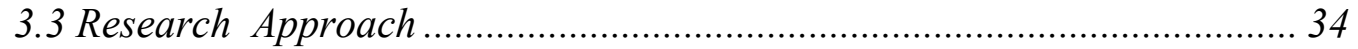

3.4 Method

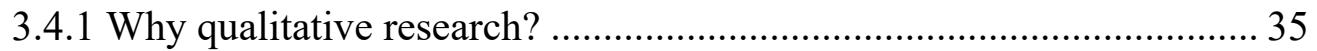

3.4.2 Overview: why I chose narrative inquiry for my study ......................... 35

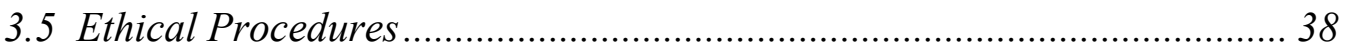

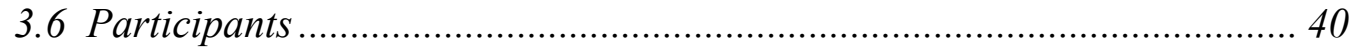

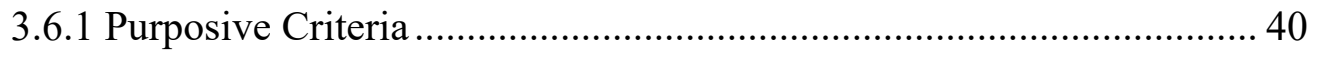

3.6.2 Participant descriptions ........................................................................ 40

Table 3.1 Participant Descriptions .............................................................. 42

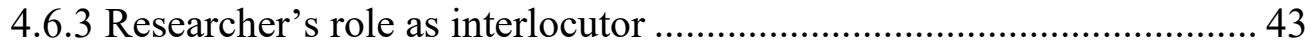


3.7 Procedure 44

3.8 Analysis 45

3.9 Conclusion. 47

Chapter 4: Findings and Discussion....................................................................... 48

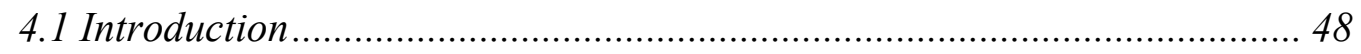

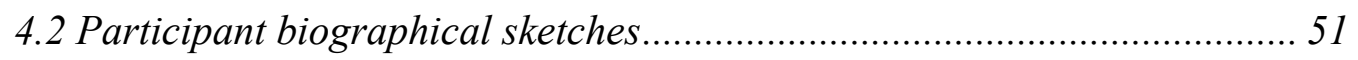

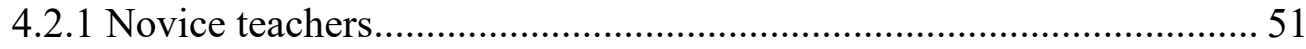

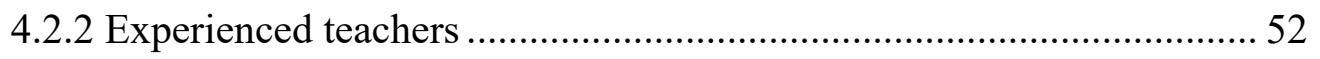

4.3 From codes to categories to themes: analysis of the participants

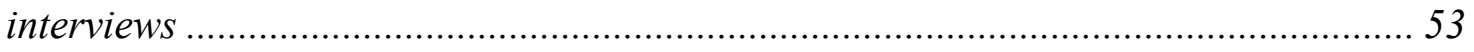

4.4 Interpretation of the Ontario written curriculum for FSL teachers............. 54

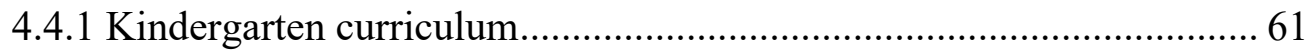

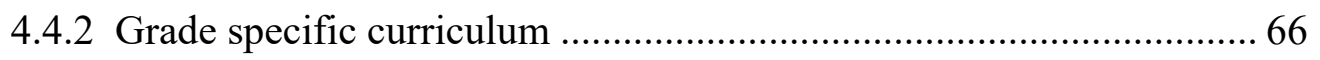

4.5 Resources and support for FSL teachers ................................................ 70

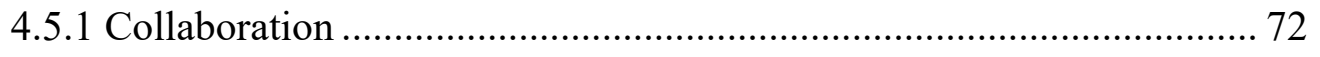

4.5.2 Teacher professional development ……………................................ 75

4.5.2.1 Teacher professional needs........................................................... 78

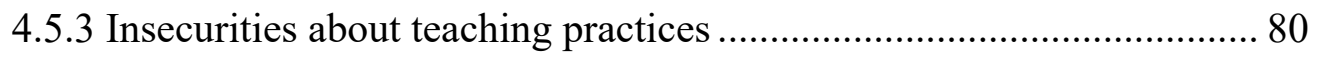

4.5.3 Classroom environment ........................................................................ 83

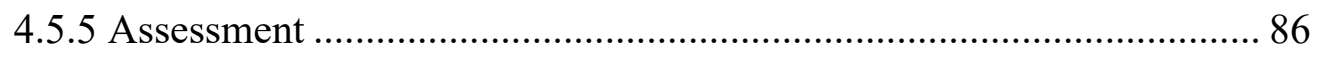

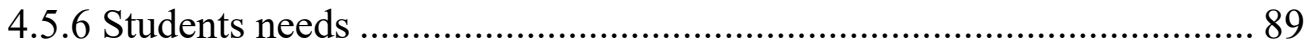


Chapter 5: Conclusion .................................................................................... 101

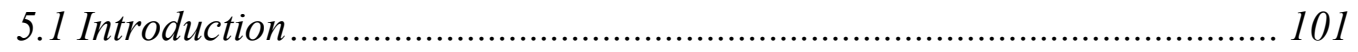

5.2 Summarizing Findings.................................................................. 102

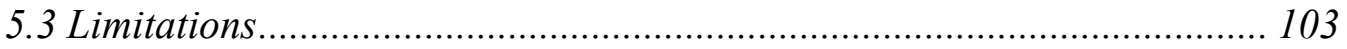

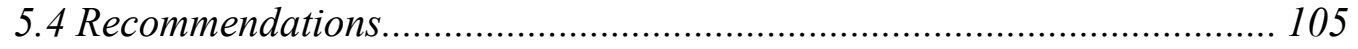

5.5 Final Remarks .................................................................................. 107

References................................................................................................................ 109

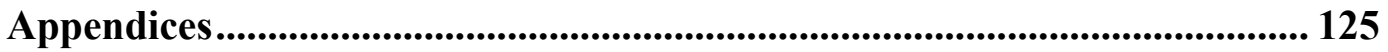

Appendix A - Ethics Protocol ........................................................... 125

Appendix B Interviews.................................................................. 134

Appendix C - Example of coding Example of Interim Text......................... 140

Appendix D - Intercoder reliability ..................................................... 144 


\section{List of Tables}

Table 3.1 Participant descriptions........................ p.42

Table 4.1 Magnitude coding.............................. p.96 


\section{List of Illustrations}

Figure 4.1 - Curriculum...................................... 55

Figure 4.2 - Desire for concrete guidelines....................... 58

Figure 4.3 - Frustration...................................... 59

Figure 4.4 - Dissatisfaction.................................. 63

Figure 4.5 - Self-doubt......................................... 82

Figure 4.6 - Classroom environment.......................... 83

Figure 4.7 - Assessment...................................... 87

Figure $4.8-$ Students needs $\ldots \ldots \ldots \ldots \ldots \ldots \ldots \ldots \ldots \ldots \ldots \ldots \ldots \ldots \ldots 1$

Figure 4.9 - Magnitude coding $\ldots \ldots \ldots \ldots \ldots \ldots \ldots \ldots \ldots \ldots \ldots \ldots \ldots . \ldots \ldots$ 


\section{List of Appendices}

Appendix A - Ethics Protocols.............................. 125

Appendix B - Interviews................................ 134

Appendix C - Example of coding.......................... 140

Appendix D - Intercoder reliability......................... 144 


\section{Chapter 1: Introduction}

\subsection{Introduction}

At the onset of the FSL program in Canada, research focused on student success during the widespread implementation in primary, secondary, and tertiary levels of schooling (Cummins, 1998; Fortune, 2011; Mady, 2007; Tardiff, 1990; Turnbull \& Dailey-O’Cain, 2009). However, some research has focused on the implementation of FSL programs in Ontario (Burger, Weinberg, Hall, Movassat \& Hope, 2011). There are three different FSL programs available in Ontario, which are Core French (CF), Extended French (EF) and French Immersion (FI). FSL research in Ontario particularly focused on the CF or FI programs (Cummins, 1998).

With Ontario having the highest enrolment of FI (Office of the Commissioner of Official Languages, 2019), there is a high demand of FSL teachers. In several cases, school boards reported difficulty with finding qualified teachers (Karsenti, Collin, Villeneuve, Dumouchel, \& Roy, 2008; Salvatori, 2009; OCOL, 2019). Studies have mentioned that there is a lack of qualified teachers to fulfill the growing needs in the FSL program (Arnett \& Mady, 2018; Cooke \& Faez, 2018; Jack \& Nyman, 2019; Karsenti et al., 2008; Salvatori, 2009). Teacher qualifications are governed by the Ontario College of Teachers (OCT). FSL teachers are expected to complete the same qualifications as their English colleagues along with additional qualifications in FSL pedagogy (Cloutier, 2018; Jack \& Nyman, 2019). In cases where a school was unable to assign a qualified 
FSL teacher, unqualified teachers are given special temporary considerations to instruct a class.

Several studies have focused on the teacher retention problem (Karsenti et al., 2008; Salvatori, 2009; Salvatori \& MacFarlane, 2009), which attributed to a growing body of research interested in teacher culture in FSL research. Teacher culture as noted above was highlighted by Hargreaves (1989), who argued that "patterns of thinking, belief, and assumption are so widely shared among the community of teachers, that they might amount to what might be called a broad occupational culture of teaching..., [which] seriously inhibits practical curriculum change at school and classroom level” (p.54). Black and Wiliam (2010) expanded Hargreaves concerns by noting that teachers are not given adequate resources and training. While previous research has investigated areas for the improvement of FSL teaching conditions, it mainly focused on the needs of novice teachers (Karsenti, et al., 2008; Salvatori, 2009). For the purpose of this study, novice teachers are defined as educators who have at most 5 years of experience based on Vonk and Schras' (1987) induction period. Vonk and Schras (1987) considered the first seven years of teachers' classroom experience to be the induction period because they typically retain insecurities about their teaching practices, whereas, after the induction period, more experienced teachers have been known to feel more secure and confident about their teaching practices. In order to mitigate potential residual insecurities about their teaching practices, I defined experienced teachers as educators who have at least 10 years of teaching experience. 


\subsubsection{Description of the FSL Program}

The Ontario Ministry of Education (MoE) published several resources and guidelines, which are available on their website (https://www.ontario.ca/page/ministry-education). The Capacity Building series provided a general guide of FSL education in Ontario. Ontario MoE (2011) highlighted that the goal of the FI program is to develop students' proficiency in French in addition to mastering English. The FSL program was developed to add an additional language to students' repertoire. Ontario MoE (2011) further explained how English and FSL teachers were supposed to establish an integrated classroom with the intent for communication skills to be developed where one language supports and reinforced the other language.

The Ontario Ministry of Education has since published A Framework for French as a Second Language in Ontario Schools: Kindergarten to grade 12, which acknowledged the federal government's support to improve outcomes in FSL education (Ministry of Education, 2013a). The Canadian-Ontario Agreement on Minority Language Education and Second Official Language Instruction agreements established partnerships to enhance FSL and French minority language (FML) across the country (Ministry of Education, 2013a). Ontario MoE (2013a) acknowledged that French is an integral part of the Canadian identity and aims to equip students to communicate with French-speaking Canadians.

Ontario MoE (2013a) listed a series of goals that coincide with those of the Ontario curriculum for FSL programs. The first goal is to increase student 
confidence, proficiency, and achievement in FSL. The second goal is to increase the percentage of students studying FSL until graduation. The final goal is to increase student, educator, parent, and community engagement in FSL. The Ontario MoE provided teachers with several language policy and written curriculum documents (Ontario MoE, 2013a,2013b; Ontario MoE, 2014). There is never a guarantee that teachers will implement or interpret the curriculum as intended by policy makers or curriculum designers (Arnott, 2012; Black \& Wiliam, 2010). The differences in teaching practices can be accounted by teachers' beliefs, assumptions, and knowledge (BAK). Teachers' BAK guide their practices tacitly and/or explicitly (Woods, 1996).

\subsection{Rationale}

While I was enrolled in the Ontario publicly funded school system, I participated in the FSL program, where I obtained my FI certificate. After spending all those years from kindergarten to grade 12, I believed that my proficiency in French should have been more native-like. While enrolled in the program, I was frustrated with certain aspects of learning French. Due to the large class sizes and unmotivated teachers, the FSL program did not satisfy my needs as a student. It was evident that some of the FSL teachers were also frustrated with the large class, lack of resources and support. The mandated textbooks for classes such as the FSL history and geography classes were in disrepair.

During my secondary schooling, I was interested in becoming a teacher myself, so I inquired about my FSL teachers experiences and teaching conditions. I was fortunate to be taught by several novice teachers who were willing to share their 
lived experiences. While researching the FSL program and accompanying studies, I also became aware of the large number of novice teachers who leave the FSL program and the undersupply of trained FSL teachers to meet demands. This prompted my curiosity regarding FSL teachers' classroom experiences and teaching conditions.

\subsection{Purpose of the study}

The purpose of this study was to explore the allocation of resources and support for FSL novice and experienced teachers. Recently, there has been more research on FSL teachers' accounts of their needs and classroom experiences (e.g., Arnott, 2011; Lapkin et al., 2006). Some research (Karsenti \& Colin, 2013; Karsenti et al. 2008; Salvatori, 2009) has focused on the retention of novice FSL teachers, as many teachers leave the profession after the initial induction period. However, there appeared to be a gap specifically focusing on the differences between novice and experienced FSL teachers. While it is important to further explore why novice teachers are exiting the profession, I felt that experienced teachers' needs were not being as well researched. I was particularly interested in novice and experienced teachers' interpretations of the curriculum, their access to resources and support, and their accounts of their classroom experience. Therefore, for the purpose of this study, I interviewed six FSL teachers in Ontario regarding their interpretation of the Ontario MoE written curriculum, available resources and support, and their lived experiences as FSL teachers.

\subsubsection{Research questions}

1. How do FSL teachers interpret the Ontario Ministry of 
Education FSL Curriculum?

2. What resources and support are FSL teachers given?

3. Are there differences between FSL novice and experienced teachers?

\subsection{Overview of the thesis}

In response to the research questions, I conducted a qualitative research study, which resulted in interviewing six FSL teachers with varying years of experience and taught various FSL programs. In Chapter two, I review literature of relevance regarding teacher perspectives of curriculum and language policies, teacher culture, FSL research, teacher attrition and differences between novice and experienced teachers. In Chapter three, I review my research methodology and method. Following this, I discuss the participants, procedure and analysis. In Chapter four, I report my research findings, which are framed by my research questions. Finally, in Chapter five, I summarize my findings, discuss the research limitations, and recommendations for future research. 


\section{Chapter 2: Literature Review}

\subsection{Introduction}

In the previous chapter, I introduced the research background, research problem, purpose of the study and research questions. As discussed in the first chapter, French as a Second Language (FSL) researchers began with monitoring student success and retention as factors for determining the success of the FSL program (Burger, Weinberg, Hall, Movassat \& Hope, 2011; Cummins, 1998; Fortune, 2011; Mady, 2007; Tardiff, 1990; Turnbull \& Daily-O'Cain, 2009). Although, more recently, there has been a shift in FSL research, where FSL teachers have become the focus (Arnott 2012, 2017; Cooke \& Faez, 2018; Jack \& Nyman, 2019; Karsenti, Collin, Villeneuve, Dumouchel, \& Roy, 2008; Salvatori, 2009). While there have been improvements on FSL teachers centered research, there are still opportunities to further address teachers' professional needs.

In this chapter, I discuss research literature of relevance to my research questions, namely: How are FSL language policies and curriculum documents from the Ontario Ministry of Education interpreted by FSL teachers? What resources and support are FSL teachers given? Are there differences between FSL novice and experienced teachers? In the present study, novice teachers are defined as those with at most 5 years of experience based on Vonk and Schras' (1987) induction period. Vonk and Schras (1987) considered the first seven years of teachers' classroom experience to be the induction period because they typically retain insecurities about their teaching practices, whereas, after the induction period, more experienced teachers have been known to feel more secure and confident about their teaching practices. In order to mitigate potential residual insecurities about their teaching practices, I defined experienced teachers as educators who have at least 10 years of teaching experience.

In this chapter, I begin by discussing the FSL program in Ontario along with the 
respective curriculum documents, FSL teaching conditions and FSL research. Following the discussion on FSL research, I discuss teachers' perspectives on the following topics: curriculum, professional learning versus professional development, teacher professional needs assessment, inclusivity of English Language Learners (ELL)s, and the differences between novice and experienced teachers. As my research questions indicate, the emphasis in my thesis is on FSL teachers' perspectives, evident in their accounts of their teaching experiences and practices. However, it is important to situate their accounts within the larger FSL program.

\subsection{FSL Program}

As discussed in the previous chapter, in Canada, the delivery of education is a provincial responsibility, which in Ontario is governed by the Ontario Ministry of Education (MoE). The Ontario MoE allocates financial support to school boards based on various factors (Coutier, 2018) such as student enrollment and demographic within a school board jurisdiction. The Ontario MoE responsibilities are not limited to funding, but also include curriculum and policy development. In this regard, the Ontario MoE has developed multiple documents pertaining to curricular expectations for elementary (e.g., The Kindergarten Program, The Ontario Curriculum: French as a Second Language: Core, Grades 4-8; Extended, Grades 4-8; Immersion, Grades 1-8) and secondary schools (e.g., The Ontario Curriculum, Grades 9-12: Core, Extended, and Immersion French) as well as a document related to the inclusion of ELLs (e.g.., Welcoming English Language Learners into French as a Second Language Programs). According to Cloutier (2018) once a school board has received funding, the school board decides how to allocate the funds based on school specifications (e.g., student population and demographic) and required staff (e.g., teachers, librarians, education assistants, custodians, administrators). 
as well as whether administrator's background knowledge and experience can have an effect on the support. The participants in this 2018 study completed an online questionnaire with a selection of some participants completing interviews. Cloutier (2018) reported that "overall, school administrators reported being supportive of their FSL teachers" (p.63), which is positive considering FSL teachers have previously indicated that they felt unsupported by their school administration (Lapkin, MacFarlane, and Vandergift, 2006). Cloutier (2018) observed that "background knowledge and experience does occasionally impact the support reportedly provided by the school administrators in the study, the majority of the participants reported being supportive of their FSL teachers" (p.68). Cloutier (2018) argued that FSL not being taken seriously by stakeholders (e.g.., parents, school administrators) had resulted in poor teaching conditions. This finding is reinforced by other studies, which were focused on teacher perspectives of teaching conditions (e.g., Lapkin, MacFarlane, Vandergift, 2006; Karsenti et al., 2008).

Mady (2013) highlighted how administrators failed to advocate for ELL inclusion in FSL programs. Cloutier (2018) argued that the failure to advocate for ELLs' enrollment stems from administrators deeming the FSL program as not important enough to pursue. After Mady (2013) published her study, the Ontario MoE (2016) published a document on ELL inclusion in the FSL program, where the previously held negative views were acknowledged and where suggestions on how to integrate ELLs into the FSL program were provided.

Lapkin, et al. (2006) also found negative mindsets, which were evident in accounts of the lack of resources for FSL. In this study, Lapkin et al. (2006) surveyed FSL teachers regarding teaching conditions, teacher resources, support from stakeholders, support from administrators, and PD opportunities. Following the study, 
Lapkin and Barkaoui (2008) further investigated the results from Lapkin et al. (2006) with particular focus on FSL teachers' lived experiences in Ontario. Regarding classroom availability, 50\% of the Core French (CF) teacher participants reported that they used a cart rather than obtaining a stationary classroom. While these studies may be slightly outdated, the allocation of stationary classrooms was more recently mentioned in the Ontario's New Teacher Handbook (Canadian Association of Second Language Teachers, 2017).

\subsubsection{FSL teachers}

The Ontario College of Teachers (OCT) regulates the teaching profession in Ontario. Cloutier (2018) discussed how the OCT governs: (1) the standardized process of obtaining a teacher license; (2) the accreditation of universities who offer the Bachelor of Education program, which is required for candidates to complete prior to receiving their license; (3) the accreditation for institutions which offer Additional Qualifications and Additional Basic Qualification courses; (4) teachers with designated Ontario certified teaching status. The OCT provides several options for obtaining FSL teacher certification in Ontario. For teachers who have already obtained their teaching certification and are proficient in French, they can complete Additional Qualification courses to add another area of specialization to what they are already qualified to teach. Although, prior to completing their teaching degree, teachers can obtain their FSL teaching qualifications while completing their Bachelor of Education.

As noted above Cloutier (2018) investigated how school administrators support their FSL teachers, as well as whether administrator's background knowledge and experience can have an effect on how they provide support. Cloutier (2018) argued that FSL not being taken seriously by stakeholders can result in poor teaching conditions, which negatively impacts teacher retention. The research by Cloutier (2018) regarding 
school administrators reinforces findings from several other studies regarding teacher retention (Karsenti \& Colin, 2013; Karsenti et al., 2008; Salvatori, 2009).

OCOL (2019) conducted a survey where some school board interviewees noted that some FSL teachers may feel overworked and do not receive enough paid and professional development leave. FSL classes are also given less consideration for scheduling, resources, staffing and professional development (Lapkin, MacFarlane, \& Vandergift, 2006). When feeling overworked, experienced FSL teachers are less likely to consider mentoring their novice colleagues as they must already accommodate their various students' needs while lacking adequate support themselves (OCOL, 2019). Also, teacher retention studies have reported that the workload of FSL teachers was a factor in their decision to leave the profession (Karsenti et al., 2008; Salvatori, 2009).

\subsubsection{FSL Research}

At the beginning of this chapter, I noted that there appears to be a shift in FSL research, which has begun to focus on teacher practices and perspectives. Teachers' perspectives have recently become of more interest to researchers regarding topics such as instructional methods (Arnott, 2012, 2017; Faez, Majhanovich, Taylor, Smith, \& Crowley, 2011), ELLs in FSL programs (Arnett \& Mady, 2018; Mady, 2016), forms of assessment (Mison \& Jang, 2011), and teacher retention (Karsenti et al., 2008; OCOL, 2019). Previously, teachers were viewed negatively by researchers (Black \& Wiliam, 2010; Hargreaves, 1989; Lortie, 1977). Hargreaves (1989) discussed the concept of teacher culture, describing teachers as present-oriented, conservative and individualistic ...[and]...tend to avoid long-term planning and collaboration with their colleagues, and to resist involvement in whole school decision-making in favour of gaining marginal improvement in time to make resources their own individual classroom easier" (p.54). The systematic barriers imposed on teachers is what Lortie (1977) coined as the egg- 
crate structure model of education as a form of criticism regarding the school system. Schools segment teachers into isolated and insulated structures (e.g.., classrooms), which inhibits their ability to discuss issues, ideas, and solutions with collaborators who otherwise could provide support (Lortie, 1977). Hargreaves (1989) argued that "isolation is.... a product of the egg-crate...[divided]...teachers from one another...[making] comparison and collaboration between them difficult" (p.55). Following Hargreaves (1989) and Lortie (1977), the insulated nature of teachers' classrooms restrict collaboration among teachers, which contributes to the negative perception of teachers in research. The implications of their environment results in teachers being resistant to change and collaboration, which extends to collaborating with researchers.

Several researchers have advocated for more professional development (Masson, Arnott, \& Lapkin, 2018; Office of the Commissioner of Official Languages, 2019). For example, Masson, Arnott, \& Lapkin (2018) examined predominant trends in 21" Century FSL research. This 2018 edition of Canadian Parents for French: the state of French as a Second Language Education in Canada. reviewed "teacher perspectives and needs as well as approaches to teaching", which emphasized areas of professional development including "inclusive pedagogy, CEFR-informed practices, digital literacies and attitudes towards English Language Learners" (p.1). There were several guest commentaries that focused on these topics. For example, there was a contribution made by Joseph Dicks entitled, "Towards a common framework of reference for language teacher competence: supporting Language Teachers" (Masson, Arnott, \& Lapkin, 2018). Several other studies have incorporated teacher perspectives into their research through focus groups and interviews (Arnott, 2012, 2017; Faez et al., 2011; Freeman \& Richards, 1993). 
Masson et al. (2018) reported how most of the studies occurred in a French immersion (FI) setting and were focused on "teacher needs and perspectives to reporting outcomes of new initiatives that teachers' launched in their classroom," (p.4). Among the studies focused on teachers, Masson et al. (2018) noted that there was an emphasis on professional development, inclusive pedagogy, Common European Framework of Reference (CEFR)-informed teaching practices and attitudes towards ELLs. The CEFR is "the common reference levels and the illustrative descriptors" (Mison \& Jang, 2011, p.100). According to Masson et al., (2018), "[t]he CEFR is a set of benchmarks created to track the linguistic and cultural competencies language learners develop over time" (p.4). Upon reviewing teacher identities and language proficiencies, Masson et al. (2018) discussed how findings demonstrated that "FSL teachers are creative and resilient when faced with challenges in their school boards" (p.4). Based on their review of the literature on FSL teacher practices, Masson et al. (2018) remarked on how there was a shift in the focus of research from research-led professional development to teacher-led professional development. Teachers are leaders in education, they build close relationships with students, which allows the teachers to best determine what their students need.

\subsection{Teacher perspectives}

As previously discussed, FSL researchers have begun investigating FSL teacher perspectives, although, it is also important to investigate teacher culture for additional insights.

\subsubsection{Teacher culture}

Teachers can play many roles (e.g., syllabus designers, needs analysts, instructors) without receiving adequate training or resources (Black \& Wiliam, 2010; Brown, 1995; Cheng \& Fox, 2017). According to Black and Wiliam (2010), learning is driven by what occurs in the classroom, yet teachers are given increasingly larger classes with little 
guidance other than what is written in the curriculum. The research suggests that teachers have very little time to read, reflect, or collaborate with their fellow teachers in using curriculum documents, which are available to them as it relates to Lortie's observation about egg-crate teaching.

Connelly and Clandinin (1988) discussed the different views of the potential relationship between the terms practice and theory in education research. These disparate views have become a divisive topic among education researchers. Connelly and Clandinin (1988) argued that the field should examine ways to collaborate on problems that have arisen in research rather than dismissing views. By adopting the dialectic view, Connelly and Clandinin (1988) explained that extracting practical and theoretical knowledge through lived experiences, then assembling that knowledge, develops a more productive relationship between teachers and researchers. This process could be replicated in educational research by creating an open dialogue with a researcher who has previous teaching experience. The researcher could be a potential mediator for collaboration between researchers and teachers' views who otherwise might not align.

The dialectic view examines practice and educational theory as inseparable because practice is evidence of theory being explored by the intended recipients. Hollingsworth, Dybdahl, and Minarik (1993) demonstrated the productive relationship between researcher and teachers through a longitudinal study, where the participants were supported by the researcher through relational knowing. Relational knowing refers to "relational development as a primary way of knowing about teaching," (p. 6). Hollingsworth et al. (1993) claimed that:

It was intended to detail our learning through the support of rich, challenging, and sustained conversation, a passionate and political belief in ourselves and urban children as knowledge creators and evaluators, a willingness to create eclectic 
approaches to literacy characterized by relational integrity, and a propensity to look critically at children, each other, and ourselves in relationship to evaluate the results. This focus was not intended to diminish the additional importance of their cognitive/logical knowledge of teaching and learning. (p.30)

The study arose from the participants' problems with insufficient pre-service education due to their teaching environment. The participants did not develop the necessary skills to address their students' needs (Hollingsworth et al., 1993).

Lapkin et al. (2006) conducted a study surveying teacher perceptions and opinions regarding teaching resources, and other resources such as classrooms, consultants, French-speaking support staff, support from key stakeholders, teaching conditions and professional development. The participants responded that there was a lack of funding for activities and available consultants to help with learning difficulties. The participants noted that the diversity of student needs was the most prevalent challenge. The results indicated that the teachers were working with students who had varying French proficiencies, the most challenging for teachers being second language (L2) ELLs, and students with learning difficulties.

\subsubsection{Curriculum}

A curriculum is a document that lists expectations in what should be taught to students (Hainer-Violand, 2013). Depending on the country, there can be both top-down and bottom-up curriculum documents (Hainer-Violand, 2013). In Canada, top-down curriculum documents are mandated by the province, which describe academic expectations. There are two different types of top-down curriculum: one with a flexible curriculum, and one with a non-flexible curriculum. In a flexible top-down curriculum, teachers can develop resources based on the curricular expectations. Teachers are also allowed to develop lesson plans with the guidance from outside organizations. Teachers 
are given autonomy to teach students without being constrained by specific materials.

The teachers are creating and developing resources based on their students' needs while meeting standards mandated by the governing body (Hainer-Violand, 2013). In non- flexible top-down curriculum, teachers are expected to teach all the requirements from the curriculum along with using the mandated accompanying materials. Teachers are expected to implement content and skills. This approach to curriculum is deskilling teachers because they are unable to teach based on their beliefs, assumptions and knowledge (BAK). Teachers were once considered curriculum designers but are now curriculum implementers of institutional strategies and content (Cochran-Smith \& Lytle, 2006; Hainer-Violand, 2013).

Bottom-up curriculum documents are planned by the teacher around the students' skill levels and needs (Aoki, 2005; Hainer-Violand, 2013). In bottom-up curriculum documents, curriculum is not limited to content and skills. Curriculum also encompasses relationships and an environment that teachers foster with their students (Hainer-Violand, 2013). With bottom-up curriculum, teachers are able to develop their skills through collaboration with their colleagues, where they can share lesson plans and materials along with evaluating the effectiveness.

2.3.2.1 Flexibility with the curriculum. Hainer-Violand (2013) highlighted the Cesar Chavez bilingual program where $50 \%$ of the content is taught in Spanish, while the other $50 \%$ is taught in English. Teachers in the program are given the flexibility to create a curriculum that addressed student needs (Hainer-Violand, 2013). Teachers are expected to comply with the district requirements for testing and teacher evaluations. In the program, teachers are required to display the lesson's objective for the class along with displaying the standards achieved on students' work (Hainer-Violand, 2013). This technique is relatively similar to the CEFR can-do statements, where teachers' present a 
list of can-do statements that demonstrate the benchmarks for achieving a certain proficiency in a language (Mison \& Jang, 2011; Picardo, North, \& Maldina, 2019).

Having discussed teachers' perspectives of curriculum, in the following section, I discuss professional development and professional learning.

\subsubsection{Teacher professional development versus professional learning}

In this section, I discuss the differences between professional development and professional learning drawn in literature regarding in-service support for teacher development. The purpose of teacher professional development and learning is to improve teaching practices for the benefit of student learning (Pedder \& Opfer, 2013; Masson, 2018). It should be acknowledged that there is a difference between professional learning and professional development. Professional development occurs when teachers are mandated to learn about a new theory or activity but are not consulted about their knowledge base or specific needs (Hainer-Violand, 2013; Cordova, 2014; WebsterWright, 2009). Opfer and Pedder (2011) discussed how professional development activities at workshops often yield disappointing results and are deemed ineffective. The activities fail to achieve their goals because, in part, developers do not recognize that professional learning is a complex and recursive process embedded in lived experiences in classroom practices. Opfer and Pedder (2011) claimed that developers have focused on the programs and activities without incorporating teaching and learning environments. While teachers are mandated to implement activities and programs (e.g., Portfolio Based Language Assessment (PBLA) for Language Instruction for Newcomers to Canada (LINC)) learned during professional development (PD) days (Fox, 2014), there is no guarantee that it will be included in their teaching practices (Coburn, 2004; Grossman, 2010; Meyer \& Rowan, 1977; Hinnant-Crawford, 2016). When teachers are not given agency in how they are being trained and what they can teach in the classroom, teachers 
can demonstrate their agency by leaving the program or workforce (Hainer-Violand, 2013; Ingersoll, 2004).

Unlike professional development, professional learning is teacher-led where they research a topic or find out where their knowledge potentially is lacking through collaborative inquiry (Cordova, 2014). The nature of professional learning is often misunderstood by researchers because they misinterpret or underplay its complexity Opfer and Pedder (2011). According to Opfer and Pedder (2011), researchers often focus on individual teachers rather than influences from schools, school boards, and Ministry of Education. Opfer and Pedder (2011) argued that acknowledging the complexity of teacher learning in research could lead to the development of more effective professional development activities.

Pedder and Opfer (2013) analyzed data from a nation-wide survey conducted in England from primary and secondary school teachers. Pedder and Opfer (2013) were particularly interested in examining "evidence of patterns...between professional learning practices and reported teacher values" (p.545). Teachers responded to a four-point Likert scale asking about teaching practices and the importance of learning opportunities. Five groups of teachers emerged: 'engaged learner', 'moderate learners', 'infrequent learners', 'individual explorers', and 'solitary classroom learners.' Among the five groupings, individual explorers were the most prevalent, whereas, engaged learners were a minority. This finding supports Hargreaves' interpretation of teacher culture, where teachers are viewed as individualistic rather than collaborative. Pedder and Opfer (2013) recommended supporting collaboration to promote effective professional learning. 
Along with investigating professional learning, there has been a growing body of literature interested in different stakeholders' perspectives of FSL language policies and curriculum documents. While many stakeholders, such as principals and parents, have an impact on student learning, teachers have the most influence because they ultimately decide how the curriculum is implemented.

Arnott (2011) conducted a case study on how CF teachers adopted the Accelerative Integrated Method (AIM) during its implementation by examining "its use in multiple contexts" (p.160). According to Arnott (2017), AIM is "a method combining exclusive target language use with emblematic gestures" (p. 259). Arnott (2011) recruited eight participants, who were each interviewed four times. The participants "seemed to consider AIM to be a pragmatic resource for their pedagogy" in deciding which procedures best fit the needs of their classroom (p.170). The findings demonstrated how flexible teachers can become based on student needs. Although, this study did not specifically investigate novice versus experienced teachers, Arnott (2011) reported that years of experience made a difference in how AIM was utilized. "While some AIM routines, activities, and strategies were implemented by all, the participating teachers also exercised their agency while using AIM, especially those with more CF teaching experience in general, and those with more AIM experience in particular" (p.172).

Arnott (2017) presented a second language (L2) perspective on micro-policy implementation and pedagogical change. The purpose of the article was to investigate the experiences and perspectives of Canadian teachers and administrators as they implemented a new teaching method called the Accelerated Integrated Method (AIM). Arnott (2017) was also interested in decisions related to its use. AIM combines exclusive target language use with emblematic gestures, choral activity, and drama among other strategies. Arnott (2017) relied on Michael Fullan's framework to understand whether 
AIM provides "meaningful" educational change. Arnott (2017) compared educator perspectives across two contexts: (1) AIM was mandated for elementary FSL teachers to use core French, and (2) AIM was an optional method for CF teachers to use. The participants consisted of 40 stakeholders from various positions relating to FSL education (FSL consultants, Ministry of Education representatives, AIM teachers, nonAIM teachers and principals). Arnott (2017) adopted a mixed-methods research where the participants were asked to complete. According to Arnott (2012), Fullan's framework indicated that it was developed "a conceptual framework to better understand the dynamics of 'meaningful' educational change" after observing numerous "failures of innovations and reforms in educational systems" (p.45). This involves "top-down and bottom-up initiatives" to come together (Arnott, 2012, p.46). Other stakeholders were asked questions about accompanying resources, decisions related to AIM in their context role of local and external agents in its implementation, the usefulness of AIM in elementary and its overall effectiveness (Arnott, 2017). The rationale for this study was to investigate what made each of the mandated and optional contexts unique and to note areas of convergence and divergence (Arnott (2017). A point of convergence was how the use of AIM had the potential to help CF teachers make French the language of the classroom and develop students' oral French fluency, which underscores the need to implement classroom-based ideas to improve CF programming. There were several points of divergence for the participants, which were related to the utility of AIM across the immediate grade levels and teacher agency. According to Arnott (2017), the participants opinions diverged "related to the utility of AIM across intermediate grade levels, teacher agency, and collaborative monitoring” (p. 276). Arnott (2017) demonstrated how teachers impact how a policy is implemented and how the policies might not satisfy the needs of the class 


\subsubsection{Teacher professional needs}

With focus on teachers' professional needs, several studies have investigated teacher retention (Karsenti \& Collin, 2013; Karsenti et al., 2008; Salvatori, 2009). The purpose of studying teacher retention was to highlight areas of improvement for teaching conditions. Karsenti et al. (2008) conducted a survey "to better understand why new French [I]mmersion teachers are leaving the profession in the first few years of service," (p.7). The survey examined why new teachers are leaving the profession, their level of satisfaction with the teaching, what opportunities new teachers have to collaborate, the relationship between their professional aspirations and their departure, who do new teachers ask for help when problems arise, and what can schools do to help new teachers (Karsenti et al., 2008). Upon analysis of participants' responses, Karsenti et al. (2008) reported five factor groups for teacher drop out such as "difficult work conditions inherent in French immersion and [FSL] teaching; lack of instructional materials (particularly immersion programs); inherent challenges in the relational aspect of teaching; underlying problems with classroom management and sometimes difficult clientele; and initial training and career choice of the drop-out" (p.57). Karsenti et al. (2008) recommended "better support in general and administrative support in particular as well as university training... and more instructional materials" (p.59). The lack of resources has been noted in several additional studies as a main issue for FSL teachers (Lapkin et al., 2006; Wise, 2011). Meanwhile, other researchers argued the lack of professional development to be the prevalent issue (Ingersoll, 2004; Masson, 2018; Salvatori, 2009; Salvatori \& MacFarlane, 2009). Lapkin et al. (2006) studied FSL teacher needs, where the teachers were concerned with meeting exceptional students' needs. There is a link between not knowing how to effectively educate students and not receiving adequate training. Following Karsenti et al. (2008) investigation on teacher 
retention, another avenue for gaining FSL teachers' perspectives could be examining pedagogical change.

Karsenti and Collin (2013) conducted a Canada-wide survey, which explored why novice teachers were leaving the profession. Karsenti and Collin (2013) was interested in novice teachers' perspectives because they were more likely to leave the profession than their more experienced colleagues. The participants indicated that lack of support was the primary reason for leaving. When some teachers were struggling, they sought help from their school administration. Some participants were fortunate to be fully supported by their administrations, whereas other participants stated that there was a lack of involvement. Some French Immersion teachers discussed how their administration failed to understand their problem or simulate "specific immersion conditions" (Karsenti \& Collin, 2013, p.146). When the administration did not address the participants needs then the novice teachers would seek help from their more experienced colleagues. Although this process was interchangeable in cases where the novice teachers first explored their problems with their colleagues, if not addressed or ameliorated, then teachers would seek help from the administration.

Salvatori and MacFarlane (2009) completed a report that outlined knowledge, skills and experiences needed to be effective second language (L2) teachers. The report highlighted previous research that acknowledged the need to support FSL ongoing skill development. It should be noted that the support should not solely be provided to novice teachers but experienced teachers as well. Fortunately, Salvatori and MacFarlane (2009) 
included several considerations for supporting FSL teachers whether it is collaborating with other FSL stakeholders or strengthening existing support for practicing educators. The report also provides information on the development of initiatives and activities by Canadian Association for Second Language Teachers (CASLT) designed to further develop L2 teacher skills and knowledge (Salvatori \& MacFarlane, 2009). Salvatori and MacFarlane (2009) reported that, at the time of the study, CASLT was developing mentoring programs for FSL teachers. The goal of the initiatives and activities were to provide opportunities for improving novice teachers' teaching practices.

Similar to Karsenti and Collin (2013) and Karsenti et al. (2008), Salvatori (2009) highlighted how there is a shortage of FSL teachers. Unlike the previously mentioned studies on teacher retention, Salvatori (2009) noted how the shortage of qualified FSL teachers has left an opportunity for often unqualified and ill-prepared teachers to be in the classroom, who otherwise would not have received the position if there were more qualified FSL teachers. In Canada, each province determines the guidelines for certifying teachers. Due to the shortage of FSL teachers in Ontario, some teachers are given yearly probationary clearance to teach FSL classes without adequate qualifications when they are unable to locate a qualified candidate for the teaching position (KippFerguson, 2013). In some cases, the teachers only have one section of this FSL teaching certificate and others are allowed to teach FSL classes based on their French proficiency. KippFerguson (2013) noted that in cases where qualified teachers are found, they often transition into English-only teaching positions because they received more funding and support from their colleagues and administration. Salvatori (2009) noted that the Ontario Ministry of Education has been concentrated on "student retention and participation in FSL 
programs, student proficiency in French, and increased teaching capacity in FSL" (p. 289). According to Salvatori (2009), many school boards facilitated collaboration between FSL teachers, where successful literacy-based projects were shared, while providing the opportunity for dissemination of knowledge. OCOL (2019) argued that there should be collaboration vertically and horizontally. Horizontal collaboration would require provinces and territories to collaborate, whereas vertical collaboration is amongst ministries of education, faculties of education at universities, and school boards. The purpose of the collaboration is to develop a long-term coordinated strategy. There should also be opportunities for collaboration within schools, where teachers can work amongst themselves with help from consultants (OCOL, 2019).

Due to FSL teachers' overwhelming workload, some participants from OCOL (2019) explained that new teachers have difficult inductions and are often left alone because experienced teachers do not have adequate time to collaborate or act as a mentor. Some of the less proficient novice teachers are assigned to Core French $(\mathrm{CF})$ classes whereas the more proficient teachers are assigned to French Immersion (FI) classes. OCOL (2019) acknowledged that to better retain teachers, teachers require access to professional development and opportunities for professional learning, which includes ongoing L2 skill development, mentorships, networking opportunities along with seminars and workshops.

Masson (2018) noted that developing a model for professional learning "rooted in a sociocultural approach" could address the problem with retaining FSL teachers by reclaiming teacher agency in the professional learning process (p.77). Masson (2018) conducted a case study, which described the formation of two Core French teachers' professional identities. The study addressed two issues: information about FSL teachers' learning experience and the potential of teachers leading their professional learning. 
Masson (2018) recruited two participants from Southern Ontario who previously participated in a Professional Learning Community (PLC). While participating in the PLC, they were given full-release days during the school year and participated in six online video conferences each year between 2012 and 2015. After interviewing the two participants, the findings suggested that developing a strong positive relationship with their school administration through open communication and negotiation benefited the FSL teacher self-actualization. By enrolling in the PLC, the participants felt supported by their peers and combated feelings of isolation through validating their professional learning inquiries.

There are several resources directed towards the professional needs of novice teachers. One of the solutions for retaining FSL teachers was to create a mentoring program. There are a specific set of requirements for the program. A school board can enroll a first-year permanent full-time or part-time position hire who is certified by the Ontario College of Teachers. The teacher must be teaching for the first time in an Ontario publicly funded school system. If teachers do not meet the requirements in their first year of teaching then they can apply in their second year (Ontario MoE, 2010). The Ontario MoE developed a series of texts for new teachers, mentors, and principals. The program was developed as a form of professional development through guided collaboration from the documents. The New Teacher Induction Program (NTIP) document for novice teachers provided month-by-month planner and suggested topics for exploration that “...many mentors and new teachers commonly explore during each month" (Ontario MoE, 2010, p.2). The informed suggestions from the document were designed to ease the transition and provide embedded support that the novice teacher can rely on during their first year of teaching. 
The Canadian Association for Second Language Teachers (CASLT) developed Ontario's The New Teacher Handbook: Surviving and Thriving in the French as a Second Language Classroom (2017). The purpose of the document was "to provide concrete [and] practical solutions to address many" of the challenges that novice teachers can be faced with at the onset of their new career. The document lists various scenarios that a novice teacher might be faced with during their first year (e.g., classroom space, their language proficiency, professional learning, student engagement).

Connelly and Clandinin (1988) further explained that theory cannot be forced onto teachers' practices because practice can evolve into a theory as practice develops through narrative experience. According to the dialectic view, practice establishes theory, although in cases where theory and practice do not align then theory is at fault. With the dialectic view, Connelly and Clandinin (1988) discussed how theory is assumed to evolve based on what is being practiced. I agree with Connelly and Clandinin's (1988) arguments for the dialectic view because teacher practices should be informed by educational theory. This further argued that professional development does not necessarily address teachers' specific needs, whereas professional learning is specific to their needs and therefore has the potential to be of greater benefit to their learning.

\subsubsection{Assessment. Abdulhamid and Fox (2020) explored seven Language} Instruction for Newcomers to Canada (LINC) “teachers' accounts for evidence of washback from PBLA on teaching and learning" in LINC programs, and identified "potential leverage points which might be responsive to intervention and support" (p.175). Washback refers to the influence that assessment has on teaching and learning (Abdulhamid \& Fox, 2020). Abdulhamid and Fox (2020) reported "negative washback effects on some instructional practices, as it encouraged teachers to adopt approaches that they would not otherwise have adopted" (p.177). 
Alviarez (2017) suggested incorporating new strategies for the purpose of developing a more inclusive classroom setting for students. As discussed in Alviarez (2017), Ontario MoE (2014b) called for assessment practices to be inclusive of students with special education needs (SEN) and those who are English Language Learners (ELLs). Despite Ontario MoE (2014b) calling for inclusion, the achievement chart particularly focuses on "vocabulary, organization of logical thoughts, and clear expression of ideas" (Alviarez, 2017, p.31), whereas the achievement criteria encouraged oral, visual and written forms of communication. Several of the participants in Alviarez (2017) reported partial mutism in their students. The participants were unable to assess their students because they were unable to orally communicate. The participants expressed frustration with the suggested assessment criteria because it was difficult to assess students when their needs do not align with language benchmarks. Alviarez (2017) suggested that diversified instructional and assessment opportunities could support and encourage students with SEN. Alviarez (2017) noted that diversified teaching practices will not appear the same amongst educators based on differing teaching preferences regarding teaching styles and practices along with varying students' needs. Some teachers might prefer to adopt an approach that focuses on students' abilities rather than their shortcomings.

Regarding addressing FSL teachers' assessment practices and needs, Mison and Jang (2011) implemented three focus groups to gain insights into the needs of Canadian FSL teachers. The focus group interviews inquired about "the teachers' and schools' French language assessment practices," (p.102). Mison and Jang (2011) observed that "transparency of the assessment process ...varied substantially across the focus groups," (p.104). During their interviews, the participants expressed concerns "over the lack of consistency within the province, school boards, and...within the same schools in terms of content and assessment," (p.104). 
Mison and Jang (2011) argued that CEFR addressed several of the concerns that arose during the interviews. Mison and Jang (2011) claimed that CEFR can support "diverse and dynamic classrooms", and also facilitate "transparency, consistency, and plurilingualism in language learning", which are all fundamental to CEFR," (p.106).

2.3.4.2 Inclusion of English Language Learners in FSL. As the population in Ontario becomes more diverse, there has been an increased amount of English Language Learners (ELLs) in the school system (Triokekar \& El Masri, 2020). As discussed by Triokekar and El Masri (2020), teachers increasingly do not share the same cultural background and experiences as their students. As the diversity among students grows, the same diversity is not represented in the teaching population. Based on data from Turner Consulting Group (2014), racial minorities represent $26 \%$ of the population, whereas they account for $9 \%$ of elementary and kindergarten teachers along with $10 \%$ of the secondary teaching population in Ontario. The differing percentages of racial minorities among the population and teaching population further highlighted how teachers are unable to understand students' lived experiences, which can hinder teachers' ability to understand and address students' needs.

Mady (2012) investigated FSL teacher beliefs and knowledge regarding the inclusion of ELL students. By conducting interviews and questionnaires in Ontario, Mady (2012) determined that FSL teachers shared positive attitudes towards "appropriate pedagogy and openness to inclusion of ELLs" regardless of their proficiency in English (p.11). Interestingly, participants from this study expressed that the use of ELLs first language (L1) may be beneficial to learning French in the FSL context. Although, this study promoted the need for further professional development in strategies like translanguaging in the classroom. Based on Gentil (2018), translanguaging refers to the use of multiple languages in the classroom as a language repertoire "mixing in complex 
dynamic ways and forming one linguistic repertoire", although, it also acts as a "backdrop of assumptions, practices, and discourses that continue to create them as separate languages" (p.123).

In another study on teacher perspectives on ELLs in the FSL program, Mady (2016) examined FSL kindergarten teachers' beliefs on the inclusion of ELLs in French Immersion beginning in Grade one. Mady (2016) reported that kindergarten teachers expressed that French Immersion is not viable "for everyone, claiming it is less suitable than $[\mathrm{C}]$ ore French and agreeing that ELLs should, at times, be exempt" from learning FSL (p.263). These beliefs were supported by the school board's information for parents that French Immersion is not for every student by describing "characteristics of successful FI students thereby implying that other students might not be successful" (p.263). Notably, the participants expressed that ELLs should "focus on learning English, that their focus on French could not help their acquisition of English, and that the students required English to be successful in FI" (p.263). Regardless of the participants' beliefs regarding the inclusion of ELLs in the FSL program, parents "were motivated to enroll their children in FI" (p.263). Mady (2016) promoted the idea of providing the kindergarten teachers with more recent information of ELLs success in the FSL program during PD days to inform parents.

Mady conducted several studies (Mady, 2014, 2015, 2018) that explored French Language proficiency in ELLs and their bilingual advantage. The purpose of these studies was to further argued for the inclusion of ELLs in the FSL program. Mady (2014) compared FSL achievement of one hundred and sixty-five students divided into three groups: Canadian-born English speaking, Canadian-born multilinguals and immigrant multilinguals. The participants were asked to complete a proficiency test and a questionnaire. The immigrant students outperformed the other groups, and the 
Canadian-born multilingual students outperformed the Canadian English speaker students. Mady (2014) claimed that the immigrant group's success cannot be attributed to "language(s) proficiency, motivation, attitude, metalinguistic awareness" or specific strategies (p.332). In Mady (2015), the comparison among the three groups was again investigated, where once again, the immigrant group of students outperforms the other groups. Although this time, Mady (2015) determined that "integrative motivation, willingness to communicate and attitude to learning situation predicted test results" (p.299).

Following the previous studies comparing different grouping of students, Mady (2018) promoted the inclusion of ELLs in the FSL program through the comparison of English and French proficiencies of Grade six participants, which were Canadian-born English speakers, Canadian born multilinguals and immigrant multilingual students. The findings indicated that the immigrant group performed better than the other two groups in French proficiency tests, although, there were no significant differences among the results for the English proficiency tests.

\subsection{Novice versus experienced teachers}

Previous research has explored novice and experienced teachers' pedagogical knowledge (Gatbonton, 2018; Okas, van der Schaaf, \& Krull, 2014). Evens, Elen, and Depaepe (2019) investigated the impact of teaching experiences on pedagogical content knowledge (PCK) with particular focus on whether novice teachers differ from experienced teachers PCK. The participants were tested with a paper-and-pencil instrument then their answers were coded in four categories. Afterwards, the answers in the four categories were compared between groups. The qualitative results revealed that experienced teachers with conceptual knowledge demonstrated more practical knowledge than novice teachers. At the time of the study, I was unable to locate research that 
investigated differences between FSL novice and experienced teachers.

While teacher attrition is a contentious issue, there are some studies that reveal unqualified teachers are more likely to leave the FSL program than qualified teachers (Miller, Brownwell, \& Smith, 1999; Salvatori, 2009). At the onset of a career, novice teachers experience feelings of insecurities about their capabilities to effectively teach their studies similar to imposter syndrome. According to Sims and Cassidy (2019) imposter syndrome is when individuals disclosed "that they do not know enough to legitimately pursue their career" (p.47). Although, as the novice teachers become confident and secure in their teaching practices, then the feelings associated with imposter syndrome dissipate.

\subsection{Conclusion}

This chapter explored previous literature investigating FSL research, teacher culture, teacher perspectives, teacher professional development, along with teacher professional needs. The purpose of the literature review was to highlight a gap in the preexisting literature landscape in FSL research. While reviewing literature that researched teacher perspectives, I was unable to locate research that explored the differences between novice and experienced teachers. The research articles that investigated teacher retention solely focused on the needs of novice teachers. Other articles investigating teacher perspectives appear to focus on their perspectives of implementing new or existing programs in their classroom.

In the following chapter, I discuss the qualitative methodology and narrative inquiry method in response to my research questions. This is followed by, how participants were recruited for the study, participant biographical sketches, procedures for the study, and ethics protocol. Finally, I review how I analyze the transcripts from the interviews. 


\section{Chapter 3: Methodology}

\subsection{Introduction}

In the first chapter of this study, I clarified the research background, purpose of the study and rationale. As discussed in Chapter one, at the onset of the Ontario French as a Second Language (FSL) program, research primarily investigated student success (Burger, Weinberg, Hall, Movassat \& Hope, 2011; Cummins, 1998; Fortune, 2011; Mady, 2007; Tardiff, 1990; Turnbull \& Daily-O’Cain, 2009). Although, researchers have begun investigating FSL teachers, (Arnott, 2012, 2017; Cooke \& Faez, 2018; Jack \& Nyman, 2019; Lapkin, MacFarlane, and Vandergift, 2006; Karsenti, Collin, Villeneuve, Dumouchel, \& Roy, 2008; Salvatori, 2009). However, this change in research direction is acknowledged, it appeared that FSL research had undervalued teacher perspectives and did not adequately address teachers' professional needs.

In Chapter two, I discussed literature of relevance to the research questions which guided my study, namely: How are FSL language policies and curriculum documents from the Ontario Ministry of Education interpreted by FSL teachers? What resources and support are FSL teachers given? Are there differences between FSL novice and experienced teachers? As an outcome of the literature review, I identified a gap, which my research could begin to address. The gap related to the lack of research examining resource allocation and support for novice as opposed to experienced teachers in FSL classrooms in Ontario. I began by defining the terms, novice teacher and experienced teacher, drawing on the distinction in Vonk and Schras (1987). As noted in Chapter two, Vonk and Schras (1987) considered the induction period for teachers to last 7 years, which spans their developing sense of competence from the onset of their careers 
(novice) to feeling competent and secure about their teaching practices (experienced). For the novice teacher participant group, I recruited FSL teachers with a maximum of five years of experience to acquire the novice teachers' perspectives prior to feeling secure and confident about their teaching practices. The second category of participants were experienced teachers who had at least 10 years of teaching experience, which I assumed was a sufficient amount of time to act as a buffer for any residual insecurities about their teaching practices.

Having reviewed the previous chapters, I begin below by describing my research methodology and research approach. This is followed by my chosen research method, the study participants, research instruments, procedures for data collection. and analysis.

\subsection{Research Methodology}

As a research methodology, narrative inquiry often appeals to researchers who study teachers because it is informed by a theoretical perspective which accounts for the nature of human life as lived experiences (Clandinin, Pushor, Orr, 2007; Connelly \& Clandinin, 1990). Narrative inquiry is defined in educational research by the "construction and reconstruction of personal and social stories ... [where] learners, teachers, and researchers become storytellers and characters in their own and other's stories" (Connelley \& Clandinin, 1990, p.2). Bruner (2002) hypothesized that the way people lived their lives prevents them from seeing the narrative structures that characterize their lives. Clandinin (2006) notes:

Perhaps ... [the]... reason we can give for engaging with others in narrative inquiry [is that]... we can slow down lives, pause and look to see narrative structures that characterize ours' and others' lives. Narrative inquiry gives us a research methodology for engaging in this study of people's experiences. (p. 51) 
Wertz, Charmaz, McMullan, Josselson, Anderson and McSpadden (2011) noted that researchers who undertake narrative inquiry should adopt a cyclical approach when analyzing data, which allows them to contextualize shared stories by slowing down lived experience to better understand participants' actions and establish patterns. In other words, narrative inquiry is open, emergent, and exploratory. It allows for a point of reference to be established for additional inquiry into what may arise in the data. Below, I will explain why I chose qualitative research and used narrative inquiry for my study of the FSL teachers' perspectives considered here rather than using ethnographic or case study research methods.

\subsection{Research Approach}

Wertz (2014) noted that qualitative research focused on exploring and analysing participants descriptions of lived experiences. These descriptions require fastidious attention to language and deep reflection on emerging patterns of human experience that are otherwise unclear and intertwined (Saldaña, 2013; Wertz, 2014). Qualitative inquiry investigates the context, outcomes, and significance of what is being investigated by describing and understanding the local and situated; to increase the meaningfulness of what is going on by virtue of 'rich and thick description' while, quantitative research is focused on the magnitude of a phenomena, which is typically measured with sophisticated statistical procedures (Wertz Charmaz, McMullen, Josselson, Anderson, \& McSpadden, 2011). Quantitative research aims to generalize key variables in a sample of a population; to make predictions (cause and effect) outside of a study on the basis of variables in the sample (e.g., age, education, first language) to a population. It requires numbers - large numbers to allow for more security in generalizing, whereas qualitative research requires words - to fully account for what is happening in a local context. 
Qualitative research allowed for a deep analysis of my research participants' accounts of their lived experience in order to address my research questions. Groups were identified (novice vs. experienced teachers), but the distinction was not meant to imply a cause-and-effect relationship.

\subsection{Method}

\subsubsection{Why qualitative research?}

Following Smart (2008), I distinguished the differences between the terms, 'methodology' from 'method':

According to this distinction, a method is a set of procedures for collecting and analyzing research data. A methodology, on the other hand, is broader: a methodology is a method plus an underlying set of ideas about the nature of reality and knowledge. (p. 56)

The chosen methodology for this study was qualitative research because it allowed for a rich and in-depth analysis of the research data. For this research study, I chose to follow the narrative inquiry method when I analyzed the data rather than using another qualitative method.

\subsubsection{Overview: why I chose narrative inquiry for my study}

Ethnographic research is adopted when researchers observe and interact in the participants' environment (Reeves, Kuper, \& Hodges, 2008). An ethnographic approach could have been beneficial, but it was not feasible especially for the rigorous ethics clearances needed for observing participants in classrooms. The introduction of COVID19 along with the necessary steps to maintain the public's safety made it impossible to observe participants inside their classroom. It would have been beneficial to not only gain their perspectives but to also observe their teaching practices. Other researchers have acknowledged that there can be a difference in mandated policy and what is practiced in 
the classroom (Coburn, 2004; Grossman, 2010; Meyer \& Rowan, 1977; HinnantCrawford, 2016). Following Lemke (1995) and Fox (2009), evidence of a community accepting change is evident in how it is discussed by the community, which argued that gaining participants' perspectives can be sufficient for research.

Case study research was not the best method for this study because I wanted to analyze and interpret the experiences of two groups (i.e., novice and experienced teachers). A case study "explores a real-life, contemporary bounded system (a case) or multiple bounded systems (cases) over time, through detailed, in-depth data collection involving multiple sources of information... and reports a case description and case themes" (Creswell, 2013, p. 97). Cousin (2005) argued that case studies are not intended to analyze data, but to define cases and explore settings. In order to effectively explore the data for a case study, I would have needed to conduct multiple case studies. Several researchers highlighted how multiple case studies can be expensive and time-consuming (Baxter \& Jack, 2008; Dyer, Wilkins \& Eisenhardt, 1991; Gustafsson, 2017; Yin, 2003). Although the participants for this study could be defined as being a part of a single group (i.e., FSL teachers), it was crucial to divide the participants into groups to better understand the differences in their experiences. Regarding the intent of this study, a multiple case study could have been effective, but I would have required more time to effectively conduct an in-depth study.

According to Clandinin and Huber (2010), narrative inquiry is "a recursive and reflective process" (p.1), which begins from the field. This involves participants sharing their lived experiences, which evolves into research texts for analysis. With narrative inquiry, there is collaboration between the researcher and participant(s) where stories are told and retold (Clandinin \& Huber, 2010; Connelly \& Clandinin, 1990). Following Connelly \& Clandinin (1990), the participants are "reflecting on their actions and 
explaining themselves to others" $(\mathrm{p}, 4)$. The participants are engaging, telling and retelling when discussing their stories.

Narrative inquiry allowed the influence of commonplaces (i.e., learner, milieu, assessment, content, teacher) to be explored through rigorous analysis by developing several texts such as, field texts, interim research text and a final research text (Connelly \& Huber, 2010). The field texts can include the notes and transcripts from the interviews. The interim text is a document of excerpts from the transcript that the researcher uses for analysis, which removed any identifying information and conversations that were not applicable to the interview questions. Finally, the final research text refers to specific excerpts from the interviews that are used to discuss the findings from the study. After the interviews, the researcher curates an interim text by selecting stories that address their interview and/or research questions (Wertz et al., 2011) then the researcher codes the collection of stories to gain further understanding of their participant and lived experiences. By understanding teachers and students educationally, there needs to be an understanding of people's narrative of life experiences. Connelly \& Clandinin (1990) explained that "[1]ife's narratives are the context for making meaning of school situations" (p.3).

During the semi-structured interviews, I asked a series of questions to elicit information about my participants' lived experience. The questions allowed the participants to converse freely in response to the questions, and allowed me, as the researcher, to further contextualize the participants' lived experiences through their accounts of their roles as teachers, how they viewed the role of their students, the content, the milieu and assessment (i.e., the commonplaces) (Connelly \& Clandinin, 1988). When I asked about their classroom settings, participants discussed how this could include the online classroom settings, to changing their classroom settings (i.e., outdoors, boardroom, 
their assigned classroom), or remaining in their classrooms to maintain an FSL mindset for their students. It should be noted that the interviews for this study were conducted prior to the COVID-19 pandemic (i.e., when teachers and students were still in schools and classrooms across the province). I inquired about their personal experiences and the social aspects of teaching. For example, I questioned how often they collaborated with their colleagues on different tasks or assignments.

In sum, following Wertz et al. (2011), I adopted narrative inquiry because it allowed for a "creative process of organizing data so that the analytic schemes" would emerge (p. 227). Narrative inquiry allowed for the development of an interim text by extracting excerpts that I deemed relevant for analysis into a separate document. The interim texts were read multiple times in consideration of how the whole illuminates the parts, and how the parts in turn offer a fuller and more complex picture of the whole", which lead to a greater understanding of the anecdotes shared by each participant (Wertz et al., 2011, p. 227).

\subsection{Ethical Procedures}

In this section, I have outlined the ethical review procedures that I used to ensure the safety, comfort and privacy of my participants. Prior to conducting interviews, I obtained ethics approval from the Carleton University Research Ethics Board (CUREB) who awarded a certificate after reviewing my study (Appendix A). As I conducted the semi-structured interviews, it was crucial to uphold the standards of confidentiality, privacy, and informed consent.

In qualitative research, there is a greater potential for participants' information to be revealed than in quantitative research (Cresswell, 2013; Wertz, et al., 2011). 
Depending on the size of the community at the focus of the research, participants might discuss events or experiences that could reveal their identity. Further, qualitative research is characterized by rich and thick descriptive detail - the richer and thicker the better. It is the researcher's responsibility to ensure the least amount of risk to the participant(s). There are some steps that a researcher can take to protect the confidentiality of participants.

The first step was to send an email invitation (see Appendix A) to any perspective participants, which described the study to give the participant a better understanding of what will be asked of them if they decide to participate in my study. The second step was to obtain consent prior to the interview but also ongoing throughout the interview up until the time that the data is analyzed. Consent is essential in qualitative interviews because the interviews can reveal unforeseen information that the participant might not wish to be revealed. In this study, consent was viewed as a dynamic ongoing process. In other words, the participant could choose to amend statements or withdraw from the interview at any time before the data was analyzed. I ensured that all of my participants signed the informed consent form where they authorized to be interviewed and audio recorded. The informed consent form gave a detailed overview of the experiment (see Appendix A) and outlined ethical implications. The location of the interview can pose risks because people may overhear information or identify the participants in the final study. This can be mitigated by conducting interviews in locations chosen by the participant away from their place of work and where the participant felt comfortable.

In order to maintain confidentiality, the participants were given pseudonyms and any identifying traits such as school names were removed. Based on the nature of my study, I did not foresee any of the questions making the participants feel uncomfortable or vulnerable, as the participants had a good understanding of what the interview entailed 
from the email invitation and consent letter. Information regarding the participants in the study is provided in the following section.

\subsection{Participants}

In this section, the criteria for recruitment, participant descriptions, and the role of the researcher are discussed. The participant descriptions included details about whether they were satisfied with their teaching practices or situation, what classes they previously taught, years of experience, brief descriptions about their students and brief descriptions of the type of area that they taught in at the time of the study (i.e., rural, suburb).

\subsubsection{Purposive Criteria}

Participants were recruited based on criterion sampling, convenience sampling, and snowballing. Criterion sampling is based on specific criteria set by the researcher when recruiting participants for the study. The participants were required to be an FSL teacher in Ontario, who taught in the public school system. Convenience sampling was helpful in recruiting people who I knew in my personal life or being referred to a potential participant. Lastly, snowballing was crucial to obtaining more participants for this study because after interviewing the participants, I asked whether they knew of anyone who not only met the criteria for the study but would also be interested in participating in the study.

\subsubsection{Participant descriptions}

There were six FSL teacher participants in this study, drawn from various teaching backgrounds, schools, and school boards. The participants were divided into two groups based on previously discussed criteria, novice and experienced teachers. As notated above, teachers with less than five years of teaching were considered to be novice teachers, whereas teachers with over 10 years of experience were classified as 
experienced teachers based on Vonk and Schras (1987) induction period.

The following table described information about the participants and was used to contextualize their responses by giving more information about their teaching history. It provides background on the number of years that they have been teaching; what levels they were teaching at the time of the study; whether their school was in an urban or rural area; whether they self-identified as male or female; and the backgrounds of their students at the time of the study. Some of their students had Individual Learning Profiles (IEPs). These are provided to students who have special learning needs, which require individual accommodation. When recruiting participants, I aimed to have a wide distribution of educators who taught at various levels such as, elementary, middle-school and high school. While interviewing the participants, I obtained general descriptions about their students to have a better understanding of their classes to contextualize their needs and experiences as a teacher. 
Table 3.1 Participant Descriptions

\begin{tabular}{|c|c|c|c|c|c|c|}
\hline Pseudonym & $\begin{array}{l}\text { Years of } \\
\text { experience }\end{array}$ & Levels & Context & Classes taught & $\begin{array}{l}\text { Self- } \\
\text { identified } \\
\text { as: F/M }\end{array}$ & $\begin{array}{l}\text { Students (L1, } \\
\text { behavioural issues, etc.) }\end{array}$ \\
\hline Brian & 3 months & Elementary & Suburb & $\begin{array}{l}\text { Grades four, five/six } \\
\text { French Immersion }\end{array}$ & Male & Majority of students have IEPs \\
\hline Alice & 4 months & Elementary & Suburb & $\begin{array}{l}\text { Grade two Extended } \\
\text { French, Grade } \\
\text { two/three, Grade } \\
\text { five extended } \\
\text { French }\end{array}$ & Female & $\begin{array}{l}\text { Majority of students have } \\
\text { English as their L1 and two } \\
\text { have Arabic as their L1. There } \\
\text { are several students have } \\
\text { Individual Education Plans } \\
\text { (IEPs) }\end{array}$ \\
\hline Anne & 11 years & $\begin{array}{l}\text { 7/8 and high } \\
\text { school }\end{array}$ & Suburb & $\begin{array}{l}\text { French Immersion (high } \\
\text { school level) } \\
\text { Core French (middle } \\
\text { school) }\end{array}$ & Female & $\begin{array}{l}\text { All students had English as } \\
\text { their L1 }\end{array}$ \\
\hline Elizabeth & 15 years & Elementary & Suburb & $\begin{array}{c}\text { Geography, Music, } \\
\text { French Immersion, } \\
\text { science }\end{array}$ & Female & $\begin{array}{l}\text { Majority of students have } \\
\text { English as their L1. }\end{array}$ \\
\hline Samantha & 20 years & Kindergarten & Suburb & $\begin{array}{l}\text { 50/50 English and } \\
\text { French Kindergarten }\end{array}$ & Female & $\begin{array}{l}\text { L1 for more students is not } \\
\text { English }\end{array}$ \\
\hline George & 27 years & High school & $\begin{array}{l}\text { Online teacher } \\
\text { in rural Ontario }\end{array}$ & $\begin{array}{l}\text { History, French } \\
\text { Immersion, Geography, } \\
\text { Civics and careers }\end{array}$ & Male & $\begin{array}{l}\text { Students' L1 } \\
\text { was English. }\end{array}$ \\
\hline
\end{tabular}




\subsubsection{Researcher's role as interlocutor}

After providing information regarding the participants in this qualitative study, I would like to address my own role as the researcher - the social other, the storyteller. Connelly and Clandinin (1990) explained how during the process of engaging with narrative inquiry, researchers become a part of the process.

Following MacLure and Stronach (1993), I recognized that my role as a researcher was just as prevalent in the data as the participant. Caine, Estefan and Clandinin (2013) observed that the "researcher's presence and investment is an important feature of narrative inquiry research (p.577). MacLure and Stronach (1993) demonstrated how data can be manipulated in various ways to satisfy chosen narratives. As the researcher, I chose the participants, interview questions and data in the interim text that was analyzed to fit my developing narrative. The narrative that I cultivated from my data attempted to address the research gap, which highlighted a lack of research investigating the allocation of resources and support for both novice and experienced teachers - but it is important to acknowledge that the narrative here reflected my own perception and involvement in the study. Another researcher, with similar research questions, might have told the story differently. This does not take away from the usefulness or meaningfulness of the study, however. I am able to address my research questions with rich and thick description - but I also need to acknowledge my role in the study. Also, the value of qualitative research given its inability to generalize allows us to better understand by increasing our awareness of what is going on by transferring our knowledge to other contexts. 


\subsection{Procedure}

As discussed in the ethics review section, participants were asked to meet with the researcher in a location of their choosing that was quiet enough for recording as well as far enough from their place of work, so the participant felt comfortable answering the interview questions. If the participants were unable to decide upon a location for the interview, I suggested multiple potential meeting locations. Upon meeting with the participant, I asked the participant to review the informed consent forms to begin the study. Each participant was given a copy of the form for their personal records.

Once the participant signed the informed consent form, I recorded six semistructured interviews. These interviews allowed me to "probe for further information, elaboration, and clarification for responses (Creswell, 2012, p. 18), whereas a questionnaire would not provide the depth required for qualitative research. The interview guide that I followed consisted of 11 questions, which was accompanied by several prompts (Appendix B). The questions explored the participants' background information, their accounts of FSL language policies and their use of curriculum documents.

The semi-structured interview format was helpful for when new lines of inquiry arose as I interviewed additional participants. As discussed, each interview was framed by the same interview questions (see Appendix B), but the responses lead to new topics during the naturalistic conversations. I also reinforced what was discussed in previous interviews while questioning participants. Narrative inquiry 
allowed for my interview questions to be open-ended as a way of getting at their lived experiences. If I were to specifically ask about the differences in novice versus experienced teachers and the attrition problem, then it could have narrowed and distorted their responses. Instead, having the novice and experienced teacherparticipants discuss curriculum documents, resources and support served as a catalyst (Fox, 2009, re: Delphi Technique), which generated their commentary, accounts, and reflections of their lived classroom experiences. After the interview was completed, each participant was given a $\$ 10$ gift card to either Starbucks or Tim Hortons as a small token of my appreciation for their participation in the research study. Each interview was later transcribed for analysis.

\subsection{Analysis}

After audio-recording the data, I transcribed each interview. I developed an interim text by including sections from the data that I deemed relevant to the interview or research questions. Each interim text was analyzed for initial codes (i.e., bottom-up coding for patterns in the data). (See Appendix $\mathrm{C}$ for an example of an interim text). According to Saldaña (2013), "a code...is most often a word or short phrase that symbolically assigns a summative, salient...attribute [to] a portion of language-based or visual data" (p.3). Following the first round of coding, I analyzed each transcript again for emotion coding, descriptive coding, and value coding (Saldaña, 2013). Emotion coding analyzed whether experiences recounted in the data elicited feelings of frustration or dissatisfaction among other emotions. Descriptive coding referred to a word or phrase to describe the theme of a passage. Finally, value coding assessed a participants' attitudes, values and beliefs (See 
Appendix D and example of coding procedures). Based on Saldaña (2013)

description of categorizing, I applied and reapplied codes to qualitative data to segregate, group and regroup to develop meaning and explanation. In other words, I organized and grouped similar coded data into categories based on shared characteristics (Saldaña, 2013). Once major categories arose and consolidated with one another, I was able to progress towards "the thematic, conceptual, and theoretical" (Saldaña, 2013, p.13) by reaching more general and higher-level constructs. For magnitude coding, I compared and contrasted the themes by recording how many times specific themes occurred in a participant's interview (Saldaña, 2013). These contributed to frequency counts, which captured the emotive force and prevalence of the themes.

From the themes, I was able to make key assertions in relation to the research questions that will be explored in following chapters. After I finished several rounds of coding, I took excerpts from various interviews then asked for a second coder, who was familiar with the study, to analyze the transcripts for topdown coding. Since I knew which themes were present in the data, we used a topdown approach to investigate whether or not the themes were valid for the data (See Appendix D). We used more general codes like teacher professional needs and classroom for top-down coding rather than bottom-up coding. This exercise resulted in $100 \%$ consensus between my own coding and that of the second coder. In the following chapter, I will summarize the different themes in the data through histograms. The histograms displayed the findings in a useful way for interpretability and synthesis. The histograms were derived from the magnitude 
coding.

\subsection{Conclusion}

This chapter discussed the qualitative methodology; and the narrative inquiry method which I chose to use in this thesis in order to respond to my research questions. I began with a description of qualitative inquiry and why it was suitable for my study along with a description of narrative inquiry. I described how the participants were recruited for this study. Following the description of recruitment strategies, I gave general descriptions of the participants, which will be further explored in the following chapter. I explained my procedures for the study along with ethics protocols. Finally, I described how I analyzed the transcripts from the interviews with participants.

Having described how the study was conducted in Chapter three, I used my research questions to frame the findings from the study by identifying and discussing themes that arose in the data in connection with the literature that was reviewed in the second chapter. In the next chapter, Chapter four, I present and discuss the findings of my research. 


\section{Chapter 4: Findings and Discussion}

\subsection{Introduction}

In the first chapter, I introduced the research context, rationale, and purpose of the present study. As discussed in the first chapter, researchers have primarily investigated the success of the FSL program through student achievement (Burger et al, 2011; Cummins, 1998; Fortune, 2011; Mady, 2007; Tardiff, 1990; Turnbull \& Daily-O'Cain, 2009), whereas, more recently, researchers began examining FSL teachers' perspectives (Arnott 2012, 2017; Cooke \& Faez, 2018; Jack \& Nyman, 2019; Lapkin et al., 2006; Karsenti, Collin, Villeneuve, Dumouchel, \& Roy, 2008; Salvatori, 2009). Although this broadened perspective is welcomed, it appeared that FSL research continued to undervalue teachers' accounts of their front-line, classroom experience, and that this might limit the impact of support in addressing the FSL teachers' professional needs. As noted in Chapter one, this thesis was motivated by my own concerns for the FSL program: I am a product of the program, maintain contact with some of my former teachers, have studied with teachers who currently work within the program, and have heard their comments about it over the years. My reflections prompted me to look more deeply into the program itself by turning initially to the research literature and later engaging in research of my own.

Thus, in the second chapter of this thesis I discussed literature of relevance to the research questions which guided my study, namely: How are FSL language 
policies and curriculum documents from the Ontario Ministry of Education interpreted by FSL teachers? What resources and support are FSL teachers given? Are there differences between FSL novice and experienced teachers? As an outcome of the literature review, I identified a gap related to the lack of research examining resource allocation and support for novice as opposed to experienced teachers in FSL classrooms in Ontario, which my research could begin to address. I defined the terms, novice teacher and experienced teacher, by drawing on the distinction from Vonk and Schras (1987). As noted in Chapter two, Vonk and Schras (1987) considered the induction period for teachers to last 7 years from the onset of their careers to developing feelings of competency and security regarding their teaching practices. For the novice teacher group, I recruited teachers with a maximum of five years of experience because I wanted to acquire the novice teachers' perspectives prior to them feeling secure and confident about their teaching practices. The second category of participants were experienced teachers who were required to have at least 10 years of teaching experience, which I considered to be a sufficient amount of time to act as a buffer for any residual insecurities about their teaching practices after the induction period (Vonk \& Schras, 1987).

In the third chapter, I discussed qualitative methodology (Saldana, 2013), the narrative inquiry method (Connelly \& Clandinin, 1990), and provided information regarding the study participants, ethics protocols, procedures, and analysis. As discussed in the third chapter, the purpose of using the narrative inquiry method was to analyze and to develop a rich and detailed understanding of 
teachers' accounts of their practice through semi-structured interviews (Connelly \& Connelly, 1990; Clandinin, 2006). I recruited six participants for this study and subsequently divided them into their respective groups based on their years of teaching experience (i.e., novice and experienced teachers). Upon converting the audio recordings of my semi-structured interviews to written transcripts, I developed an interim text then analyzed the data based on several techniques described in Saldaña (2013). An interim text is a document of excerpts from transcripts that the researcher uses for analysis, removing any identifying information and commentary that is not applicable to the interview questions. Upon the development of the interim text, I coded the collection of stories to gain further understanding of the participants and their lived experiences.

In the present chapter, I begin by providing additional context for the participants' accounts based on brief sketches of their lived experiences and a review of their biographies. The biographical sketches described their teaching history and their views of teaching, learning, and their students at the time of the interviews. I used my research questions to frame the findings from the study to examine how the curriculum is interpreted by the participants, and the allocation and availability of resources and support for novice and experienced teachers, which was reinforced by literature of relevance previously discussed in the second chapter. The participants biographical sketches were divided by novice and experienced teachers to address the following research question: Are there differences between FSL novice and experienced teachers? 


\subsection{Participant biographical sketches}

Participants' biographical sketches were brief descriptions about the participants divided into their respective groups (i.e., novice and experienced teachers) in an attempt to provide further detail about the participants' experiences and where they taught at the time of interviews. The purpose of the participant biographical sketches contextualized to a limited degree their responses to the interview questions

\subsubsection{Novice teachers}

Brian was a male teacher who worked at an elementary school in a suburban area in a large city in Eastern Ontario. At the time of the interview, Brian had 3 months of teaching experience in an Ontario publicly funded school board. Brian was in the process of completing his Master's in Education at a mid-sized Canadian university. As a result, he had a 0.75 day contract, where he taught a Grade five/six extended French class, a kindergarten class and a developmental education class where he instructed students with physical disabilities. Several of the students in his Grade five/six class had Individual Education Plans (IEPs). IEPs are accommodations awarded to a student for a variety of reasons such as the student having a learning disability. For example, students can be awarded additional time on tests and assignments or receiving modified assignments. These modifications could include the spacing or colour of the assignment sheet

Alice was a female teacher who worked in a residential area in a large city within Eastern Ontario at the time of the study. At the time of the interview, Alice 
had 4 months of teaching experience working in the Ontario publicly funded school system. She was teaching two FSL Grade two classes, a Grade two/three class and a Grade five class. Two of Alice's students in her Grade five class were ELLs along with several students who had IEPs.

\subsubsection{Experienced teachers}

Samantha was a female teacher who was teaching in a residential area in a large city Eastern Ontario. Samantha taught for 20 years in the Ontario publicly funded school system, but she had been working as an FSL teacher for the previous three years. After being forced into teaching FSL classes, she was thrown back into a new subject, which resulted in her experiencing imposter syndrome (Sims and Cassidy, 2019). Samantha taught a 50/50 English French kindergarten class, where $50 \%$ of the content is taught in English, while an additional $50 \%$ of the content is supposed to be taught in French. Due to the students' proficiencies in English and French, the 50/50 distribution was not feasible. Samantha mentioned how the majority of the students have lower socio-economic status and were ELLs. She received help from two Early Childhood Educators (ECEs) Luckily, the ECEs often spoke the same Home Languages as the students, but the ECEs did not speak French.

George was a male teacher who taught online classes in rural Eastern Ontario. George had been teaching in Quebec and Ontario for 27 years. George previously taught high school FSL History, Geography, Civics and Careers. At the time of the study, he was one of two teachers at his school who taught online FSL classes. 
Anne was a female teacher who taught in a suburban area with a mix of commercial and residential properties in a large city within Eastern Ontario. She had 11 years of experience teaching French. During her first year of teaching, she taught an FSL class in England. After the year abroad, she returned to Ontario to teach in the publicly funded school system. She had only worked in middle schools and high schools where she taught ELLs, students with behavioural problems, and learning difficulties. Anne has taught history, Core French, French Immersion, Religion, Grades seven/eight Social Science, along with Civics and Careers.

Elizabeth was a female teacher who taught in a suburban neighbourhood in a large Eastern Ontario city. She had 15 years of teaching experience, where she taught various classes mainly in Ontario. Elizabeth briefly taught French and Music classes in Australia. In Ontario, she taught grade four, five, six French Immersion classes, kindergarten, seven/eight science, and art classes.

\subsection{From codes to categories to themes: analysis of the participants interviews}

Having presented the participant biographical sketches, in the following section, I elaborated on how the participants described their interpretation of the Ontario FSL curriculum, and accounted for their FSL teaching experiences in relation to the research question that guided the present study. As discussed in Chapter three, I developed interim texts and analyzed transcripts of the interviews using emotion coding, descriptive coding, and value coding. Upon organizing and grouping similar codes, I noticed clusters of categories that I was able to develop into themes. The following themes appeared in the data:

- curriculum, 
- desire for more concrete guidance,

- frustration,

- dissatisfaction,

- self-doubt,

- classroom environment,

- assessment,

- student needs,

Upon analyzing the participants' discussion of the curriculum, I explored the kindergarten and grade-specific curriculum interpretations, which highlighted the flexibility that can arise from the curricular expectations.

\subsection{Interpretation of the Ontario written curriculum for FSL teachers}

As previously discussed, the first question guiding the present study was How are FSL language policies and curriculum documents from the Ontario Ministry of Education interpreted by FSL teachers? The purpose of questioning participants' interpretation of the curriculum was to determine whether the participants could benefit from additional resources and support. While interviewing participants, I asked the same 11 questions in each of the six semistructured interviews and presented several prompts to contextualize the questions regarding curriculum documents (Appendix B). When the participants were asked about which documents that they use, they all remarked how they only focused on the document that pertained to their classes (e.g., The Kindergarten Program (Ontario MoE, 2016a); and, that they might have previously seen the Ontario MoE (2013a) A Framework for French as a Second Language in Ontario Schools, 
Kindergarten to Grade 12). However, as seen in Figure 4.1, all of the participants discussed the Ontario MoE written curriculum to some degree.

Figure 4.1

Curriculum

8

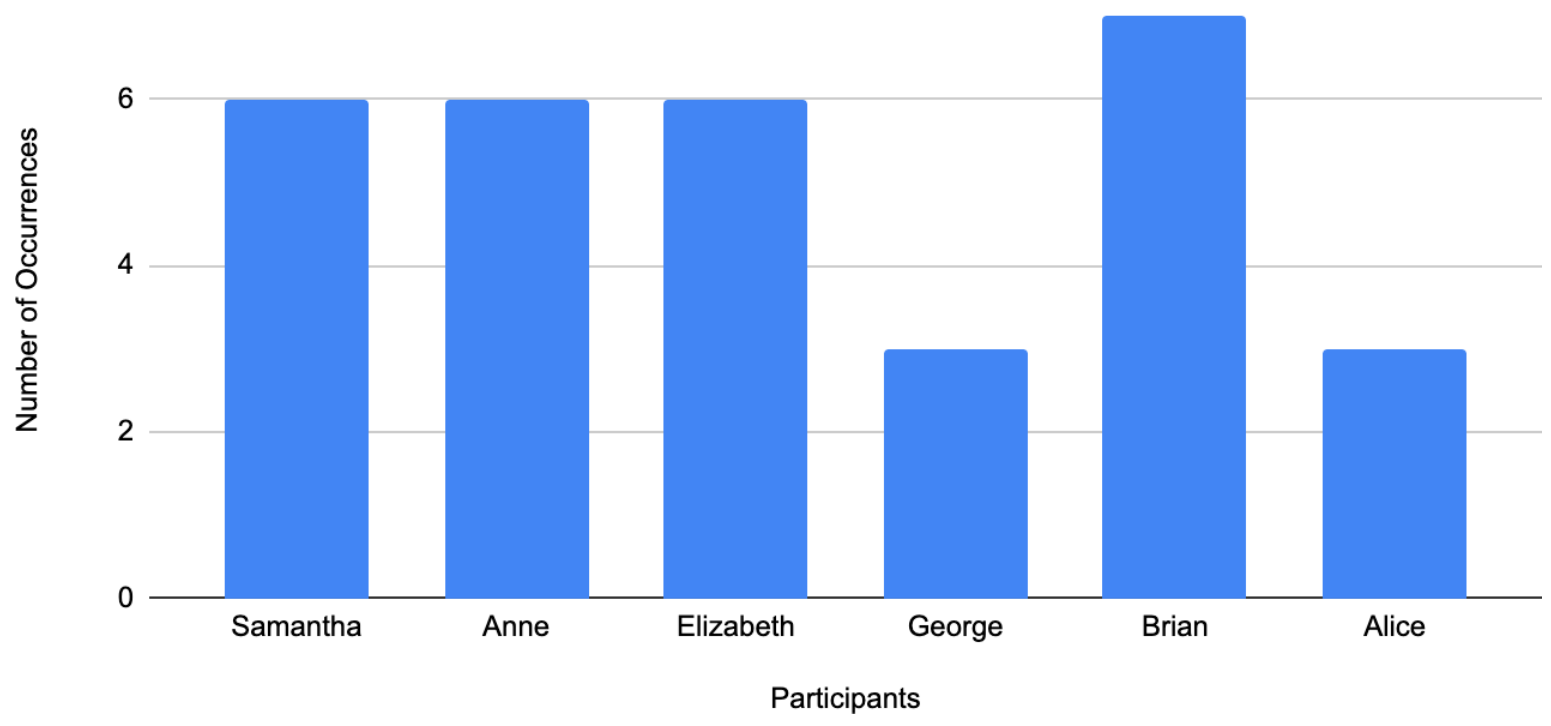

I recorded number of occurrences that the participants referred to the curriculum. The purpose of the histogram was to provide a visual representation of the data, which made it easier to summarize. Samantha, Anne and Elizabeth discussed the curriculum 6 times during their respective interviews (Figure 4.1). George and Alice discussed the curriculum 3 times during their interviews, whereas Brian discussed the curriculum the most at 7 times. This may have been because at the time of the interviews, Brian was pursuing his master's degree in Education.

When the participants were asked how they interpret the FSL curriculum, an overwhelming number reported that they view the curriculum as a "guideline". Brian remarked how: 
Maybe this is just me and I need to look at it more in-depth, but I would say that this is more like a guideline to follow. This is what I need to follow, here are my four pillars and as long as I can get my class to those attainable goals then that's kind of how I see it

As his comment suggests, Brian viewed the curriculum as a guideline rather than a step- by-step protocol on exactly what to teach. This finding is similar to that of Cloutier (2018) who, argued that the Ontario MoE curriculum documents provided general guidance for FSL programs, special education and English Language Learners (ELLs). After Brian was asked about the FSL Curriculum, he stated that "I mean...I looked at where they're at roughly in terms of what the document expects but the document has the same general expectations". Brian's response was similar to Anne's and reflected the organization of the curriculum, which is divided into separate grades followed by their respective expectations. Anne stated “...basically the curriculum's very similar from grade to grade. The expectations are pretty...like they're basically verbatim, word for word the same thing... what does differ is the examples that they give."

Interestingly, Alice (a novice teacher) and Anne (an experienced) shared the same interpretation of limitations of the curriculum. They both struggled with which benchmarks to implement because of their similarities. In other words, due to the openness and overlapping choices of wording across levels, some participants had difficulty understanding what was expected by level in the FSL program. Upon discussing the general guidelines in the curriculum, several participants requested more concrete guidelines specific to program levels and encouraged more 
systematic progression across years and levels of the program. Anne discussed how she hoped for more detail and specific information from the curriculum, stating,

by the end of this year, your kids need to know this exact material and that's not quite what it does. I think that it guides, especially French teachers, to have responsibility in that they need to meet certain requirements every year. I just wish that some of those requirements were more concrete.

As seen in Figure 4.2, the desire for concrete information, specific strategies and other material resources was not addressed in all of the interviews. The two participants, George and Elizabeth, who expressed that they were satisfied with the curriculum, did not express a desire for more specificity in the curriculum. This may suggest that they had developed strategies, materials, and so forth to meet their own students' needs, which were better addressed by a flexible curriculum such as the Ontario MoE curriculum.

However, Samantha, Anne, Brian and Alice (Figure 4.2) were interested in more concrete guidance in the curriculum, which will be further explored in the discussion below, regarding the kindergarten and grade-level curriculum. 
Figure 4.2

Desire for more concrete guidance in the MoE curriculum

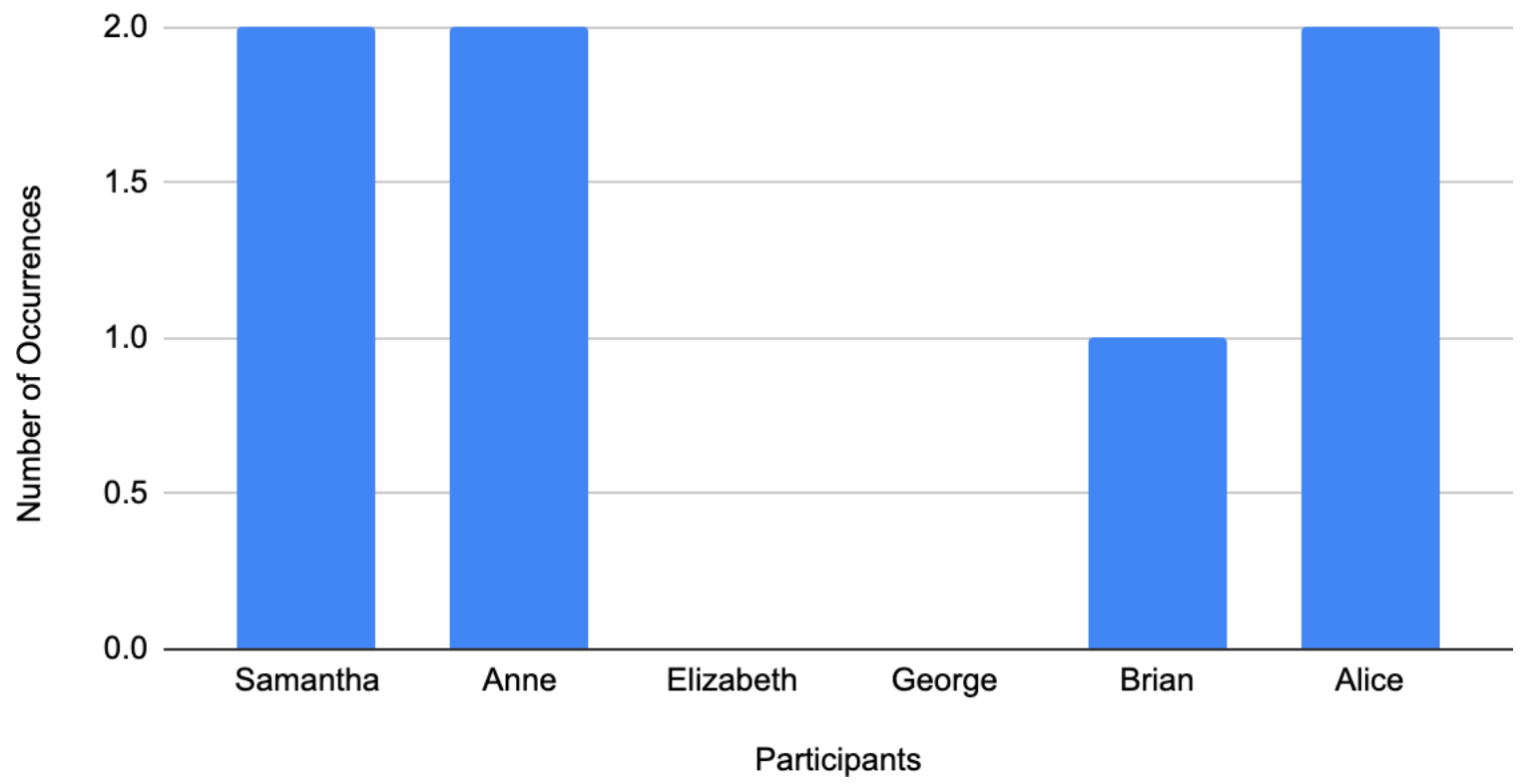

During their respective interviews, Samantha, Anne, Brian, and Alice all indicated a desire for more detailed information in the Ontario MoE FSL curriculum. Anne argued that new teachers should be able to rely on the information in the curriculum to support and guide their classroom practices (e.g. with specific suggestions for strategies, content, approaches). In his respective interview, Brian reinforced this idea by stating:

the new teachers who aren't doing it like the ones making mistakes like me and others. Not saying that it's not right but the ones making mistakes and not learning, I think they definitely need a step-by-step. It would be helpful because then you're avoiding mistakes then there is no opportunity to learn as a teacher and meeting your class where they are at too with their lived experiences and matching it to the curriculum between where they are and where the curriculum is to find that space so they can grow in between. 
Brian indicated that a guided curriculum and additional resources could benefit teachers who are struggling with their teaching practices and otherwise are not seeking help.

I also explored what participants found frustrating in their ongoing teaching experience. Frustration was recorded when the participant explicitly stated that they were frustrated with a particular problem. For example, Anne said that "I do think that it's very frustrating that I dedicated that much of my post-secondary education to it and that anybody can walk into the job."

\section{Figure 4.3}

\section{Frustration}

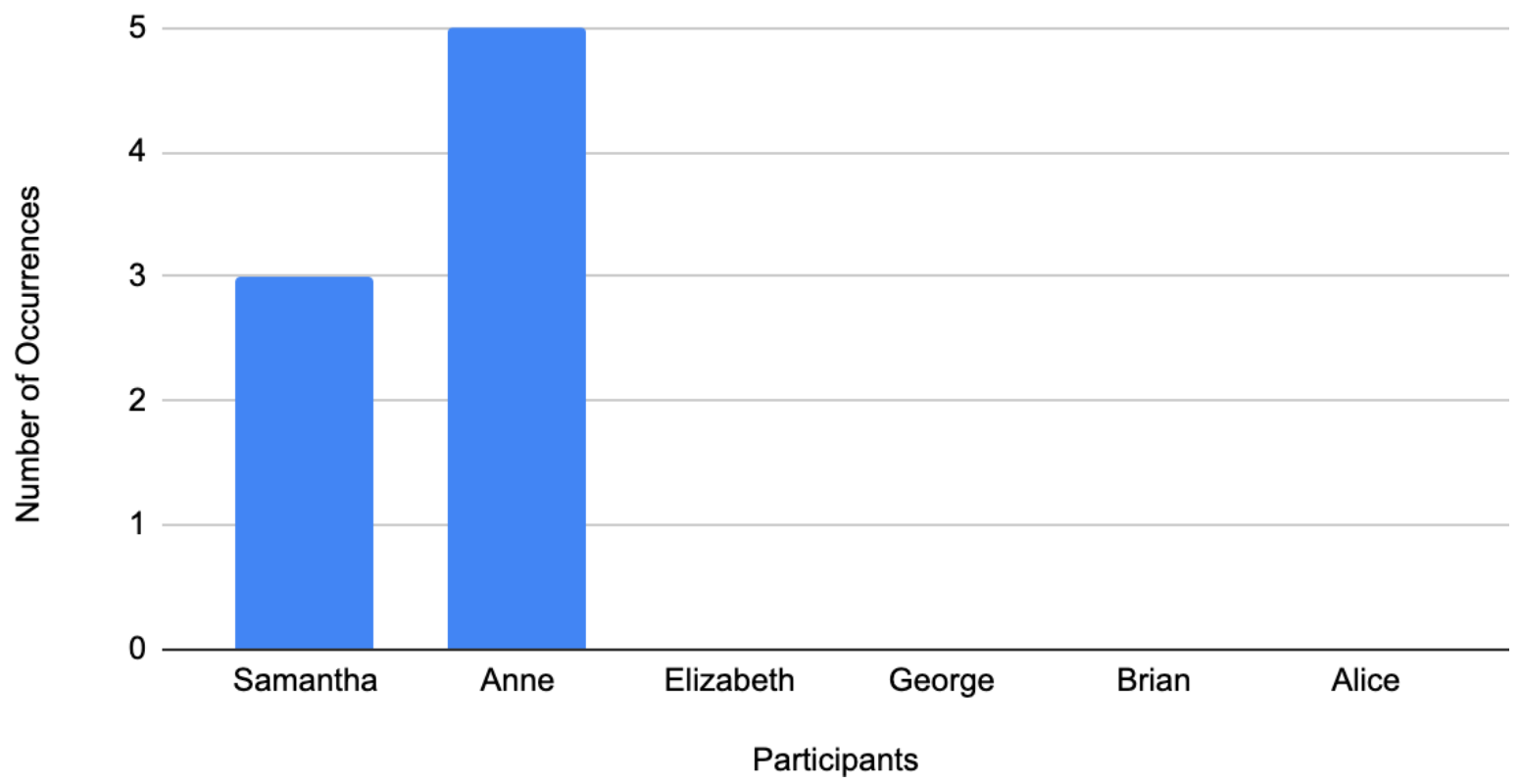

As seen in Figure 4.3, Samantha and Anne, who were both experienced teachers, expressed frustration about what they identified as an issue in the FSL program, namely, the lack of consistency in hiring practices. For example, Anne remarked quite forcefully that she was disappointed about how seemingly easy it 
was for unqualified teachers to obtain an FSL teaching position based solely on their ability to speak French:

It happens all the time, two of my sisters are French teachers, and they're phenomenal French teachers, and one is a vice principal now. But we took extended French in high school, and they were strong, and they make damn good French teachers. But they got hired out of teacher's college into French positions, with no French background after high school, where I did my degree in French, and they have the same job.

Anne dedicated a notable amount of time and education towards her FSL certification to receive the same teaching position as her sisters, who never obtained their FSL teaching qualifications, yet they were able to secure similar teaching positions. Notably, unqualified teachers may secure an FSL teaching position, but they are more likely to leave the program than their qualified colleagues (Miller, Brownwell, \& Smith, 1999; Office of the Commissioner of Official Languages, 2019; Salvatori, 2009).

Meanwhile, Samantha also expressed considerable frustration in what she perceived to be a lack of consistency in allocating teachers without training or experience to teach new FSL levels. The inadequacy of the curriculum was highlighted by this practice because, in her view, it failed to provide adequate guidance. For example, in her consideration of the kindergarten curriculum, she said: "I found it really frustrating that nobody actually just said to me: 'Okay, you will teach the following things in French in kindergarten.' It's just like 'speak to them half the day in French, and deliver some of the curriculum', but we don't 
actually know what..." It is possible that Samantha's teaching situation is unique, but at the time of the interview, she had received minimal guidance regarding what and how to teach FSL other than one PD day that she attended at the beginning of the new 50/50 program. As noted in Samantha's biographical sketch at the beginning of this chapter, the new 50/50 program required half of the content to be presented in French and the other half of the content to be presented in English.

Most of the teachers expressed a need for more specific information by level for themselves or for teachers newly hired to teach a new level in the FSL program. There were differences in the degree of frustration that they expressed and the reasons for their frustration seemed to differ as well to an extent. Differences in their experiences were at times specific to the level they were teaching, as reported below with regard to the Kindergarten curriculum and the Grade-specific curriculum.

\subsubsection{Kindergarten curriculum}

In contrast to other participants, Samantha reported a completely different experience with the curriculum for kindergarten students, The Kindergarten Program (Ontario MoE, 2016a). Although, the kindergarten curriculum is divided into four frames. The four frames of the curriculum are belonging and contributing, self-regulation and well-being, demonstrating literacy and mathematics behaviours, and problem-solving and innovating (Ontario MoE, 2016a). Samantha acknowledged that the Kindergarten curriculum is:

...divided into four frames, there's belonging and contributing, there's self- 
regulation and well-being. There's demonstrating literacy and math behaviors and there's innovating and problem solving. So those are the four kind of categories of like where they put the individual expectations into those four things. Okay, none of the four frames are French.

Among the four frames in the kindergarten curriculum, there were no expectations for educators regarding what content should be taught in French. The kindergarten curriculum is dissimilar to the grade-level curriculum documents because there is a separate FSL-specific curriculum document, as is the case for subjects like math, art and science. Samantha was especially worried about the lack of concrete guidelines in FSL but also how relevant it is at their school:

Well, there's no assessment criteria for French. I can assess anything in the early learning. I don't know if you've seen the early learning or the early years that used to be called the kindergarten curriculum, but it's about this thick. It's two years but it's this enormous document with millions of expectations and I can... essentially as far as I can tell I can teach any of them in French, or none of them in French! Well, no, but like $50 \%$ of them but randomly selected I guess so, yeah. It's an interesting situation that I found myself in. Okay. What am I supposed to do?

Samantha expressed considerable concern over the state of FSL for kindergarten and her frustration with the lack of specific expectations regarding what she should teach her students. After conducting magnitude coding (Saldaña, 2013) to compare the different themes that arose in the data, Samantha, one of the 
most experienced participants, was one of the two participants who expressed their frustration and dissatisfaction most strongly, (Figure 4.3 and Figure 4.4, respectively), about teaching conditions. Dissatisfaction was coded with regard to gaps in support. In general, it did not carry the same emotive force as an explicit statement such as:

Like I found it really frustrating that nobody actually just said to me: "Okay, you will teach the following things in French in kindergarten." It's just like "speak to them half the day in French, and deliver some of the curriculum, but we don't actually know what."

Figure 4.4

Dissatisfaction

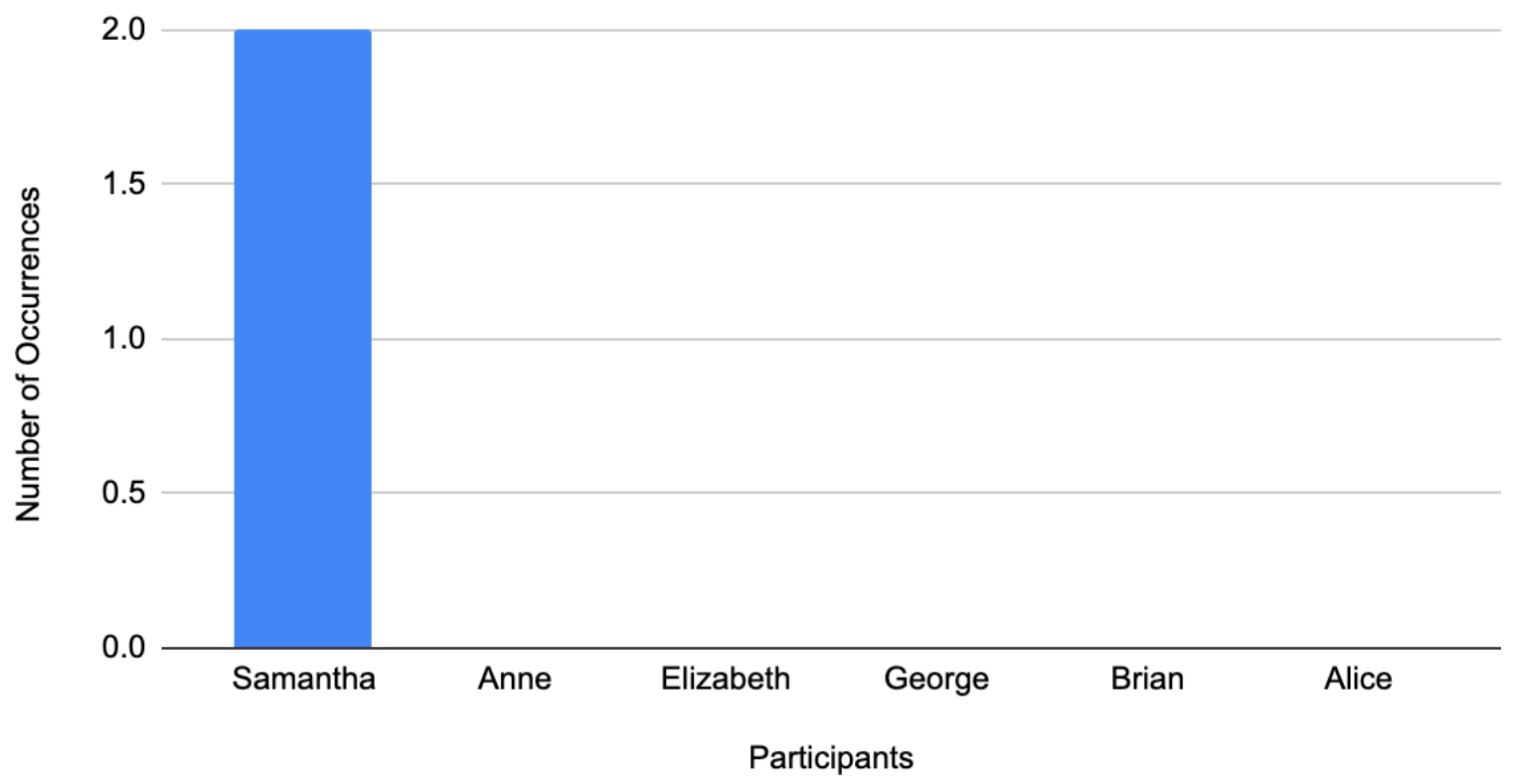

Samantha indicated at various points throughout the interview that she was dissatisfied with the lack of FSL curricular expectations. At Samantha's school board, the kindergarten classes have to be 50/50 split with FSL and English because 
of demand. Samantha explained: "so our school board decided to make all kindergarten classes 50/50 English and French...we had all these class size caps imposed by the government... and they also at the same time implemented the mixed age groups as well as best practice". Samantha suggested that the purpose of the 50/50 English and French classes was to have fewer kindergarten classes, because at some schools with a high demand for FSL classes sometimes there would be multiple full capacity FSL classes and small English classes. It is logical to assume that the implementation of the 50/50 English-French classes were more cost effective.

According to Samantha, with the mandatory 50/50 English and French kindergarten classes, there was typically an English and French teacher who determined which of the four frames from the kindergarten curriculum were to be taught in French and what content was to be taught in English. Samantha observed that all teachers but particularly FSL kindergarten teachers:

need some directions. And honestly, I would rather have... personally I'd rather have too much direction than not enough. Like I found it really frustrating that nobody actually just said to me: "Okay, you will teach the following things in French in kindergarten." It's just like "speak to them half the day in French, and deliver some of the curriculum, but we don't actually know what." We need to have some sort of consistency across the board. Like if I have a kid who I taught for two years and then they move to [another city] or whatever, then there needs to be some sort of flow to their education 
At the time of the interviews, there was no mandate indicating which aspects of the curriculum should be taught in French and what should be taught in English: “most people teach with a cohort who's teaching in English and you kind of decide amongst yourselves who can teach what". Samantha expressed how the lack of concrete curricular expectations could lead to problems when a student transfers schools or entered Grade one. As seen in Figure 4.2 and 4.3, Samantha was one of the participants who expressed the most frustration about the lack of concrete guidance in the FSL program, inadequate explanation or detail regarding developmental progression, and a lack of systematic material resources. Due to the lack of guidance for FSL kindergarten education, teachers at different schools could decide on instructing certain subjects in French that do not align with the Grade one FSL curriculum guidelines or if a student transferred to a different school during the schoolyear then there was no guarantee that the new teacher would decide to teach the same frames of the kindergarten curriculum document in French.

With the shortage of FSL teachers (Karsenti et al., 2008; OCOL, 2019; Salvatori, 2009), Samantha assumed the role of both English and French teacher for her class. Samantha's frustrations align with observations found in OCOL (2019), which reported that some school boards faced challenges with hiring qualified FSL teachers because there was a lack of a hiring pool where a number of candidates apply for the purpose of school boards securing qualified FSL teachers.

Having discussed teachers' perceptions and accounts of the kindergarten curriculum, in the section that follows below, I discussed the participants' accounts of the grade-specific curriculum. 


\subsubsection{Grade specific curriculum}

As discussed in the literature review, there are two grade-level written curriculum documents for teacher's referral (Ontario MoE, 2013b,2014). In the following subsections, I highlighted what the participants reported with regard to the Grade-specific Curriculum. The participants indicated that they appreciated the flexible nature of the written curriculum allowing for the participants to tailor their teaching practices to their participants needs, which is consistent with HainerVioland's (2013) findings.

4.4.2.1 Curriculum guidelines. The primary and secondary school curriculum documents are divided into the following four sections: reading, writing, listening and speaking. Some of the participants indicated that they appreciated the flexible nature of the written curriculum because it allowed for the participants to tailor their teaching practices to their participants needs, which is consistent with Hainer-Violand's (2013) findings. At the same time, with regard to the more general expectations in the curriculum, participants identified problems with determining how to satisfy the expectations through activities and projects engaged in by students and leading to forms of assessment. With the curriculum expectations being similar from grade to grade, Anne noted: "when it's exactly identical in some areas of the curriculum, it's hard to decide what's most applicable. Some schools worked on transitions to decide what to teach students year to year". During the interviews, as noted above, almost all of the participants mentioned how they desired more concrete content, examples, outcomes or requirements. All of the participants who taught primary- and secondary-level 
grades described how the requirements were the same from year to year.

4.4.2.2 Curriculum flexibility. Some of the participants indicated that they appreciated the flexibility of the Ontario MoE written curriculum, but they desired more concrete expectations. A trend emerged while discussing whether participants were satisfied with the FSL Curriculum. Anne expressed that: "I think that it guides, especially French teachers, to have responsibility in that they need to meet certain requirements every year. I just wish that some of those requirements were more concrete.". When the participants were more secure in their teaching practices, they enjoyed the freedom in how they taught their classes. Elizabeth, who is an experienced teacher, explained that "I really like how the document offers concrete ideas on what to teach. For example, they should listen for meaning, for example they should learn vocabulary through songs, oh perfect I'm going to use that." Experienced teachers generally found the curriculum gave them enough information to allow them to draw from their teaching repertoires of exercises, activities, resources and such, in their classrooms. The curricular guideline that students should "listen for meaning" elicited a number of possible activities that would satisfy this requirement.

However, other participants expressed that they were insecure not only about their teaching practices, but also their ability to effectively teach the class based on their lack of qualifications. In reflecting on this finding, I thought that the participants would benefit from a program that shared certain attributes of the Cesar Chavez bilingual program (Hainer-Violand, 2013), where the teachers had weekly grade-level meetings and day-long professional development (PD) days to discuss 
lesson plans and what activities had been beneficial to student learning. The Cesar Chavez program shared criteria regarding expectation, similar to the transparency recommended by Common European Framework of Reference for Languages (CEFR), which recommends discussing explicit expectations for activities or projects with students (Mison \& Jang, 2011; Piccardo, North \& Maldina, 2019).

On the other hand, if a more detailed, fully specified curriculum were to be implemented then there would not be as much flexibility in tailoring the requirements in relation to students' needs (Aoki, 2005; Hainer-Violand, 2013). The benefits of such a flexible curriculum are that it can be inclusive of individual student needs and teacher preferences when teaching. However, this is only effective if the teachers have the necessary knowledge to interpret their students' needs (Cheng \& Fox, 2017).

When asked about how she perceived the curriculum, Alice, one of the novice participants, viewed the curriculum as "just a list of requirements to meet". She explained that:

I would say it's more of just a list of expectations to meet. And what I've been told as especially a new teacher, is to try and look at the overall expectations because every grade has... it starts with an overall expectation and then it goes into specific expectations. I don't know how familiar you are with the curriculum documents, but that's how basically it goes and what I've been told, from, you know, the French consultants in my board, especially for social studies is to look at... start by just looking at the overall expectation and try not to treat it as like a 
whole list to check off every single specific expectation. Because it happens that you don't cover every single specific expectation throughout the year. There's a lot to cover. But yes, I don't find there's... I find that document is a lot more just focused on the list of like, okay get this done.

She was advised by her French consultant to focus on the overall expectations for each section because it is unrealistic to expect a teacher to satisfy every specific curricular requirement within a year. Contrary to the other participants, Elizabeth stated how she had no problem with the curriculum document:

I have to admit I only read the part that's specific to me, I really like how the document offers concrete ideas on what to teach. For example, they should listen for meaning, for example they should learn vocabulary through songs, oh perfect I'm going to use that, so this is my listening mark, and they've given me a tangible task that I can do with as I please.

Elizabeth, one of the most experienced teachers, was satisfied with the FSL curriculum because she had already obtained the necessary skills and teaching practices to effectively interpret what the document communicated. Due to her teaching experience, she had an extensive repertoire of activities that she could use when teaching. It seems likely that the satisfaction of having a more flexible curriculum is favourable for more experienced teachers like George and Elizabeth because they relied on their pre-existing knowledge, repertoire of activities and forms of assessment based on their years of teaching experience.

Having presented how the participants responded to the interview questions about 
their experiences with the Ontario MoE written curriculum, in the following section I explored what resources the participants were given access to, which had contributed to their experiences with professional learning and development. I also explored the participants' account of their professional needs.

\subsection{Resources and support for FSL teachers}

As previously noted, the second research question guiding this study was: What resources and support are FSL teachers given? The purpose of inquiring about resources and support was to provide insight into what the participants' taught their students, since I was unable to observe the participants in their classroom. Another reason for the exploration into resources and support was because the Ontario Ministry of Education Curriculum was reportedly acting as a guideline for the participants rather than a collection of resources and specific or detailed material.

Although all of the participants were teaching in the Ontario public school system at the time of the study, this did not guarantee that they received the same number of resources, based on the participants' accounts of what was supplied to them. Indeed, the participants received varying amounts of support from their schools, school boards and colleagues. At the same time, all of the participants desired more resources and support to better their teaching practices. This finding is similar to that of Lapkin, Vandergift, and MacFarlane (2006) who observed that FSL teachers considered resources were not adequate enough for their needs. As discussed in the biographical sketch, Anne had previously taught French Immersion (FI) classes. Lapkin et al. (2006) discussed how FI teachers are more dissatisfied with materials, whereas Core French 
(CF) teachers have more available resources specific to their students' needs (cf., Arnott, 2011).

However, Anne discussed how support for a new curriculum failed in spite of resources and materials:

she [the curriculum leader] and I got permission from the board to work, we had five days, to work alongside the French high school teachers ... to talk about transitions, and what their kids were lacking, and using the new curriculum, what we should be implementing at every grade. We were the ones who initiated it, and I'll never forget the teachers there. And they've since changed their minds because they were like, "they can't make me change how I teach." And I'm like yes, I can it's government mandated, like this your job, you don't get to choose. If you want to choose then you need to change your job and write curriculum. But it was a very frustrating five days, with an entire French department at the high school level, who had no interest of actually adopting the new curriculum. Now that has since changed and ironically, they were the ones, two of them the two that were so anti-new curriculum, were the two presenting this big, really useful charts [relating] to CEFR at the last French PD [workshop].

Later, Anne determined that the new curriculum and resources were not addressing the needs of her students, so she collaborated with teachers at another school that was also resistant to change. Fortunately, the teachers became professional learning leaders by developing new resources. These findings highlighted that teachers who were previously resistant to pedagogical change can alter their perspectives when they have 
professional learning opportunities (Hargreaves, 1989).

\subsubsection{Collaboration}

Resources do not have to be limited to solely physical resources; human support can also be a critically important resource for FSL teachers. As previously discussed in Chapter two, and as evident in the example of Anne's response to the new curriculum, Hargreaves (1989) discussed the concept of teacher culture, wherein he considered teachers to be present oriented, individualistic, and isolated in their classrooms. The systematic barriers imposed on teachers is what Lortie (1977) coins as the "egg-crate" model of education, where the school relegates teachers like eggs in an egg-crate - all in the same school, but structurally and systematically prevented from engaging with each other in day-to-day collaboration within their schools. The structural limitations (e.g., time for collaboration, collective problem solving) isolated teachers and inhibited their ability to discuss issues, ideas, and solutions with collaborators, who otherwise could provide support (Lortie, 1977). Unfortunately, such a lack of collaboration seemed to be a problem for several of the participants. For example, Samantha reported that she did not have any opportunities to collaborate with her colleagues:

I've rarely seen the other French teacher that teaches kindergarten at my school, like rarely, like I see her in the hallway to say hi in the morning and that's it. Like I don't sit down with her, we're supposed to have team meetings once a month after school, but that's not what we talked about. We talked about the practicalities like field trips, and supplies, and that kind of thing. Yeah, there's very little professional collaboration unless you seek it out yourself, and really put your mind to it, which I don't, at this point. 
Karsenti et al. (2008) conducted a study to determine why FSL teachers are leaving the profession. Based on Karsenti et al.'s (2008) findings, one important reason for teacher attrition is a lack of formal collaboration and interaction with teacher colleagues. Karsenti et al. (2008) discussed how a primary factor of attrition is a lack of formal collaboration. Formal collaboration refers to the allocation of a certain amount of time by school boards or schools for teachers to discuss teaching practices. As highlighted by Samantha, on occasion when she did see her FSL kindergarten colleagues, the intention of the meetings was not to discuss what activities they implemented in their class, but rather to plan activities like field trips. The lack of opportunities to collaborate with her colleagues suggests that Lorte's (1977) egg-crate structure is still present in the school system.

Similarly, Brian expressed how experienced teachers were hesitant to supply novice teachers with support and resources:

I find that most teachers will help you if you bug them. "Hey, I'm looking for this, do you have anything?' and they go yes. And maybe they've learned not to step on people's toes. Maybe some new teachers, they felt that they needed help and go 'here this is all my stuff'. I can help you if you want to sit later. But they've received feedback saying that the new teacher 'my stuff is no good. You just want to replace all the stuff that I'm doing,'. I don't know. Personally, I would love to have all this stuff thrown at me but that's why she said that she was hesitant. You can come and ask me but I'm not going to put it on you and I'm like okay, alright. 
Brian mentioned how previously, novice teachers informed the school administration that they felt their resources were not adequate after the novice teachers were approached by the experience teachers. Brian's colleagues informed him that if he required help with developing assignments or projects then it was up to him to seek help. Although, it is completely understandable that Brian's colleagues were hesitant to provide support based on their past experiences for fear of undermining the confidence of novice teachers. Developing a widely accessible database of resources could address the problem of teachers previously hesitating to share resources

Interestingly, Alice and Brian, who were categorized as the novice teachers in the present study, went to the same teacher's college and taught similar grades. However, they did not share their resources. During their separate interviews, Brian and Alice mentioned how they used resources to support their transition of becoming novice teachers. Alice was enrolled in the New Teacher Induction Program (NTIP) (Ontario MoE, 2010), whereas Brian was provided with Ontario's The New Teacher Handbook: Surviving and Thriving in the French as a Second Language Classroom for support during his first year of teaching (Canadian Association for Second Language Teachers, 2017). When I interviewed Alice, she had no knowledge of the CASLT (2017), whereas Brian did not note the existence of NTIP program (Ontario MoE, 2010). Although Brian would not qualify for NTIP, his school setting created some informal opportunities for mentorship and collaboration because several teachers shared offices. However, the lack of communication between Alice and Brian could be attributed to teacher culture (Hargreaves, 1989) where the egg-crate structure dominated their perspectives on how to manage the demands of their profession, in spite of the evidence accumulated from 
the literature on the benefits of relational knowing (e.g., Hollingsworth, Dybdahl, and Minharic, 1993) in supporting teachers' professional development.

Having described the findings regarding collaboration, the following section further explored professional development.

\subsubsection{Teacher professional development}

The purpose of teacher professional development and learning is to improve teaching practices for the benefit of student learning (Pedder \& Opfer, 2013; Masson, 2018). As discussed in Chapter two, there is a difference between professional learning and professional development. Professional development is when teachers are mandated to learn about a new theory or activity. The theories and activities were decided upon without discussing the needs of the teachers (Hainer-Violand, 2013; Cordova, 2014; Webster-Wright, 2009). A governing body who is imposing the professional development does not consult the specific group of teachers on their knowledge base or specific needs of a school or school board (Hainer-Violand, 2013).

As discussed in Salvatori (2009), there is an influx of unqualified FSL teachers entering the workforce based on the increased interest in FSL programing without allocating qualified FSL teachers. Anne agreed, “...what's happening right now is that a lot of French teachers are being hired who shouldn't necessarily be teaching French, because there's such a demand for it, because even my board is expanding the French program, but they don't have the French teachers to fill it." While teacher attrition is a contentious issue, as noted previously, there are some studies that reveal unqualified and novice teachers were more likely to leave the program than qualified teachers (Miller, 
Brownwell, \& Smith, 1999; KippFerguson, 2013; Karsenti \& Collin, 2013; Karsenti et al., 2008; Salvatori, 2009). Without effective training, there is high chance of attrition because of the teachers' inability to cope with the demands of the job (Karsenti et al., 2008). Although, the problem with lack of training is typically expressed by novice teachers. This sentiment is echoed in Samantha's frustration with her current teaching position. When the 50/50 French-English kindergarten classes began, there was a PD day to explain the new program in attempt to prepare the teachers. Since the first French focused PD day, Samantha had not been invited to attend another FSL focused kindergarten PD day. The lack of collaboration can lead to emotional toll, where teachers feel isolated and alienated (Hargreaves, 1989; Karsenti et al., 2008; OCOL, 2019). For example, Samantha seemed upset when she discussed the minimal interactions with other FSL kindergarten colleagues. As discussed in OCOL (2019), Samantha could be having a difficult induction (Figures 4.3 and 4.4). Since Samantha is considered to be an experienced teacher, her administration might not have recognized how the change in her career had affected her perception of her teaching practices.

Upon investigating FSL professional learning, Masson (2018) observed that with an open dialogue with their school administration, FSL teachers were able to benefit from their self- actualization.

Out of all the participants in this study, Alice was awarded the most resources and support compared to the other participants in this study. She mentioned how she was able to communicate directly with a French consultant and was involved in a mentorship through the NTIP program. 
Yeah, so that NTIP program that I was telling you about...so I chose to be part of it and you have to pick a mentor, so I have a mentor in my school who also teaches similar grades to me, and I luck out because we share an office and so we get to cheat. Well, she supports me a lot that way where we'll be working, or we'll be on prep and we'll be working together. We also get release days, not many we get two between the two of us, and that allows us to book a supply teacher so that her and I can meet up and conference and plan or whatnot. So what we're planning is using that in the new year once report cards are starting because it will be my first time writing like big report cards. I did progress reports in the fall, but those are not... they aren't quite as complicated. So, there's quite a bit of opportunity, but that applies to both French teachers and English teachers.

During the release days, Alice and her mentor were provided with supply teachers, so they could focus on the suggestions that were made in the document or potentially other issues that might have arose during Alice's teaching practices (Ontario MoE, 2010). The release days did not include them meeting during their prep time, whereas Brian only had an opportunity to collaborate with his colleagues in their shared office.

There seemed to be a problem with the dissemination of information and an overall lack of communication between teachers. This finding is similar to that of Lortie (1977) and his discussion of constraints found in the school system, which acts as a barrier for communication. For example, Brian and Elizabeth worked at the same school but unlike Elizabeth, Brian was instructed how to get more assessment opportunities from projects and activities - not his 
colleagues:

A lot of them are open ended projects for sure. So, I'm trying to give them explore at your own pace so whether, I try to avoid group work because there is a lot of conflicting personalities. I get some in there but the majority tends to be their own little French presentations to get their oral marks and their social studies so they can get up and talk and do it in a way that feels most comfortable to them.

Brian learned during teacher's college that an activity or project should yield multiple opportunities for assessment, such as tasking students with presentations in order to have an opportunity to assess their FSL oral communication skills and social studies knowledge.

\subsubsection{Teacher professional needs}

Based on several research studies exploring FSL teachers' professional needs (Black \& Wiliam, 2010; Cochran-Smith \& Lytle, 1999; Hopkins, 2000; Karsenti \& Collin, 2013; Karsenti et al., 2008), the Ontario MoE appeared to address the professional needs of novice educators. The Ministry of Education had implemented NTIP (Ontario MoE, 2010) and published the Ontario's The New Teacher Handbook (CASLT, 2017). Although, there seemed to be less focus on experienced teachers' professional needs. Studies on professional learning have acknowledged how teachers continuously learn throughout their career (Opfer \& Pedder, 2011; Karsenti et al., 2008), yet initiatives targeting professional needs are typically directed at novice teachers (CASLT, 2017; 
Ontario MoE, 2010).

Samantha, one of the experienced teachers, became an FSL teacher later in her career unlike other experienced participants in this study who had been FSL teachers since the onset of their careers. There is a possibility that she did not receive adequate support because her administration was not aware of the problems that she was having with assessment and teaching practices. This is supported by Karsenti et al. (2008), who indicated that some of the novice FSL teachers did not have the confidence to approach their school administration for help. Samantha became an FSL teacher based on necessity and indicated that she did not consider herself to be a real FSL teacher because she lacked the adequate qualifications. It did not help that she was not invited to a FSL PD day:

Well, we have focuses, foci, but we haven't had a PD day that's just been about French any time in recent history. But you know what? I might not be invited to them now that I think about it. We had one at the very beginning of this new 50/50 program. I did attend and they showed us a whole bunch of... I think most teachers... it doesn't make sense to me, but most teachers decide they're going to try and do math mostly in French, which is a big disconnect for me because math is now taught in English even in French immersion, it's taught in English. It didn't used to be, it used to be if you're in French immersion, math was in French. Yeah, I would say that's probably true and I would say also that I likely get sent if there's options for PD. I like to get sent to kindergarten PD versus FSL PD, because I'm not really teaching like French classes. But 
yeah, as I said we did have at the very beginning of this, probably two to three years ago maybe longer, we had a PD day about teaching the new kindergarten curriculum in French. And yeah, we just were shown a lot of resources for math, story books and that sort of thing is what I would call... And there was a lot of emphasis on trying to get kids to actually productive language as a means of learning and retaining and all that sort of thing.

Instead of attending FSL PD days, Samantha attended to kindergartenfocused PD days. Unfortunately, she was unable to indicate whether her FSL colleagues also attended the kindergarten PD days with her rather than attending FSL PD days at her school board.

\subsubsection{Insecurities about teaching practices}

As discussed in Chapter two, some unqualified teachers are able to teach FSL classes because of a shortage of qualified teachers (Karsenti et al., 2008; OCOL, 2019; Salvatori, 2009). Since Samantha completed high school with her FSL diploma and can speak French, she was asked to take on the responsibility of the FSL teacher for her class. OCOL (2019) observed that due to the shortage of qualified FSL teachers, school boards relied on self-assessment techniques for teachers' proficiency in French.

Samantha mentioned how she dedicated more time outside of work for her professional development at the beginning of her career. "I remember when I first graduated from teacher's college I was all about professional reading and all that kind of stuff.". Depending on teacher's responsibilities, they do not have time to focus on their professional development outside of school hours since they are already tasked with 
developing lesson plans and marking (Karsenti et al., 2008). Although Samantha has 20 years of overall teaching experience, she is relatively new to teaching FSL classes. Samantha considers herself unqualified for her teaching position because she has not completed the FSL certification. Although imposter syndrome is often associated with someone at the beginning of their career, it can appear when there is a change in someone's career (Sims \& Cassidy, 2019).

As discussed in Chapter two, experienced teachers can encounter feelings similarly found in the imposter syndrome. When new situations occur, there is a learning curve, which may be shorter for more experienced teachers than novice teachers. In Samantha's case, she did not consider herself to be a real FSL teacher because she lacked all of the necessary qualifications. As seen in Figure 4.5, she seemed to doubt her abilities as a FSL teacher because she lacks the adequate qualifications. Samantha reported that, "I've only taken part one of the of the three-part additional qualification series" 
Figure 4.5

Self-doubt

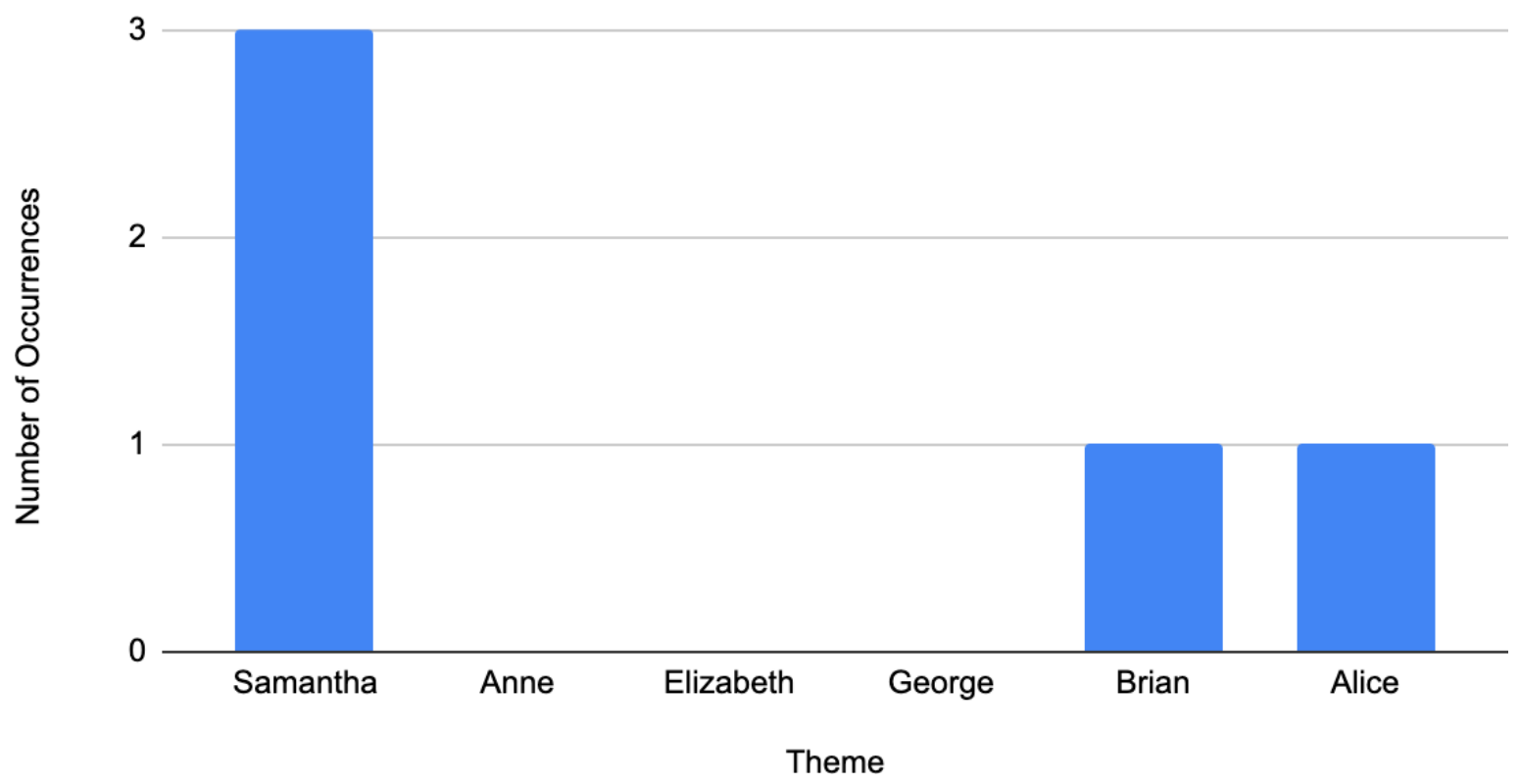

As seen in Figure 4.5, the novice teachers, Brian and Alice, indicated that they were insecure more about their ability to adequately speak French to their students than their ability to teach. The more experienced teachers, all of whom have ongoing experience in the FSL program, Anne, Elizabeth, and George, did not indicate that they were insecure about their teaching practices or proficiency. It is logical to conclude that if Samantha had not undergone a change in her career, she would have responded similarly to the other experienced teachers who did not indicate insecurities about their teaching practices.

Following the discussion of professional development and participants insecurities about their practices, the next section explored the teachers' accounts of their classroom environment. 


\subsubsection{Classroom environment}

Following Connelly and Clandinin (1988), the commonplaces refer to "a set of factors or determinants that occur in statements about the aims, content, and methods of the curriculum", which consists of the role of the teacher, assessment, milieu, learners, and content (p.84). The role of the classroom was addressed differently among the participants. As seen in Figure 4.6, the theme was prevalent during the interviews with Samantha, Elizabeth, Brian and Alice.

\section{Figure 4.6}

Classroom environment

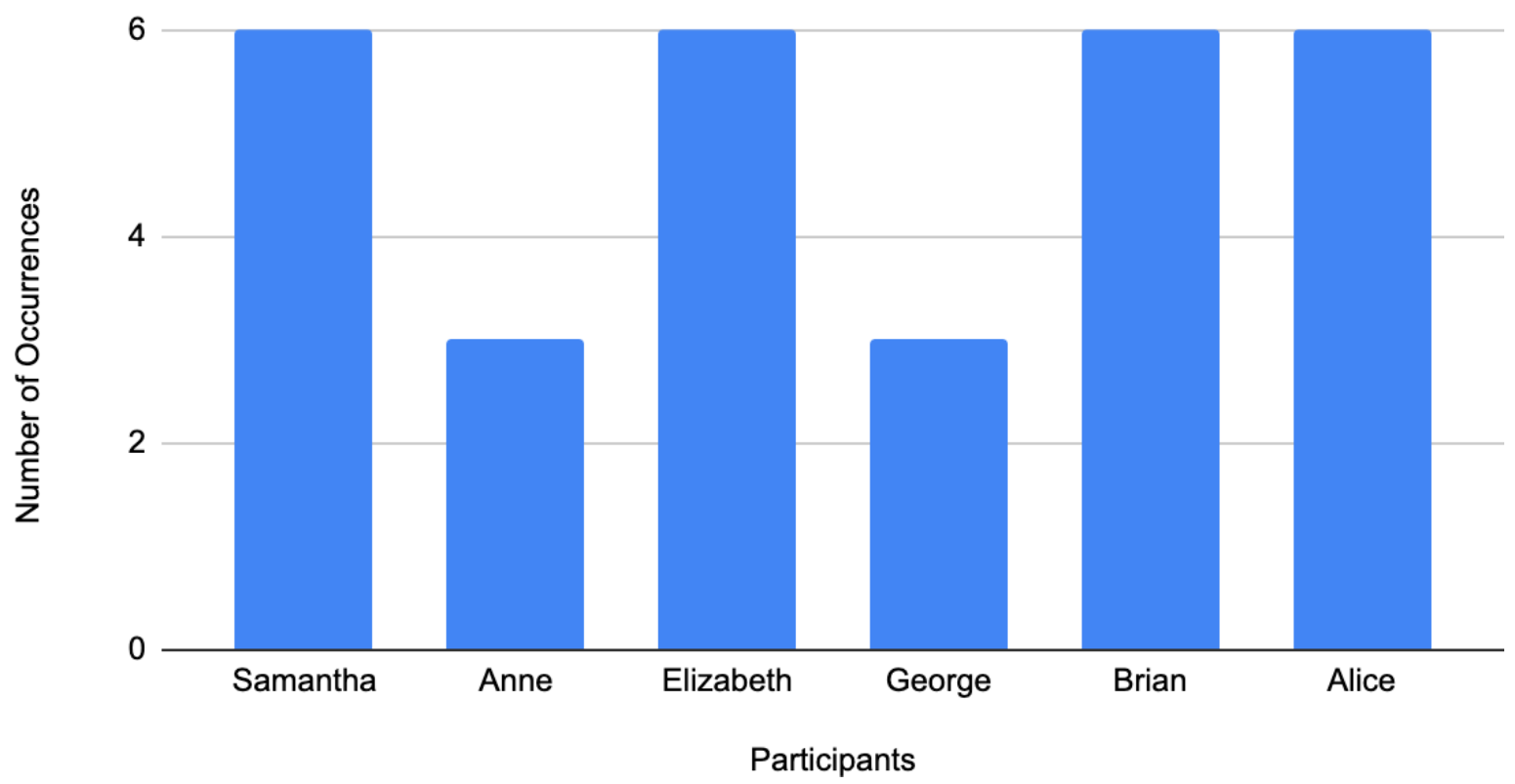

In Figure 4.6, as it was one of the interview questions, all of the participants discussed the classroom environment to some extent during their interview. However, some of the participants mentioned the theme less than others. During their respective interviews, it appeared that Anne and George did not refer to their classrooms as often as the other participants, at 3 occurrences, whereas the other participants discussed their 
classroom 6 times each. The majority of both novice and experienced teachers remarked how there was no mention of the role of the classroom in the FSL curriculum.

Samantha referred to the classroom as "the third teacher". Since kindergarten is play-based, the centers set out for the students are based on what the children are interested in to spark interest in learning. Samantha explained:

The third teacher? Yes, it's huge in kindergarten because everything is playbased now, so really the beginning of the year, we look at the group that we have, and you can kind of figure out how your years going to go... [students] just come in and choose what they want to do and we just focus on helping them interact successfully with each other and with the equipment and furniture and stuff like it's pretty basic.

With the new kindergarten play-based curriculum, the teachers were expected to help the students interact successfully with each other and the activities. Samantha reported that:

So, you put out what are called invitations, or there's another word for them to, provocations. So, I'll put on a table for example a dice and some Domino's and maybe some number cards. And then the kids can like roll the dice and count the dots and then find a matching number card and match them up. Or, I will sit and play with for example, we have those plastic animals that belong to my children that I brought in. So, I'll stay with them and they're playing with them, and so I'll do like okay, what is this 
called or what is it called in French, that kind of thing, where you just integrate into their play and try and direct them.

Based on the play-based model, Samantha would integrate new vocabulary words, while her students were fascinated with different items in the classroom, whereas Elizabeth used a different tactic to interest her students. Elizabeth used various classroom arrangements and activity centers as a way to make her practices more engaging:

Yeah, I think it does, but I think the bigger factor is the teacher themselves. I know I tend to have my classes in different rooms. For example, we might do an activity in the cubby area, we might do an activity in the library, the conference room, around the piano, we'll be outside. So, our environment tends to change. I do have a dedicated classroom, and the kids move to me, but I won't always teach in that room, I might teach in the gym, I might teach outside. Again, that's like a teacher preference.

Based on what was described, Elizabeth changing classrooms did not have a direct impact on learning, which was the case with Samantha's kindergarten class. There is no obligation for the participant to teach in different settings. Elizabeth expressed that changing the classroom setting is more engaging for the students, which contradicts what was discussed in Ontario's The New Teacher Handbook: Surviving and Thriving in the French as a Second Language Classroom (CASLT, 2017). CASLT (2017) discussed how it is important to establish a specific area or develop cues to transition a classroom 
for French. Mnknjian (2016) argued that learning environments can facilitate student success by engaging and motivating students.

As noted above, the participants noted that there was no mention of the role of the classroom in the grade-specific curriculum. Fortunately for Brian, CASLT (2017) discussed the importance of simulating a French-specific learning environment with specific cues. Brian discussed how:

With the handbook, it's mostly designed to provide tricks of the trade, so tips of being a new teacher. You should bring a cart around because even if you don't have a full class to yourself. They recognize the cart and recognize you and they know what time it is the second they see it. It gives a lot of symbolism stuff. I would say that it gives a lot of classroom management and classroom teaching and all that stuff. Most French teachers go from class to class, I've found.

CASLT (2017) stated that often the classrooms that FSL teachers were teaching in were most likely not theirs, and suggested techniques to employ in order to make the classroom environment more amenable to the FSL program. These changes were designed to put students in a frame of mind which would make them more receptive to learning French.

\subsubsection{Assessment}

The Ontario MoE (2014) published a written curriculum document, which called for assessment practices to take into account students' needs, 
whether the student had special educational needs or were ELLs.

\section{Figure 4.7}

Assessment

12

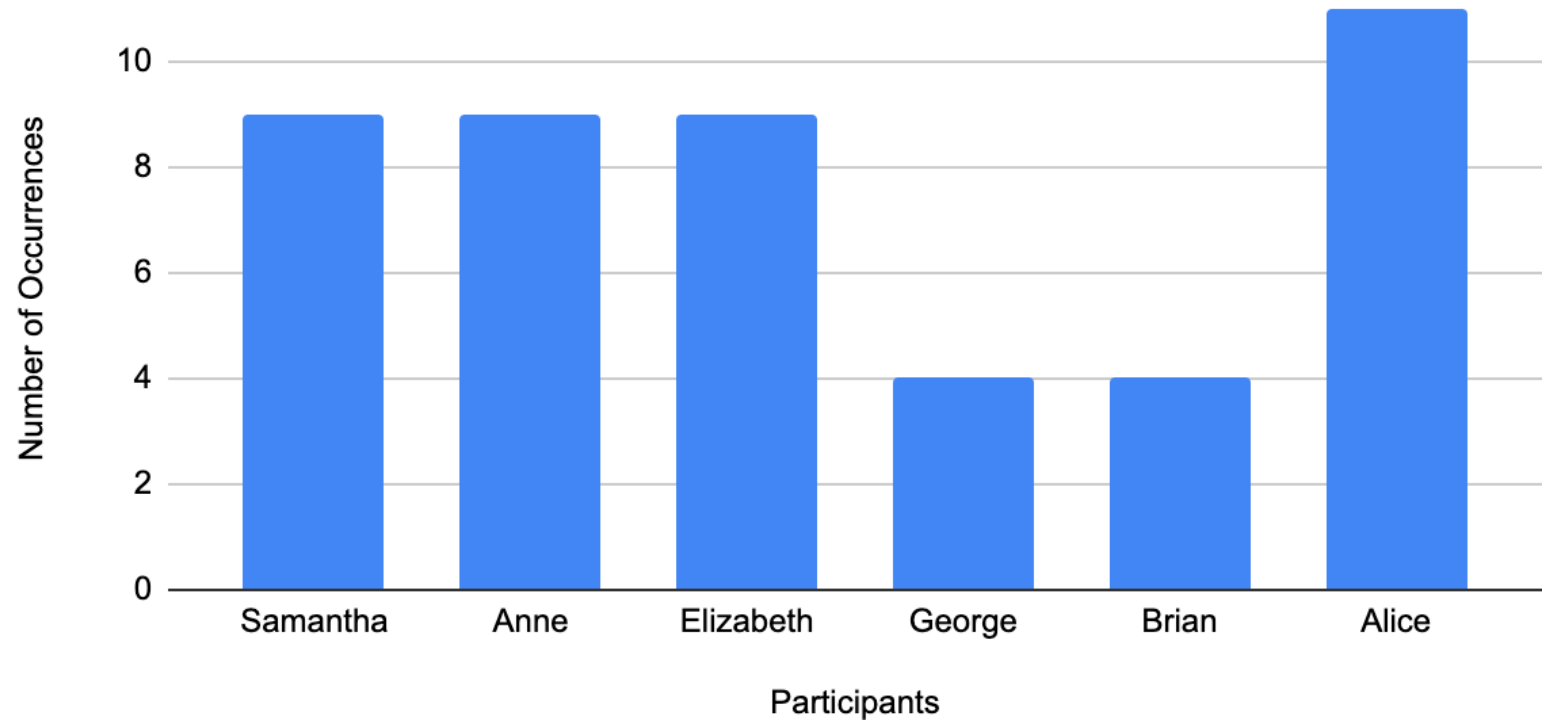

While interviewing the participants, it appeared that the participants preferred to use projects and presentations rather than using worksheets as a form of assessment which were better able to accommodate very different levels of proficiency and capability in their classes. Brian discussed how the projects he chose were based on students' skill level and language proficiency:

A lot of them are open ended projects for sure. So, I'm trying to give them explore at your own pace so whether, I try to avoid group work because there is a lot of conflicting personalities. I get some in there but the majority tends to be their own little French presentations to get their oral marks and their social studies so they can get up and talk and do it in a way that feels most comfortable to them. Um, and I have very different expectations depending on where they are. I would say that's the easiest. 
The presentations appeared to have been a way to get the most out of an activity by getting marks for both French and social studies. It was interesting that both novice teachers used this method.

One of the experienced teachers, who also taught at the same level, remarked on a desire for guidance regarding how to assess students' French proficiency and social studies knowledge in the same activity. The novice participants also modified assessments to the benefit of the students' abilities. Brian provided opportunities for assessment based on his students' skill level and whether they have special education needs (SEN). Brian discussed how one of his students has a much higher proficiency in French than the other students in the class,

It gives him a chance too because he's so advanced to modify him. I've given him either if they're doing a short 4 or 5 questions. We'll try to work on that and build it. I'll give him quite a bit more or something that has been good for him. He's a good writer but he makes a lot of grammatical mistakes because he's just a speaker. So, giving him something to copy down is fun to watch because he'll make little mistakes in the grammar or as he's listening that he's an oral language person and his writing is good. I think that's an area of improvement and I think it's been very good for him

For example, if a students' abilities were more advanced than the rest of the students then the teacher would alter the assignment to better match the students' skills. Brian implemented a form of needs analysis in order to gauge how to effectively meet your 
students' needs while still satisfying curriculum (Cheng \& Fox, 2017).

Especially for the novice and kindergarten participants, there was interest in having more assessment tools. Assessment for kindergarten teachers was fairly different than the grade- specific teachers. When Samantha assesses her students, she conducted:

small group learning where I'll do, you know, I do a math game with them or I'll do guided reading with them or that kind of thing so that that's more control then I can pull them three at a time and make sure I get through everybody. But yeah, a lot of it is just through their play and through just regular conversation, so I could be playing outside, and we'll talk about you know, what we're seeing about the weather, what we're seeing about the tree in our yard and that kind of stuff. It's very loosey-goosey. They just come in and choose what they want to do and we just focus on helping them interact successfully with each other and with the equipment and furniture and stuff like it's pretty basic.

According to Samantha, kindergarten teachers are expected to assess how the students are interacting with the activities.

\subsubsection{Students needs}

Several of the participants noted that they were faced with diverse students' needs. Brian had multiple types of difficult students in his classes. Many of his students were unmotivated and had learning disabilities or disorders. "Um, and I have very different expectations depending on where they are. I 
would say that's the easiest". Brian tailored his assessments based on his students' skill levels. Brian mentioned how, "[a] lot of the IEPs require organizational stuff, so a lot of it is me making them checklists". Also, many of Brian's students had behavioural problems, “[B]ecause they're so low, there's fighting over who gets to be in the front of the line and they're in grade 6 . I mean come on guys. Fighting over who's going to be in the front of the line for recess. That's just my frustration". He expressed that he was overwhelmed because he was never trained on how to effectively teach students with students' educational needs (SEN). Alviarez (2017) argued that the lack of resources could make it difficult for teachers to attend to students' needs. Brian's description of his students' needs was similar to findings found in Karsenti et al. (2008), which indicated that there were three types of difficult student bodies: students with behavioural problems and/or learning disorders, classes with diverse learning needs, and unmotivated contumacious or violent students. It is important to note that there is a potential to have multiple types of students within the same class (Karsenti et al., 2008).

In Figure 7, Samantha demonstrated that she was particularly attuned to her students' needs, which she was unable to address, which resulted in her being frustrated. Samantha indicated that:

So yeah, they're still learning English. So the amount of curriculum I can deliver in French realistically is not where it would be at a regular school, I would say so, I'm really just doing like the sort of instructions that I give every day. I will do those in French and I do read to them in French and that 
sort of thing but I can't... we're not at the point generally even by the end of the second year that I teach them, they're not really conversing a lot with me in French or English. Yeah, because they're literally just beginning to learn, so.

At Samantha's school board, kindergarten students remain with their teacher for both years of kindergarten. Samantha expressed that the fact that her students are ELLs hinders her ability to teach FSL because her practices rely on her students' proficiency in English. Based on her FSL teaching knowledge, she was unable to effectively teach her students because of their minimal proficiency in English. Karsenti et al. (2008) indicated that the various difficulties (i.e., lack of resources and support, difficulties with student body) could lead to teacher attrition.

\section{Figure 4.8}

Student needs

\section{8}

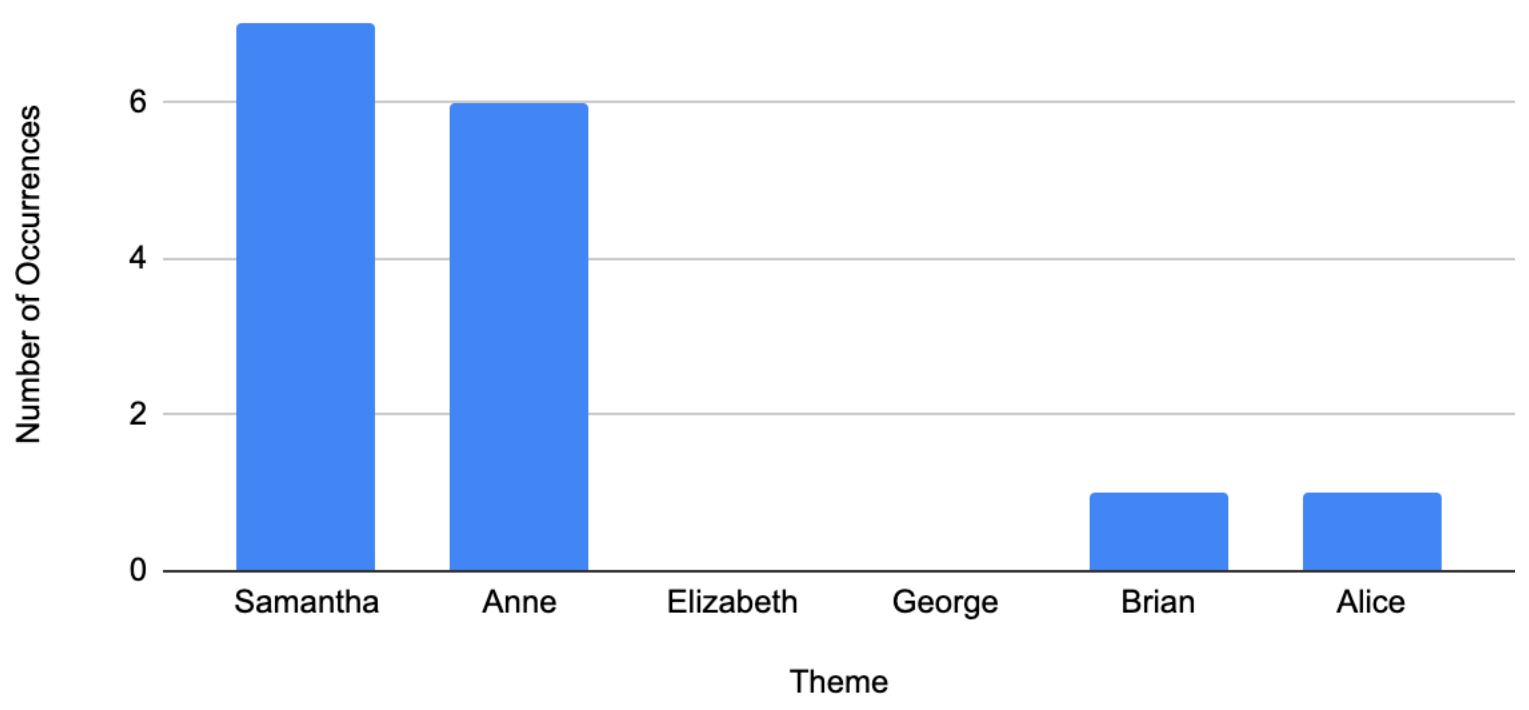


As seen in Figure 4.8, the participants did not acknowledge students' needs with the same frequency. Samantha and Anne appeared to frequently mention their students' needs. This finding contradicted arguments made by Cloutier (2018) in which she argued once teachers are not focused on their professional development, they will focus more on their students' needs. In my study, the participants who were particularly attuned to their students' needs were the teachers who have students with learning disabilities and ELLs in their classes, whereas Elizabeth and Brian did not indicate during their respective interviews that these characteristics were present in their participants.

4.5.6.1 Diversity. Gentil and Séror (2014) noted how in Canada, English is the chosen language for disseminating knowledge in research contexts. This can be limiting for those who do not have English as their L1. The FSL program in Ontario is based on the assumption that students L1 is English. While this is true for many students, there is an increasing number of ELLs in Ontario as the population becomes more diverse (Trilokekar \& El Masri, 2020). Unfortunately, the teaching population does not reflect the same level of diversity as the student population. According to Trilokekar and El Masri (2020), teachers increasingly do not share the same lived experiences as their students because they do not share the same ethnic background and values as their students.

The Ontario MoE published a document, Welcoming English Language Learners into French as a Second Language programs, to promote 
ELLs in the FSL program. In the section discussing strategies for supporting ELLs in FSL, Ontario MoE (2016b) claims that "FSL educators are well suited" to support ELLs in FSL (p.10). This statement assumes that the FSL teacher is qualified and has an arsenal of educational tools when teaching an FSL class. Ironically, the two participants, Alice and Samantha, who have ELLs in their FSL classrooms are not qualified to teach FSL because they lack the qualifications. Samantha discussed how:

because I've only taken part one of the of the three-part additional qualification series and I teach at a very.... Well we're the number one raised index, that school, I think in the province. So we're like socioeconomically the most disadvantaged, so all of our kids are recent... their parents are recent immigrants to Canada at least so we have a lot of ESL kids, like stage one ESL, or step one.

As discussed in Samantha's participant biographical sketch, the majority of her students are ELLs. She stated that:

there are a whole bunch of second language English speakers speaking to each other and I'm the only proficient English speaker in the classroom. Even my ECE partners generally are not first language English speakers. That's what's happening too now, which is great because often they speak Somali or they speak Arabic and that's what a lot of my kids speak. So the ones that have no English at least have a way to communicate with staff in the building. 
Although she does not speak the same L1 as her students, she has ECEs who, fortunately, speak the same L1 as the students, which provided a buffer. Utilizing the ECEs is similar to translanguaging, which uses multiple languages in the classroom to build tools so that students can better understand the course content (Gentil, 2018). Samantha conveyed that it can be difficult teaching FSL when her students barely speak their home language let alone English.

Samantha disclosed that:

they're still learning English, so the amount of curriculum I can deliver in French realistically is not where it would be at a regular school, I would say so, I'm really just doing like the sort of instructions that I give every day. I will do those in French and I do read to them in French and that sort of thing but I can't... we're not at the point generally even by the end of the second year that I teach them, they're not really conversing a lot with me in French or English. Yeah, because they're literally just beginning to learn, so.

Samantha highlighted how her students' proficiency in French was not where she believed it should be by the end of Kindergarten. She also expressed having difficulty with trying to teach in accordance with the curricular expectations while addressing her students' language needs. This finding is similar to Mady (2016), where the participants disclosed that FSL was for all students. One of the participants from Mady (2016) advocated for exempting a student from the FSL program because their needs were not 
being addressed in the class. Mady conducted several studies advocating for the inclusion of ELLs in the FSL program comparing ELLs with bilingual and monolingual Canadian-born students. The participants from Mady $(2012,2014,2015)$ were grade 6 and had a better grasp of language whether it was their Home Language, English or French, whereas Samantha's students were beginning to develop their linguistic repertoires.

Having discussed the allocation of resources among the participants, this next section will explore the differences between the novice and experienced FSL teachers.

\subsection{Differences between novice and experienced teachers}

As previously discussed, the third research question guiding this study was: Are there differences between FSL novice and experienced teachers? Similar to Arnott (2012), I explored areas of convergence and divergence in the accounts of the participants. As seen in Table 4.1, magnitude coding was beneficial for comparing how many times a participant discussed different themes during their respective interviews (Saldaña, 2013). Table 4.1 demonstrate the different themes that arose in the data during each interview, while Figure 4.9 better highlighted how the salience of certain themes during the interviews, which was an indication of the theme's importance.

Table 4.1 - Magnitude coding 


\begin{tabular}{|l|c|c|c|c|c|c|}
\hline Theme & Samantha & Anne & Elizabeth & George & Brian & Alice \\
\hline Self-doubt & 3 & 0 & 0 & 0 & 1 & 1 \\
\hline Students needs & 7 & 6 & 0 & 0 & 1 & 1 \\
\hline Class environment & 6 & 3 & 6 & 3 & 6 & 6 \\
\hline Assessment & 9 & 9 & 9 & 4 & 4 & 1 \\
\hline Curriculum & 6 & 6 & 6 & 3 & 7 & 3 \\
\hline $\begin{array}{l}\text { Desire for more } \\
\text { concrete guidance }\end{array}$ & 2 & 2 & 0 & 0 & 1 & 2 \\
\hline Frustration & 3 & 5 & 0 & 0 & 0 & 0 \\
\hline \begin{tabular}{l} 
Dissatisfaction \\
\hline
\end{tabular} & 2 & 0 & 0 & 0 & 0 & 0 \\
\hline
\end{tabular}

Figure 4.9

Magnitude coding

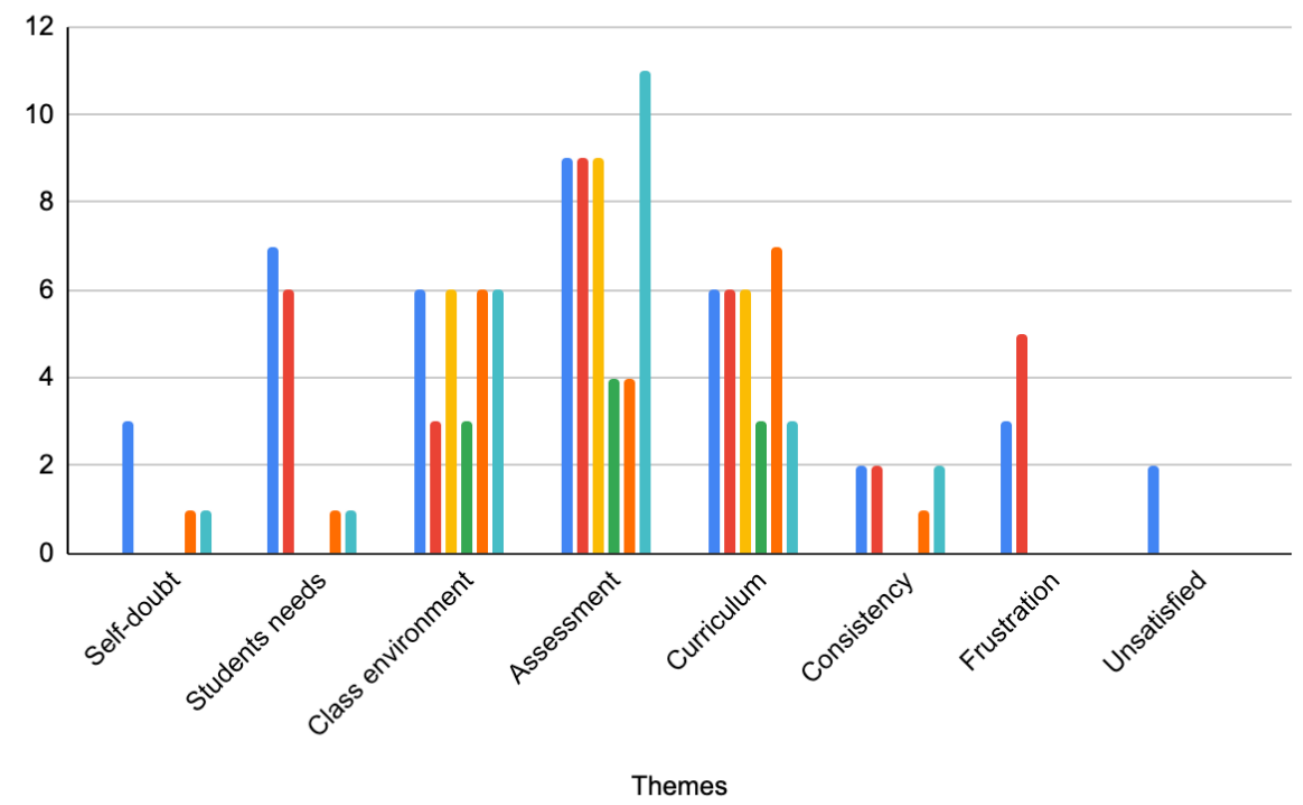

Figure 4.9 further highlighted the distribution of themes across the participants and drew attention to areas of convergence and divergence. As previously illustrated by Figure 4.7, assessment was a prevalent theme that 
emerged in the analysis of all the participants' accounts of their teaching experience. However, Samantha, Anne, and Elizabeth, who were all experienced teachers, were more focused on assessment, whereas George and Brian discussed assessment, but it was not a dominant concern. Out of all of the participants, Alice appeared to focus the most on assessment during the interview.

Among the participants, an area of divergence was the satisfaction or frustration with the curriculum. Regarding the curriculum Brian was more enthusiastic about the curriculum than most of the other experienced teachers. In general, there were almost no difference among the novice and experienced teachers in their accounts of the curriculum. The majority of the participants requested more resources regardless of their teaching experience. The main difference among the novice and experienced teachers was their perceived need for additional allocation of resources and support. Based on the data from the interviews, novice teachers received more resources than their experienced colleagues. For example, Brian shared an office with another FSL teacher who gave him regular support by sharing resources and methods of assessment, and Alice was enrolled in NTIP during her first year of teaching. Alice was formally paired with a mentor with whom she met on a regular basis. Both of the novice teachers, Alice and Brian expressed a desire for more resources and workshops to better tailor their teaching practices, not only to meet curriculum requirements but also to address student difficulties. Brian suggested that: 
... there should be a giant resource database where here is everything that every teacher has tried. I think that would be helpful. I know that's too in a dream world. I don't see why it wouldn't be because I think every child should have access to an equal opportunity education. There should be an online connection for the ministry but how would you filter that.

Brian thought it could be constructive to have a database where teachers could upload different resources, so teachers could have agency in their professional learning. This could be a beneficial form of collaboration because it could disseminate resources that would otherwise be confined to specific schools or school boards.

Among the participants, a key area of divergence was their level of satisfaction and frustration. As previously seen in Figure 4.4, Samantha and Anne, who were both experienced teachers expressed that they were frustrated in their respective interviews. Although all of the participants refer to assessment during their interviews, the play-based model and lack of FSL in the kindergarten written curriculum (Ontario MoE, 2016a) appeared to have a negative effect on Samantha's teaching practices. Samantha explained that:

The difficulty that I find is that I'll do that [a play-based activity] with a little group of kids, but what about the kids who didn't choose to do that? So then I've only covered it with the kids who chose to participate. So then how do I assess and whatever. So a lot of it is observations and 
anecdotal notes and that kind of thing.

The play-based assessment strategies from the curriculum made it fairly difficult for Samantha assess her students, because the students were allowed to choose whether or not to engage the activity. Abdullhamid and Fox (2020) discussed the importance of assessment for both teachers and learners. At the time of this study, Samantha was new to FSL instruction, she was frustrated with the lack of support for assessment strategies that she is supposed to use. Her frustration stemmed from her need for additional human and material support in this new teaching context even though she was a very experienced teacher.

As previously discussed, Anne expressed that she was frustrated about how seemingly easy it was for unqualified teachers to obtain a teaching position. She had dedicated much of her time and education to teaching FSL but ended up with a teaching position that was similar in all respects to positions offered to unqualified individuals. As seen in several studies on teacher retention, unqualified teachers have a higher chance of exiting the profession within the first five years of teaching, whereas qualified teaching candidates will remain in the profession (OCOL, 2019; Salvatori, 2009).

\subsection{Conclusion}

This chapter presented the findings and discussion based upon the analysis of the data, which investigated teachers' accounts of the interpretation of curriculum, allocation of resources and support for novice and experienced teachers. It explored six teachers' accounts of curricular and human resources 
in teaching FSL. Having identified recurring themes in their responses, I

looked for areas of convergence and divergence in their accounts. Finally, I

conducted a synthesis of how novice and experienced FSL teachers interpreted the curriculum and were allocated resources and support.

Having discussed how the research questions framed the findings, in the following chapter, I summarize key findings that arose from the analysis along with limitations and implications for future research. 


\section{Chapter 5: Conclusion}

\subsection{Introduction}

The study presented in this thesis was guided by the following research questions: How are FSL language policies and curriculum documents from the Ontario Ministry of Education interpreted by FSL teachers? What resources and support are FSL teachers given? Are there differences between FSL novice and experienced teachers? The study aimed to highlight teachers' accounts of the allocation of resources for novice and experienced teachers who, at the time of the study, were teaching in the FSL program in Ontario schools. I defined the terms, novice teacher and experienced teacher, by drawing on the distinction from Vonk and Schras (1987). As noted in Chapter two, Vonk and Schras (1987) considered the induction period for teachers to last seven years from the onset of their careers to developing feelings of competency and security regarding their teaching practices. For the novice teacher group, I recruited teachers with a maximum of five years of experience because I wanted to acquire the novice teachers' perspectives prior to their feeling secure and confident about their teaching practices. The second category of participants were experienced teachers who had at least ten years of teaching experience, which I considered to be a sufficient amount of time to act as a buffer for any residual insecurities about their teaching practices after the induction period (Vonk \& Schras, 1987). Having discussed the findings in Chapter four, in this final chapter, I have briefly summarized the findings, discussed the limitations of the study, provided recommendations that emerged from the study and important next steps for future research. 


\subsection{Summarizing Findings}

Various key themes emerged from the analysis of the teachers' accounts. The participants in this study reported that the Ontario Ministry of Education (MoE) French as a Second Languages Curriculum was essentially a list of abstract guidelines, a finding which was similar to a finding reported by Cloutier (2018). Depending on the teachers' experience, they requested more concrete guidance and resources. Two of the teachers, Brian (a novice teacher) and Elizabeth (a very experienced teacher), did not share the same desire for concrete guidance, which suggested that they had already developed strategies, materials, and so forth and appreciated having a flexible curriculum. Although, Samantha (an experienced teacher), was frustrated and dissatisfied with the lack of concrete guidance and resources for the Kindergarten Program (Ontario MoE, 2016a), it should be noted that Samantha also had only recently begun teaching FSL at the kindergarten level. Similar to findings from Sims and Cassidy (2019), Samantha expressed feelings of insecurity about her teaching practices and a desire for additional support, which suggested that the differences among novice and experienced teachers cannot be simply attributed to years of teaching experience, as stated Vonk and Schras (1987). When teachers experience substantive changes in their careers, they can have insecurities about their teaching practices, which are typically felt by novice teachers (Sims \& Cassidy, 2019).

Regarding the allocation of resources, the study suggested that 
resources should not be viewed solely as physical or material ones (e.g., assessment tools, textbooks, data bases). An even more significant resource is the human support provided by colleagues and other professional stakeholders through the creation of opportunities to collaborate. Such opportunities can arise in both formal (e.g., assigned mentors, needs-based professional development events) and informal (e.g., shared office spaces, time for interaction, mentoring relationships with colleagues) initiatives (cf., Hargreaves, 1989; Hainer-Violand, 2013).

Further, the results of this study suggested that most of the professional learning opportunities and learning resources focused on novice teachers (e.g., NTIP and Ontario's New Teacher Handbook). However more experienced teachers in this study also desired opportunities for collaboration with their colleagues similar to those occurring during mentoring sessions found in NTIP. Unfortunately, not all teachers are afforded opportunities for collaboration due to the egg-crate structure/ educational model (Lortie, 1977), which still characterizes the school system and prevents collective and collaborative interaction amongst teachers.

Having summarized the key findings from this study, the following section will discuss the study's limitations.

\subsection{Limitations}

There are several limitations to this study. The first limitation was 
the inability to observe the participants demonstrate their teaching practices. As discussed in Chapter three, I recognized that there is a difference in reported practices and practices adopted in the classroom (Coburn, 2004; Grossman, 2010; Meyer \& Rowan, 1977; Hinnant-Crawford, 2016). With the advent of the global pandemic (i.e., COVID-19), I was unable to observe the teachers actually teaching in their classrooms. Further, this may not have been possible regardless of the pandemic. Although, I was able to obtain ethics clearance from Carleton, it is a more rigorous process at the school board level in Ontario.

The second research limitation was the number of participants that I was able to recruit for this study. With such a small group of participants, it is impossible to generalize the findings from this study (Creswell, 2013). However, this was a qualitative study that had as its intent to provide rich and thick contextual information about six FSL teacher's lived teaching experiences. Hopefully readers will find the study trustworthy and credible and will be able to transfer some of its findings to their own contexts. Clearly, more data would have enriched the contextual detail provided in the study, but I relied on semistructured interviews as my source of data. The study could have been improved through the use of other methods as a triangulating approach. In conducting this qualitative study, I recruited participants who taught various grades to provide a wide array of accounts of the FSL teaching experience in Ontario classrooms. However, this also created a 
limitation. Recruiting such a wide array of participants, who taught at so many different levels of FSL in the Ontario public school system, meant I sacrificed $a$ richer description of FSL teachers in a particular cohort (e.g., FSL kindergarten teachers). Although the advantage of recruiting a wide array of participants was that it allowed for a better understanding of what was going on across the FSL program, and it allowed for considerations of convergence and divergence in the teachers' accounts, it also limited the meaningfulness of my findings, which could have been enhanced by focusing on FSL teachers from a particular cohort or grade level (e.g., FSL kindergarten teachers, grade specific teachers).

\subsection{Recommendations}

With these limitations in mind, I recommend facilitating learning for FSL teachers through collaboration between researchers and FSL teachers (Hollingsworth, Dybdahl, and Minharic, 1993) and among teaches themselves. This could give them more agency in their professional learning, which could motivate teachers, who are otherwise resistant to pedagogical change through bottom-up professional development. During her interview, Anne discussed how colleagues who were previously resistant to change became leaders in pedagogical change by developing resources in collaboration with others. Their change in perspective was facilitated by being given opportunities for professional learning through collaboration with her colleagues

As discussed in Chapter 4, some participants, Alice (novice teacher) and Anne (experienced teacher) indicated that they had difficulty 
determining the curricular expectations due to the lack of specificity, and abstractness of the wording. It would not be unrealistic to assume that other FSL teachers could have the same challenges with interpreting the Ontario written curriculum documents. It could be beneficial for the Ontario MoE to develop a resource that is widely available to all teachers that fleshes out curriculum expectations and resources for teachers across all grades. Then they could invite teachers who need additional support to use the resource, and allow those teachers who do not, to continue drawing on their own teaching repertoires in their teaching.

Finally, I recommend the promotion of professional learning by providing opportunities for collaboration between teachers. In designing professional learning opportunities, more attention needs to be directed at the teachers' needs themselves - what do the teachers in a school or at a particular level say they need? Needs analysis is a fundamental classroom assessment strategy in teaching, and teachers routinely organize their activities around their students' needs. This does not appear to be a routine assessment approach with regard to teacher professional learning. Building formal learning events such as a PD day for teachers expressed needs within a school community (e.g., in a school, across a level) would build relationships - collective and collaborative. This study suggests that teachers are not generally asked for their feedback on their own needs. Too many PD days are centrally organized and "top down" in terms of information, procedures, planning that teachers in general need to 
understand and apply. A strong recommendation that emerged from the present study was the need for more time during PD days for FSL teachers to discuss problems arising in their day-to-day teaching practices (e.g., activities, issues in student motivation, forms of assessment). This would allow for teacher professional learning - from one another - and build community. All of these recommendations suggest future research regarding,

- FSL teachers' perspectives on their professional needs,

- differences between novice and experienced FSL teachers accounts of their teaching,

- forms of assessment or resources, which are beneficial to FSL teachers' practices, and

- the situations, circumstances and causes for FSL teacher

\subsection{Final Remarks}

The FSL program relies on teachers who require professional learning to develop their teaching practices. Professional learning arises from collaboration and mentoring opportunities. Following OCOL (2019), qualified FSL teachers are more likely to remain in the program, meanwhile, unmotivated and under-qualified teachers are more likely to leave the program. As a former student, I recall having an amazing FSL history teacher, who made quite an impact on my feelings towards FSL. For example, this teacher divided the class into small groups to develop a board game based on different battles from the first and second world war. I 
fondly recall looking forward to attending my FSL history class with the intention to learn. How my FSL teacher developed strategies for assessment made the class memorable and enjoyable.

Unfortunately, I was also being taught by teachers who simply handed out worksheets for the class to complete, who made the process of learning French almost unbearable. When FSL teachers are motivated to engage their students, students are more likely to remain in the program and potentially contribute by conducting research or becoming motivated and qualified FSL teachers themselves. By developing improved hiring practices and addressing teachers' needs for professional learning, the FSL program could retain more motivated students who in turn could become motivated and qualified teachers. 


\section{References}

Abdulhamid, N., \& Fox, J. (2020). Portfolio Based Language Assessment (PBLA) in Language Instruction for Newcomers to Canada (LINC) Programs: Taking Stock of Teachers' Experience. Canadian Journal of Applied Linguistics/Revue canadienne de linguistique appliquée, 23(2), 168-192.

https://doi.org/10.37213/cjal.2020.31121

Alvarez, R. (2017). Towards Inclusive Pedagogy: Including Students with Communicative Challenges and Special Education Needs in Ontario's French as a Second Language Classrooms. Retrieved from:

https://tspace.library.utoronto.ca/bitstream/1807/76906/1/Alviarez_ Reshara_201706_MT_MTRP.pdf

Aoki, T. T. (2005). Legitimizing lived curriculum toward a curricular landscape of multiplicity. In W.F. Pinar \& R.L. Irwin (Eds.), Curriculum in a new key: The collected work of Ted T. Aoki (199215). Mahwah, NJ: Lawrence Erlbaum

Arnett, K., \& Mady, C. (2018). The influence of classroom experience on teacher belief systems: New French second language teachers' beliefs about program options for English language learners and students with learning difficulties. McGill Journal of Education/Revue des sciences de l'éducation de McGill, 53(3), 590- 
611. https://doi.org/10.7202/1058418ar

Arnott, S. (2011). Exploring the dynamic relationship between Accelerative Intergrated Method (AIM) and the core French teachers who use it: Why agency and experience matter. Canadian Journal of Applied Linguistics, 14(2), 156-176.

Arnott, S. (2012). Why AIM? - Educator perspectives and implementation of an instructional method for teaching core French as a second language in Ontario (Unpublished doctoral dissertation). University of Toronto, Canada.

Arnott, S. (2017). Second language education and micro-policy implementation in Canada: The meaning of pedagogical change. Language Teaching Research, 21(2), 258-284. DOI: $10.1177 / 1362168815619953$

Baxter, P. \& Jack, S. (2008). Qualitative case study methodology: Study design and implementation for novice researchers. The Qualitative Report, 13(4), 544-556.

Black, P. \& Wiliam, D. (2010). Inside the Black Box: Raising standards through classroom assessment. Phi Delta Kappan, 92(1), 81-90. https://doi.org/10.1177/003172171009200119

Brown. J.D. (1995). Elements of language curriculum. Boston, MA: Heinle \& Heinle. 
Bruner, J. (2002). Narratives of human plight: A conversation with Jerome Bruner. In R. Charon and M. Montello (Eds.), Stories matter - The role of narrative in medical ethics (pp. 3 - 9). New York, NY:

Routledge.

Burger, S., Weinberg, A., Hall, C., Movassat, P., \& Hope, A. (2011).

French immersion studies at the University of Ottawa: Programme evaluation and pedagogical challenges. In D.J. Tedick, D. Christian and T.W. Fortune (eds.), Immersion education practices, politics, possibilities. Bristol, UK: Multilingual Matters, pp. 123-142.

Caine, V., Estefan, A., \& Clandinin, D. J. (2013). A return to methodological commitment: Reflections on narrative inquiry. Scandinavian journal of educational research, 57(6), 574-586. DOI: $10.1080 / 00313831.2013 .798833$

Canadian Association of Second Language Teachers. (2017). Ontario’s New Teacher Handbook: Surviving and thriving in the French as a Second Language classroom. Retreived from: https://www.omlta.org/wp-content/uploads/2017/09/New-FSL$\underline{\text { Teacher-Handbook.pdf }}$

Cheng, L. \& Fox, J. (2017). Assessment in the Language Classroom. London, UK: Palgrave Press.

Clandinin, D. J. (2006). Narrative inquiry: A methodology for studying lived experience. Research Studies in Music Education, 27(1), 44- 
54.

Clandinin, D.J., \& Huber (2010). Narrative Inquiry. In P. Peterson, E. Baker, B. McGaw, (3 ${ }^{\text {rd }}$ eds) International Encyclopedia of Education, p. 436-441. https://doi.org/10.1016/B978-

\section{$\underline{0-08-044894-7.01387-7}$}

Clandinin, D. J., Pushor, D., \& Orr, A. M. (2007). Navigating sites for narrative inquiry. Journal of teacher education, 58(1), 21-35. DOI: $10.1177 / 0022487106296218$

Cloutier, A. (2018). Exploring how Ontario school administrators' FSL background knowledge and experience influence their support of FSL teachers (Thesis, Université d'Ottawa/University of Ottawa). Retrieved from: https://ruor.uottawa.ca/bitstream/10393/37763/5/Cloutier_Amanda _2018_thesis.pdf

Coburn, C. (2004). Beyond decoupling: Rethinking the relationship between the institutional environment and the classroom. Sociology of Education, 77(3), 211-244.

Cochran-Smith, M., \& Lytle, S. L. (1999). Relationships of knowledge and practice: Teacher learning in communities. Review of research in education, 24(1), 249-305.

Cochran-Smith, M., \& Lytle, M. (2006). Troubling images of teaching in no child left behind. Harvard Educational Review, 76(4), 668-726. 
Connelly, F. M., \& Clandinin, D. J. (1988). Teachers as curriculum planners: Narratives of experience. New York: Teachers College Press.

Connelly, F. M., \& Clandinin, D. J. (1990). Stories of experience and narrative inquiry. Educational researcher, 19(5), 2-14.

Cooke, S., \& Faez, F. (2018). Self-Efficacy Beliefs of Novice French as a Second Language Teachers: A Case Study of Ontario Teachers. Canadian Journal of Applied Linguistics/Revue canadienne de linguistique appliquée, 21(2), 1-18.

Cousin, G. (2005). Case Study research. Journal of Geography in Higher Education, 29(3), 421- 427.

Cordova, E. A. R. (2014). Opportunities for Teacher Professional Learning: Two Case Studies of Experienced Teachers in Ontario, Canada (Thesis, University of Toronto). Retrieved from:https://space.library.utoronto.ca/bitstream/1807/65532/11/Ros ales_Elizabeth_A_20 1406_MA_thesis.pdf

Cresswell, J. W. (2013). Qualitative inquiry and research design: Choosing among five approaches. Thousand Oaks, CA: Sage.

Cummins, J. (1998). Immersion Education for the Millennium: What We Have Learned from 30 Years of Research on Second Language Immersion. In M. R. Childs \& R. M. Bostwick (Eds.) Learning 
through Two Languages: Research and Practice, Second Katoh

Gakuen International Symposium on Immersion and Bilingual

Education. (pp. 34-47). Katoh Gakuen, Japan.

Dyer, W.G., Wilkins, A.L., \& Eisenhardt, K.M. (1991). Better stories, not better constructs, to generate better theory: A rejoinder to Eisenhardt; better stories and better constructs: The case for rigor and comparative logic. The Academy of Management Review, 16(3), 613

Faez, F., Majhanovich, S., Taylor, S. K., Smith, M., \& Crowley, K. (2011). The power of "Can Do" statements: Teachers' perceptions of CEFR- informed instruction in French as a second language classrooms in Ontario. Canadian Journal of Applied Linguistics, 14(2), 1-19.

Fortune, T.W. (2011). Struggling Learners and the Language Immersion Classroom. In D.J. Tedick, D. Christian and T.W. Fortune (Eds.). Immersion Education: Practices, Policies, Possibilities (pp. 251270). Bristol, UK: Multilingual Matters, Ltd.

Fox, J. (2009). Moderating top-down policy impact and supporting EAP curricular renewal: Exploring the potential of diagnostic assessment. Journal of English for Academic Purposes, 8(1), 26-42. https://doi.org/10.1016/j.jeap.2008.12.004

Fox, J. (2014). Portfolio based language assessment (PBLA) in Canadian immigrant language training: Have we got it wrong? Contact, 
Special Research Symposium Issue, 40(2), 68-83.

Freeman, D., \& Richards, J. C. (1993). Conceptions of teaching and the education of second language teachers. TESOL, 27(2), 193-216.

Gatbonton, E. (2008). Looking beyond teachers' classroom behaviour: Novice and experienced ESL teachers' pedagogical knowledge. Language Teaching Research, 12(2), 161-182. DOI:

$10.1177 / 1362168807086286$

Gentil, G. (2018). Modern languages, bilingual education, and translation studies: The next frontiers in WAC/WID research and instruction. Across the Disciplines, 15(3), 114-129.

Gentil, G., \& Séror, J. (2014). Canada has two official languages-Or does it? Case studies of Canadian scholars' language choices and practices in disseminating knowledge. Journal of English for Academic Purposes, 13, 17-30.

https://doi.org/10.1016/i.jeap.2013.10.005

Grossman, F. (2010). Dissent from within: How educational insiders use protest to create policy change. Educational Policy, 24(4), 655-686.

DOI: $10.1177 / 0895904809335110$

Gustafsson, J. (2017). Single case studies vs. multiple case studies: A comparative study. (Thesis, Halmstad University). Retrieved from: https://www.divaportal.org/smash/get/diva2:1064378/FULLTEXT01.pdf Hainer-Violand, J. (2013). (Re) Defining Priorities: Teachers' 
Perspectives on Supporting Diverse Learners Within a

Flexible Curriculum in a High-stakes Testing Atmosphere

(Thesis, University of Toronto). Retrieved from:

https://tspace.library.utoronto.ca/bitstream/1807/42622/1/Hai

ner-Violand_Julia_C_201311_MA_thesis.pdf

Hargreaves, A. (1989). In Curriculum and Assessment Reform.Toronto,

ON: OISE Press.

Hinnant-Crawford, B. (2016). Education Policy Influence Efficacy:

Teacher Beliefs in Their Ability to Change Education Policy.

International Journal of Teacher Leadership, 7(2), 1-27.

Hollingsworth, S., Dybdahl, M., \& Minarik, L. T. (1993). By chart and chance and passion: The importance of relational knowing in learning to teach. Curriculum inquiry, 23(1), 5-35.

Hopkins, D. (2000). Powerful learning, powerful teaching and powerful schools. Journal of Educational Change, 1(2), 135154.

Ingersoll, R. M. (2004). Why Do High-Poverty Schools Have Difficulty Staffing Their Classrooms with Qualified Teachers?. Renewing Our Schools, Securing Our Future - A National Task Force on Public Education; Joint Initiative of the Center for American Progress and the Institute for America's Future, Retrieved from:https://pdfs.semanticscholar.org/a1f9/e391189ced32a4ac3c60e 
ba4a1365bb09a6f.pdf

Jack, D., \& Nyman, J. (2019). Meeting Labour Market Needs for French as a Second Language Instruction in Ontario. American Journal of Educational Research, 7(7), 428-438.

Karsenti, T., \& Collin, S. (2013). Why are new teachers leaving the profession? Results of a Canada-wide survey. Education, 3(3), 141-149.

Karsenti, T., Collin, S., Villeneuve, S., Dumouchel, G. and Roy, N. (2008). Why are new French Immersion and French as a Second Language Teachers Leaving the Profession? Results of a Canada-Wide Survey, Canadian Association of Immersion Teachers, Ottawa.

KippFerguson, S. (2013). Attitudes Towards Native and Non-Native French Speaking Teachers in Ontario. Ontario Institute for Studies in Education, University of Toronto.

Lapkin, S., \& Barkoaui, K. (2008). Teaching core French in Ontario: Teachers' perspectives. Toronto, ON: OISE/UT Modern Language Centre.

Lapkin, S., MacFarlane, A., \& Vandergift, L. (2006). Teaching French in Canada: FSL teachers' perspectives. Ottawa, ON: Canadian Teachers' Federation.

Lemke.J. (1995). Textual politics: Discourse and social dynamics. London: Taylor \& Francis.

Lortie, D. (1977). Schoolteacher: A sociological study. Chicago, IL: 
University of Chicago Press.

MacLure, M., \& Stronach, I. (1993). Jack in two boxes: a postmodern perspective on the transformation of persons into portraits. Interchange, 24(4), 353-380.

Mady, C. (2007). Allophone Students in French Second-OfficialLanguage Programs: A Literature Review. Canadian Modern Language Review, 63(5), 727-760.

DOI:10.3138/cmlr.63.5.727

Mady, C. (2012). Inclusion of English Language learners in French as a second official language classes: Teacher knowledge and beliefs. International Journal of Multilingualism, 9(1), 1-14.

DOI:10.1080/14790718.2011.565877.

Mady, C. (2013). Moving towards inclusive French as a second official language education in Canada. International Journal of Inclusive Education, 17(1), 47-59. DOI: 10.1080/13603116.2011.580463

Mady, C. (2014). Learning French as a second official language in Canada: comparing monolingual and bilingual students at Grade 6. International Journal of Bilingual Education and Bilingualism, 17(3), 330-344.

DOI: $10.1080 / 13670050.2013 .76778$

Mady, C. (2016). French immersion for English language learners?: 
Kindergarten teachers' perspectives. Alberta Journal of Educational Research, 62(3), 253-267.

Mady, C. (2018). Multilingual immigrants' French and English acquisition in Grade 6 French immersion: Evidence as means to improve access. Language and Intercultural Communication, 18(2), 204-224.

Masson, M. (2018). Reframing FSL teacher learning: Small stories of (re) professionalization and identity formation. Journal of Belonging, Identity, Language and Diversity, 2(2), 77- 102.

Masson, M., Arnott, S., \& Lapkin, S. (2018). Teachers in K-12 FSL programs: What issues are top of mind in 21st century research? Ottawa, Canada: Canadian Parents for French. Retrieved from https://cpf.ca/en/files/State-of-FSL-Education-ReportWeb.pdf

Meyer, J. W., \& Rowan, B. (1977). Institutionalized organizations: Formal structure as myth and ceremony. American Journal of Sociology. 83(2), 340-363.

Miller, M. D., Brownell, M. T., \& Smith, S. W. (1999). Factors that predict teachers staying in, leaving, or transferring from the special education classroom. Exceptional

children, 65(2), 201-218.

Mison, S., \& Jang, I. C. (2011). Canadian FSL teachers' assessment practices and needs: Implications for the adoption of the CEFR in 
a Canadian context. Synergies Europe, 6, 99-108.

Mnknjian, S. (2016). Effective Strategies for Enhancing the Language

Learning Experience in the FSL Classroom (Unpublished Master of

Teaching research project), Ontario Institute for Studies in

Education, University of Toronto.

Office of the Commissioner of Official Languages (2019). Accessing

opportunity: A study on challenges in French-as-a-second-

language education teacher supply and demand in Canada.

Minister of Public Works and Government Services Canada:

Ottawa, ON.

Okas, A., van der Schaaf, M., \& Krull, E. (2014). Novice and experienced teachers' views on professionalism. Trames, 18(4), $327-344$.

Ontario Ministry of Education. (2010). Partnering for Success:

Getting the most out from Ontario's New Teacher Induction

Problem: A resource handbook for new teachers. Toronto:

Queen's Printer for Ontario. Retrieved from:

http://www.edu.gov.on.ca/eng/teacher/NTIPTeacher.pdf

Ontario Ministry of Education. (2011). Capacity Building Series: French Immersion in Ontario. Literacy and Numeracy Secretariat. Toronto: Queen's Printer for Ontario

Ontario Ministry of Education (2013a). A Framework for French as a Second Language in Ontario Schools: Kindergarten to grade 
12. Toronto: Queen's Printer for Ontario.

Ontario Ministry of Education. (2013b). The Ontario Curriculum

Grades 1-8: French as a Second Language. Toronto: Queen's

Printer for Ontario

Ontario Ministry of Education (2014). The Ontario curriculum grades

9 to 12: French as a Second Language. Toronto: Queen's

Printer for Ontario

Ontario Ministry of Education (2016a). The Kindergarten Program.

Toronto: Queen's Printer for Ontario.

Ontario Ministry of Education (2016b). Welcoming English Language

Learners into French as a Second Language Programs. Toronto:

Queen's Printer for Ontario.

Opfer, V. D., \& Pedder, D. (2011). Conceptualizing teacher

professional learning. Review of educational research, 81(3), 376-407.

Pedder, D., \& Opfer, V. D. (2013). Professional learning orientations: patterns of dissonance and alignment between teachers' values and practices. Research Papers in Education, 28(5), 539-570.

Piccardo, E., North, B., \& Goodier, T. (2019). Broadening the scope of language education: Mediation, plurilingualism, and collaborative learning: The CEFR companion volume. Journal of e-Learning and Knowledge Society, 15(1).

Reeves, S., Kuper, A., \& Hodges, B. D. (2008). Qualitative 
research methodologies: ethnography. BMJ, 337: 512-

514.

Saldaña, J. (2013). The Coding Manual for Qualitative Research (2 $\left.{ }^{\text {nd }} \mathrm{ed}.\right)$. London: Sage Publication Ltd.

Salvatori, M. (2009). A Canadian perspective on language teacher education: Challenges and opportunities. The Modern Language Journal, 93(2), 287-291.

Salvatori, M. (2009). Profiles and pathways: Supports for developing FSL teachers' pedagogical, linguistic and cultural competencies. Ottawa, Ontario: Canadian Association of Second Language Teachers.

Smart, G. (2008). Ethnographic-based discourse analysis: Uses, issues and prospects. In V.K. Bhatia, J. Flowerdew and R. Jones (Eds). Advances in discourse studies (pp. 66-76). Routledge.

Sims, W. L., \& Cassidy, J. W. (2019). Impostor phenomenon responses of early career music education faculty. Journal of Research in Music Education, 67(1), 45-61.

Tardif, C. (1990). French language minority education: Political and pedagogical issues. Canadian Journal of Education/Revue canadienne de l'education, $15(4), 400-412$.

Trilokekar, R., \& El-Masri, A. (2020). Internationalizing Teachers' Preparedness: The Missing Link in Ontario's Strategy for K-12 International Education 
Canadian Journal of Education/Revue canadienne de l'éducation, 43(1), 170-196.

Turnbull, M., \& Dailey-O'Cain, J. (Eds.). (2009). First language use in second and foreign language learning. Bristol, UK: Multilingual Matters.

Turner Consulting Group. (2014). Teacher diversity gap. https://turnerconsultinggroup.weebly.com/blog-tana$\underline{\text { turner/teacher-diversity-gap }}$

Vonk, J. H. C., \& Schras, G.A. (1987). From beginning to experienced teacher: A study of the professional development of teachers during their first four years of service. European Journal of Teacher Education, 10(1), 96-110.

Webster-Wright, A. (2009). Reframing professional development through understanding authentic professional learning. Review of educational research, 79(2), 702-739.

Wertz, F. J., Charmaz, K., McMullen, L., Josselson, R., Anderson, R., \& McSpadden, E. (2011). Five ways of doing qualitative analysis: Phenomenological psychology, grounded theory, discourse analysis, narrative research, and intuitive inquiry. New York, NY: Guilford Press

Wertz, F. J. (2014). Qualitative inquiry in the history of psychology. Qualitative Psychology, 1(1), 4-16. 
http://dx.doi.org/10.1037/qup0000007

Wise, N. (2011). Access to special education for exceptional students in French immersion programs: An equity issue. Canadian Journal of Applied Linguistics, 14(1), 177-193.

Woods, D. (1996). Teacher Cognition in Language Teaching.

Cambridge University Press.

Yin, R.K. (2003). Case study research: Design and methods. Thousand Oaks, CA: Sage. 


\section{Appendices}

\section{Appendix A - Ethics Protocol}

Subject: Invitation to participate in a research project on French as a Second Language (FSL) teachers

Dear Sir or Madam,

My name is Megan Ouellette and I am a Master's student in the School of Linguistics and Language Studies at Carleton University. I am working on a research project under the supervision of Professor Janna Fox

I am writing to you today to invite you to participate in a study entitled "Teachers interpreting documents: novice versus experienced French as a Second Language (FSL) teachers". This study aims to determine whether there is a difference in how novice and experienced teachers interpret Ontario FSL language policies and curricular documents.

This study involves one 30-60 minute interview that will take place in a mutually convenient, safe and quiet location away from your place of work. With your consent, interviews will be audio-recorded. Once the recording has been transcribed, the audio-recording will be stored on an encrypted USB and locked in a secure cabinet.

While this project does not involve risks other than what is expected in daily life or in a conversation with a professional colleague, care will be taken to protect your identity. This will be done by keeping all responses anonymous.

You will have the right to end your participation in the study at any time, for any reason. If you choose to withdraw, all the information you have provided will be retained up to the point of withdrawal.

As a token of appreciation, I will be providing you with refreshments during the interview along with a $\$ 10$ Starbucks or Tim Hortons gift card. (The compensation is yours to keep, even if you choose to 
withdraw)

All research data, including audio-recordings and any notes will be encrypted. Any hard copies of data (including any handwritten notes or USB keys) will be kept in a locked cabinet. Once the recording has been transcribed, it will be deleted. Research data will only be accessible by the researcher and the research supervisor.

The ethics protocol for this project was reviewed by the Carleton University Research Ethics Board, which provided clearance to carry out the research. Clearance expires on: October 31, 2020.

\section{CUREB-A:}

If you have any ethical concerns with the study, please contact the Carleton University Research Ethics Board-A (by phone at 613-520-2600 ext. 2517 or via email at ethics@carleton.ca).

If you would like to participate in this research project, or have any questions, please contact me at meganeouellette@cmail.carleton.ca or the researcher supervisor, Janna Fox at janna fox@carleton.ca.

Sincerely,

Megan Ouellette 


\section{Carleton}

U N I V E R I T Y

Canada's Capital University

\section{Carleton}

U N I V E R S I T Y

Canada's Capital University

\section{Letter of Invitation}

Title: Teachers interpreting documents: Novice versus experienced French as a Second Language (FSL) teachers

Date of ethics clearance: October 17, 2019

\section{Ethics Clearance for the Collection of Data Expires:}

October 31, 2020 December 3, 2019

Dear Sir or Madam,

My name is Megan Ouellette and I am a Master's student in the School of Linguistics and Language Studies at Carleton University. I am working on a research project under the supervision of Professor Janna Fox.

I am writing to you today to invite you to participate in a study on how novice and experienced teachers interpret French as a Second Language (FSL) language policies from the Ontario Ministry of Ontario. This study aims to contribute to a growing body of literature on teacher culture and FSL educators.

This study involves one 30-60-minute interview that will take place in a mutually convenient, quiet and safe location, which is away from your place of work. With your consent, interviews will be audio-recorded using a digital recording device. Once the recording has been transcribed, the audio- recording will be stored in an encrypted file, which will require a password on a password-protected computer. Once the recording has been transcribed, it will be deleted. 
This project does not involve risks other than what would be expected in daily-life or a professional encounter with a colleague. It should be noted that care will be taken to protect your identity. This will be done by keeping all responses anonymous.

You will have the right to end your participation in the study at any time, for any reason. If you choose to withdraw, all the information you have provided will be retained.

As a token of appreciation, I will be providing you with refreshments during the interview as well as a $\$ 10$ gift card for Starbucks or Tim Hortons.

All research data, including audio-recordings and any notes will be encrypted. Any hard copies of data (including any handwritten notes or USB keys) will be kept in a locked cabinet at Carleton University. Research data will only be accessible by the researcher and the research supervisor.

This ethics protocol for this project was reviewed by the Carleton University Research Ethics Board, which provided clearance to carry out the research. Should you have questions or concerns related to your involvement in this research, please contact:

\section{CUREB-A:}

If you have any ethical concerns with the study, please contact the Carleton University Research Ethics Board-A (by phone at 613-520-2600 ext. 2517 or via email at ethics@carleton.ca).

If you would like to participate in this research project, or have any questions, please contact me at meganeouellette@cmail.carleton.ca or contact Janna Fox at janna fox@carleton.ca.

Sincerely,

Megan Ouellette 


\section{Informed Consent Form}

Name and Contact Information of Researehers:

Megan Ouellette, Carleton University, School of Linguistics and Language Studies

Email: meganeouellette@

Supervisor and Contact Information: Professor Janna Fox, janna_fox@carleton.ca

\section{Project Title}

Teachers interpreting documents: Novice versus experienced French as a Second Language (FSL) teachers

\section{Carleten University Projeet Clearance}

Clearance U: $111614 \quad$ Date of Clearance: October 17, 2019

\section{Invitation}

You are invited to take part in a research project because you are a FSL teacher or taught FSL classes in Ontario. The information in this form is intended to help you understand what I will be asking of you so that you can decide whether you agree to participate in this study. Your participation in this study is voluntary, and a decision not to participate will not be used against you in any way. As you read this form, and decide whether to participate, please ask all the questions you might have, take whatever time you need, and consult with others as you wish.

\section{What is the purpese of the study?}

The primary abjective of the current study is to determine whether there is a difference in how novice and experienced teachers interpret Ontario French as a Second Language (FSL) language policies and curricular documents. Based on the participants answers to the interview questions, I hope to determine whether the dialectic theoretical perspective (Connelly \& Clandiain, 1988) informs policy and curriculum documents in felation to teacher practices. From the dialectic perspective, theory is viewed as flexible based on practice because practice informs theory, and theory accounts for practice.

What will I be asked to do?

If you agree to take part in the study, I will ask you to: comment on Ontario FSL curriculum or language policies in a one-on-one interview. The interview will take approximately 30-60 minutes and will be recorded using a digital audio-recording device. 


\section{Risks and Incenveniences}

I do not anticipate any risks to participating in this study other than what is expected in daily life or a professional encounter with a colleague.

\section{Pessible Benefits}

You may not receive any direct benefit from your participation in this study. However, your participation may allow researchers to better understand how teachers interpret FSL language policies and curricular documents from the Ontario Ministry of Education.

\section{Cempensation/Incentives}

As a token of appreciation, you will receive refreshments and a $\$ 10$ gift card to either Tim Hortons or Starbucks.

\section{No waiver of your rights}

By signing this form, you are not waiving any rights or releasing the researchers from any liability.

\section{Withdrawing from the study}

If you withdraw your consent during the course of the study, all information collected from you before your withdrawal will be retained.

\section{Cenfldentiality}

I will remove all identifying information from the study data as soon as possible, which will be after stored in an encrypted file on a password-protected computer. Research records may be accessed by the Carleton University Research Ethics Board in order to ensure continuing ethics compliance. All data will be kept confidential and anonymized, unless release is required by law (ę․ child abuse, harm to self or others).

The results of this study may be published or presented at an academic conference or meeting. but the data will be presented so that it will not be possible to identify any participants unless you give your express consent. You will be assigned a code [or pseudonym] so that your identity will not be directly associated with the data you have provided. All data, including coded information, will be kept in a encrypted and password-protected file on a secure computer. I will encrypt any research data that I store or transfer and will be stored in a locked cabinet. Once the data is transcribed, I will delete the audio-file. Any reference to the data will be through pseudonyms only. 


\section{Data Retention}

After the study is completed, your de-identified data will be retained for future research use. The data will be retained only for submitted to journals as a condition of publication. The deidentified data will be stored in an encrypted file, which requires a password on a password protected computer.

New information during the study

In the event that any changes could affect your decision to continue participating in this study, you will be promptly informed.

\section{Ethics review}

This project was reviewed and cleared by the Carleton University Research Ethics Board A. If you have any ethical concerns with the study, please contact Carleton University Research Ethics Board [by phone at 613-520-2600 [ext. 2517 for CUREB A or by email at ethics ecarleton.ca).

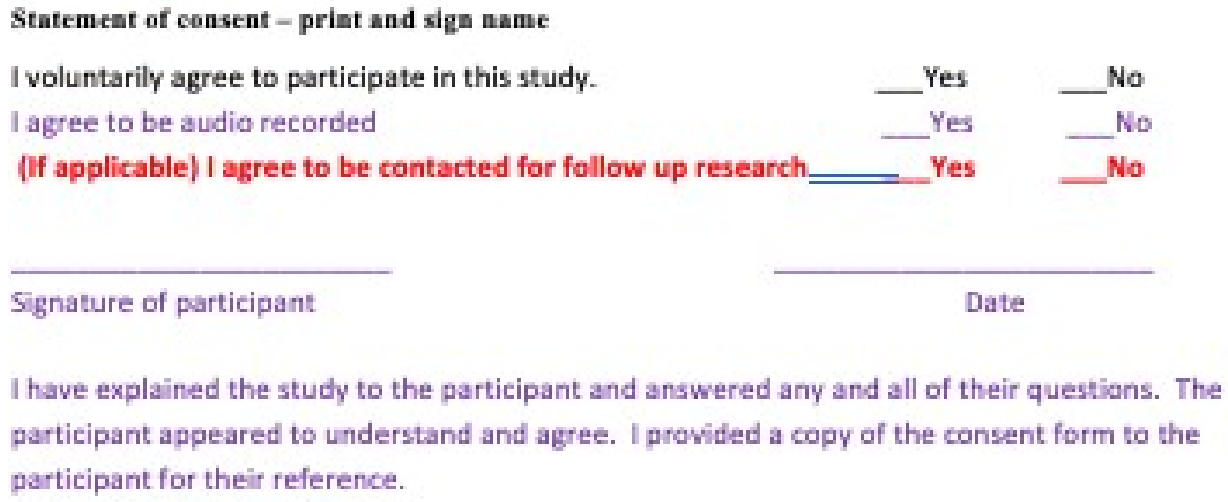

Signature of researcher 
Office of Research Ethics

503 Robertson Hal | 1125 Colonel By Drive

Ottawa, Ontario K1S 5B6

613-520-2600 Ext: 2517

ethics.pcarleton.ca

\section{CERTIFICATION OF INSTITUTIONAL ETHICS CLEARANCE}

The Carleton University Research Ethics Board-A (CUREB-A) has granted ethics clearance for the research project described below and research may now proceed. CUREB-A is constituted and operates in compliance with the Tri-Council Policy Statement: Ethical Conduct for Research Involving Humans (TCPS2).

Ethics Protocol Clearance ID: Project \# 111614

Project Team Members: Megan Ouellette (Primary Investigator)

Prof. Janna Fox (Research Supervisor)

Project Title: Teachers interpreting documents: novice versus experienced French as a Second Language (FSL) teachers

Funding Source (If applicable):

Effective: October 17, 2019

Expires: October 31, 2020.

Please ensure the study clearance number is prominently placed in all recruitment and consent materials: CUREB-A Clearance \#111614.

\section{Restrictions:}

This certification is subject to the following conditions:

1. Clearance is granted only for the research and purposes described in the application.

2. Any modification to the approved research must be submitted to CUREB-A via a Change to Protocol Form. All changes must be cleared prior to the continuance of the research.

3. An Annual Status Report for the renewal of ethics clearance must be submitted and cleared by the renewal date listed above. Falure to submit the Annual Status Report will result in the closure of the file. If funding is associated, funds will be frozen.

4. A closure request must be sent to CUREB-A when the research is complete or terminated.

5. During the course of the study, if you encounter an adverse event, material incidental finding. protocol deviation or other unanticipated problem, you must complete and submit a Report of Adverse Events and Unanticipated Problems Form, found here: https://carleton.ca/researchethics/forms-and-templates/

Failure to conduct the research in accordance with the principles of the Tri-Council Policy Statement: Ethical Conduct for Research Involving Humans 2 nd edition and the Carleton University Policies and Procedures for the Ethical Conduct of Research may result in the suspension or termination of the research project. 
Upon reasonable request, it is the policy of CUREB, for cleared protocols, to release the name of the PI, the title of the project, and the date of clearance and any renewal(s).

Please contact the Research Compliance Coordinators, at ethics gecarleton.ca, if you have any questions.

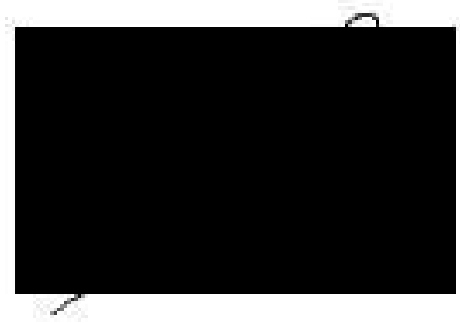

Natasha Artemeva, PhD, Chair, CUREB-A

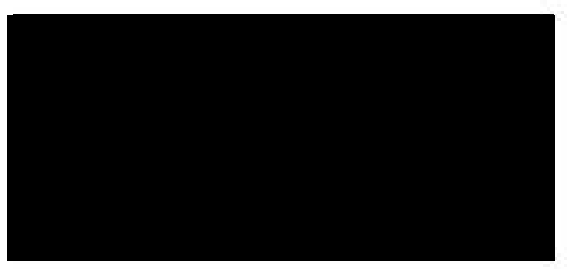

Janet Mantler, PhD, Vice-Chair, CUREB-A

\section{PANEL ON}

RESEARCH ETHICS

\section{TCPS 2: CORE}

\section{Certificate of Completion}

This document certifies that

Megan Ouellette

has completed the Tri-Council Policy Statement:

Ethical Conduct for Research Involving Humans

Course on Research Ethics (TCPS 2: CORE)

Date of Issue: 9 March, 2019 


\section{Appendix B Interviews}

The participants were asked of the following texts, which one is familiar:

1. A framework for French as a Second Language in Ontario

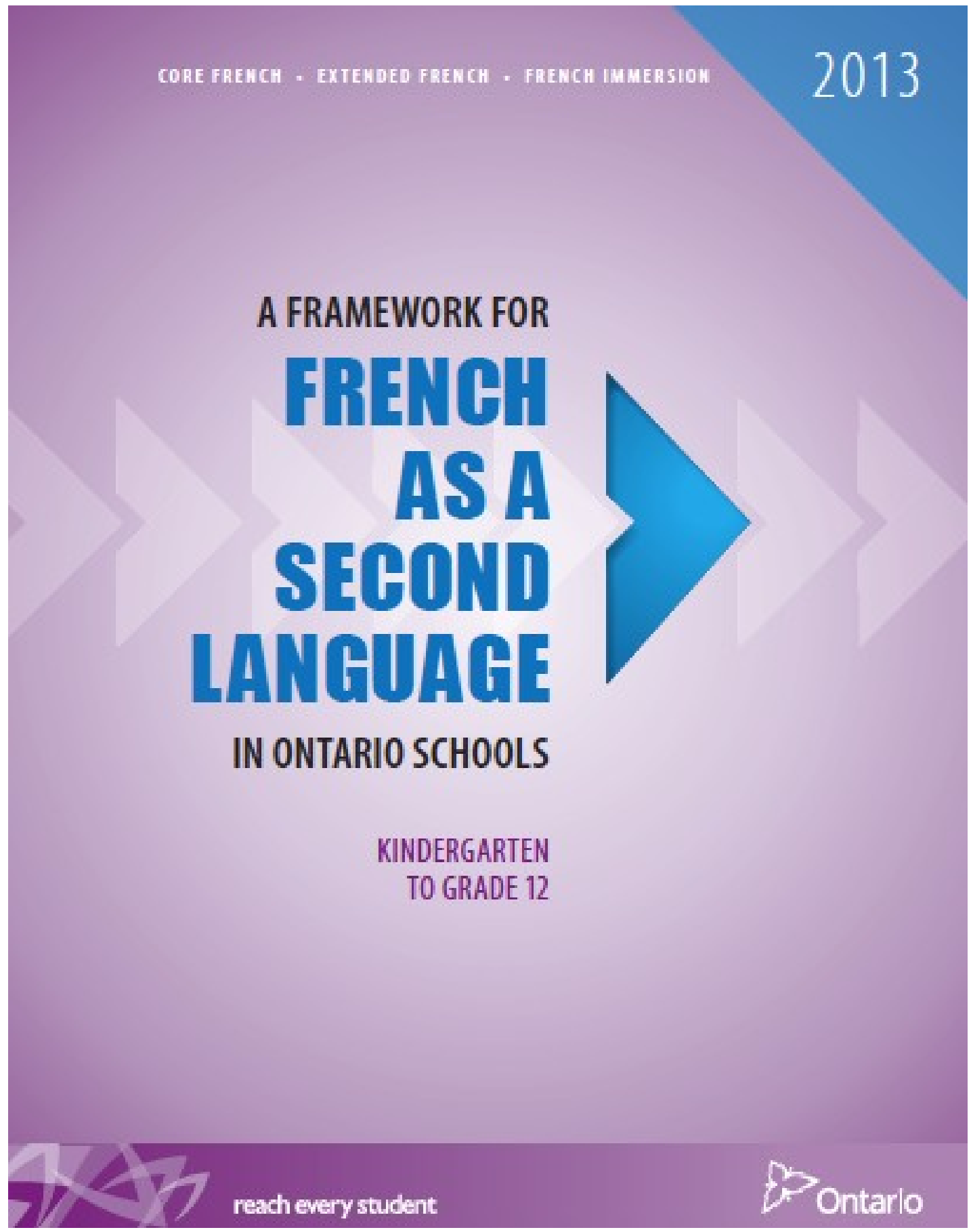


2. The Ontario curriculum grades 9 to 12: French as a Second Language

The Ontario Curriculum

Grades 9 to 12

\section{French as a} Second Language

CORE FRENCH • EXTENDED FRENCH • FRENCH IMMERSION

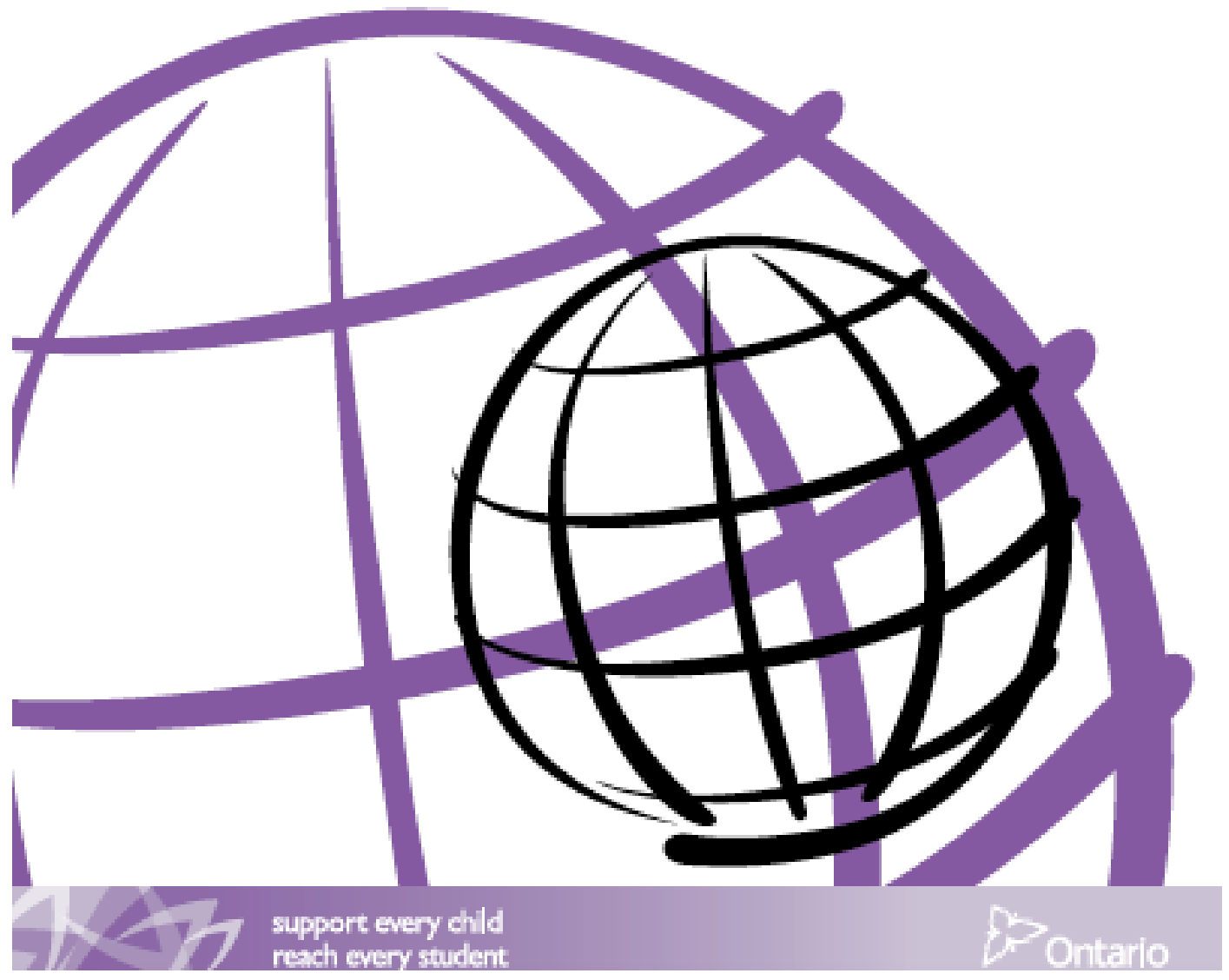




\section{Capacity Building Series: French Immersion in Ontario}

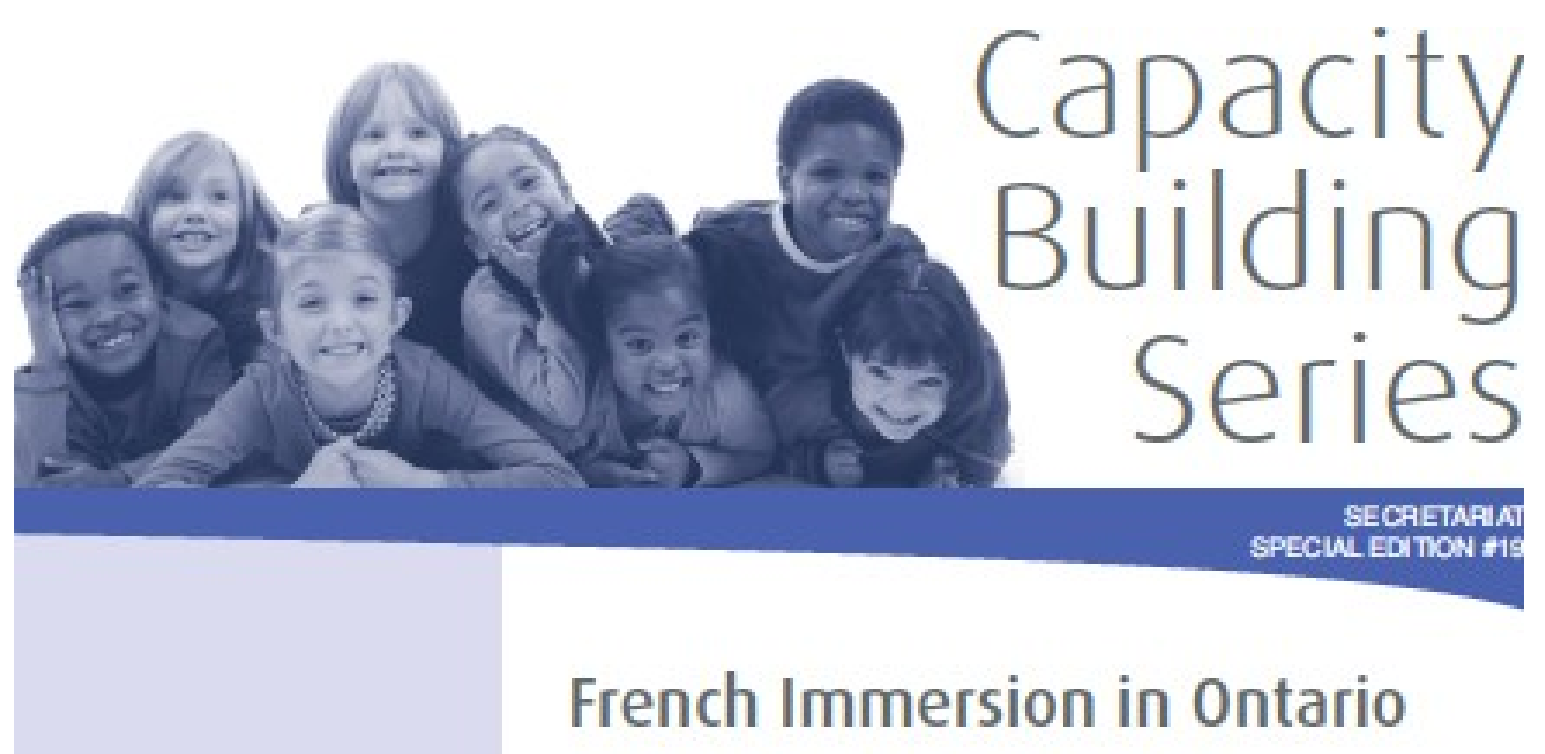

Why shared literdy Instruction?

The sume oppooches b effective liaxy Intudion apply-regurks of stadent' firs languge a the hinguge of hitudion.

These indude:

- a strong cal language conponent

- scaffelding on pribr knowiadge and experiences

- a fous on tigher erder thinking

- ertikd hterocy prodikes Ontarib Mristry of Eluadion, 2004

April 2011 155N: 19138482 (Print) I5SN: 19138490 (Onllins)

\section{Two languages ... A shared approach}

The goal of French Immersion is to develop students proficlency in French while bullding mastey of English - that is, not to replace a first language with an additional one but to develop proficlent communication skills in both. Researchers suggest that French immersion programs enjoy success in meeting this goal because the cognitive and lingulstic component skills required for learning to read, write, speak, vlew and represent in a student's first banguage support Itteracy development in a second. The transfer of skills works both ways. Students developing abilities in French also support their continuing growth In English.

Dt Jim Curnmins (OISE) has helped to create an influentlal body of emptical research supporting the notion of knowledge transfer (Cuminins 1998). Studles of dual language programs in Canada and elsewhere suggest that students' Ilteracy skills in a first language provide the schernata for itheracy learning (eg phonological and phonemic awareness, thinking/processing skills, comprehension strategles) which will transfer from a frst language to a second and, vice versa, from a second language to a first. Cummins "Interdependence hypothesk" not only explahs why students who are literale in their first language are ikely to be advantaged in the acquistion of a second, but it also holds implications for those responsible for planning and instruction in Ontarlo schools.

This monograph has been developed to support the work of dual language teaching teams as they explore effective literacy instruction and implement practices to improve not only French immersion instruction but ilferacy instruction overall.

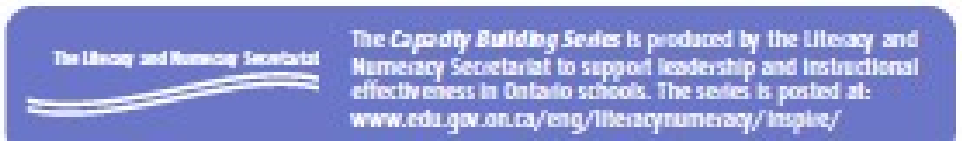


4. Ontario Schools Kindergarten to Grade 12: Policy and Program Requirements

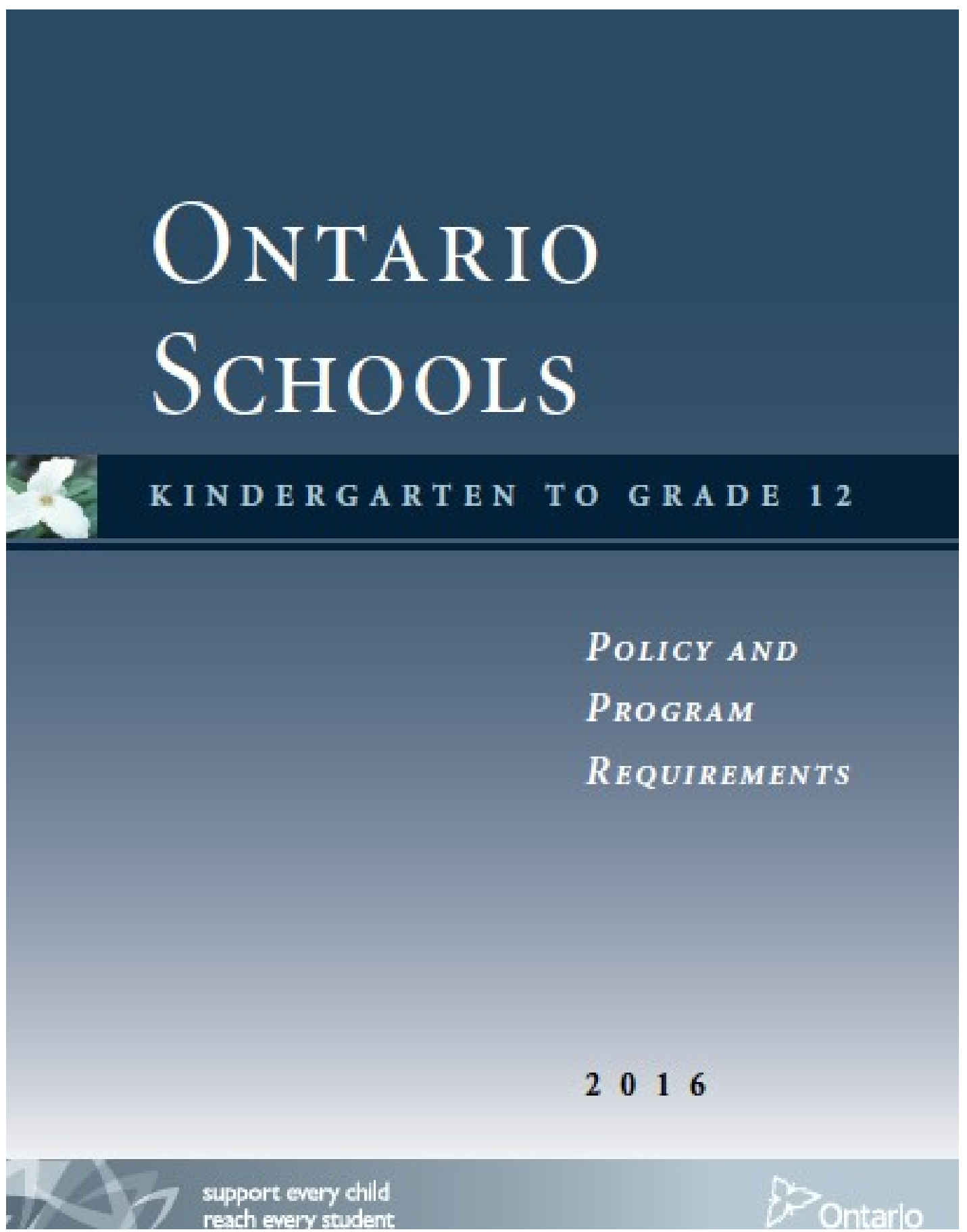




\section{Interview Questions}

The following questions will be used for the semi-structure interview: Background information:

1. How long have you been a teacher?

2. How long have you been teaching FSL classes?

3. What age ranges and subjects have you taught in the past?

FSL language policy and curriculum documents prompt (prompt would be chosen based on answers from survey:

4. Of the following texts, which ones are familiar:

a. A framework for French as a Second Language in Ontario

b. The Ontario curriculum grades 9 to 12: French as a Second Language

c. Capacity Building Series: French Immersion in Ontario.

d. Ontario Schools Kindergarten to Grade 12: Policy and Program Requirements

5. Of the documents chosen, which document do you refer to?

6. How does the document address the role of the teacher?

7. How does the document address the role of the classroom?

8. What jumps out at you?

9. What is the purpose of the Ministry of Education publishing curriculum and language policies?

10. What do you think the document mainly focuses on? How to better help teachers educate students? Or is the document solely focused on student learning? Teaching practices: 
11. How would you apply the language policies and curriculum documents in your classroom? Can you give me examples? 


\section{Appendix C - Example of coding}

\section{Example of Interim Text}

\section{Participant \#4}

So far I've assessed on... for when it comes to listening and speaking for French, I use my calendar and my daily questions as one of my main ways to track it, so I track it almost daily. And so I'm able to see if there's a progression there, if they're struggling, if we need to work on something. For reading, I'll take some short text, they need to be very basic. Yeah, and we'll work on like a letter sound combination. Like "ou” for example, like O and U, and we'll read it, we'll practice it many times, and once we've practiced it a lot then I sit with each student while my other students are working and we'll do like a reading little assessment where they read to me and I track. You know if they make mistakes, if they correct themselves, how fluent they are, that kind of thing. in terms of writing, I use it mainly in my projects and so they have a very structured way of needing to write sentences.

Yeah, so I use rubrics. I could send you one of my sample rubrics if you're interested. I'll see if I can find it on here. It might be a little cramped on here because it's on my phone. But the way I assess, and this was something that was given to me again from an experienced teacher who kind of showed me what she's done, my mentor.

Yes, yes, there's lots... it's very wordy, very overwhelming. And for like FSL in particular I mentioned this before but, the expectations are word for word the same from grade 2 . And so we were actually discussing... I was at an, oh, I forgot to mention this, I was at an FSL PD day for those who voluntarily signed up, like I voluntarily signed up for it, for new teachers. I'm part of a program called NTIP. It's the new teacher induction program. And so it was for FSL teachers and we were talking about how it would almost be nicer if the curriculum was laid out like: okay here is the expectation, which is verbatim written the same way, either way, for every age. And then just saying: for 
grade one here's an example of what you could do. Grade two, an example grade three, an example, instead of using all those pages to write the same thing over and over again.

Yeah, it's really good. I think t's a provincially recognized program, like NTIP, but they send out emails every month and we'll have a list of PD events that you can attend and so the board covers it, you get a supply teacher to come in for you while you go. It's a good program so far from what I've gotten. Once you get permanent you get a lot more release days. So like I have two release days between me and my mentor, so basically like one day each kind of thing. Whereas permanent I think get five, between the two of them. So, who told you about NTIP? Was it just starting at your job? Well, I knew from my placement at Thomas Darcy McGee there was a leadership consultant that would come in every once in a while. And so I knew her through that, and I ran into her at the beginning of the year this year and when she saw that I had an LTO she said hey just send me an email and we'll put you into this program. And so that was pretty much how. It's just because of the people I knew and the connections I made beforehand in the board as well. Otherwise, I don't know that I would have actually signed up for it or known about it.

For the curriculum document? So, they give... basically the FSL curriculums very similar from grade to grade. The expectations are pretty... like they're basically verbatim word for word the same thing. Like from grade four to six it's all the same, grade one to three it's pretty much all the same. What does differ is the examples that they give. So they'll give examples of questions that you can ask to back up a specific point in the curriculum. So, if it's saying you know, students will write... students will learn to write simple texts in a variety of forms. Then it will give examples of questions or types of text that they can write that kind of thing. It's a very broad example, there's no like... It's very much up to interpretation by the teacher, like the teacher can really make it their own. Which is 
good, but also it takes away that kind of way to make it uniform, from teacher to teacher, you know, but it is good because it gives us an ability to be creative with how we want to present it.

It's just because of the people I knew and the connections I made beforehand in the board as well. Otherwise, I don't know that I would have actually signed up for it or known about it. For the curriculum document? So, they give... basically the FSL curriculums very similar from grade to grade. The expectations are pretty... like they're basically verbatim word for word the same thing. Like from grade four to six it's all the same, grade one to three it's pretty much all the same. What does differ is the examples that they give. So they'll give examples of questions that you can ask to back up a specific point in the curriculum. So, if it's saying you know, students will write... students will learn to write simple texts in a variety of forms. Then it will give examples of questions or types of text that they can write that kind of thing. It's a very broad example, there's no like... It's very much up to interpretation by the teacher, like the teacher can really make it their own. Which is good, but also it takes away that kind of way to make it uniform, from teacher to teacher, you know, but it is good because it gives us an ability to be creative with how we want to present it. 
Example of coding

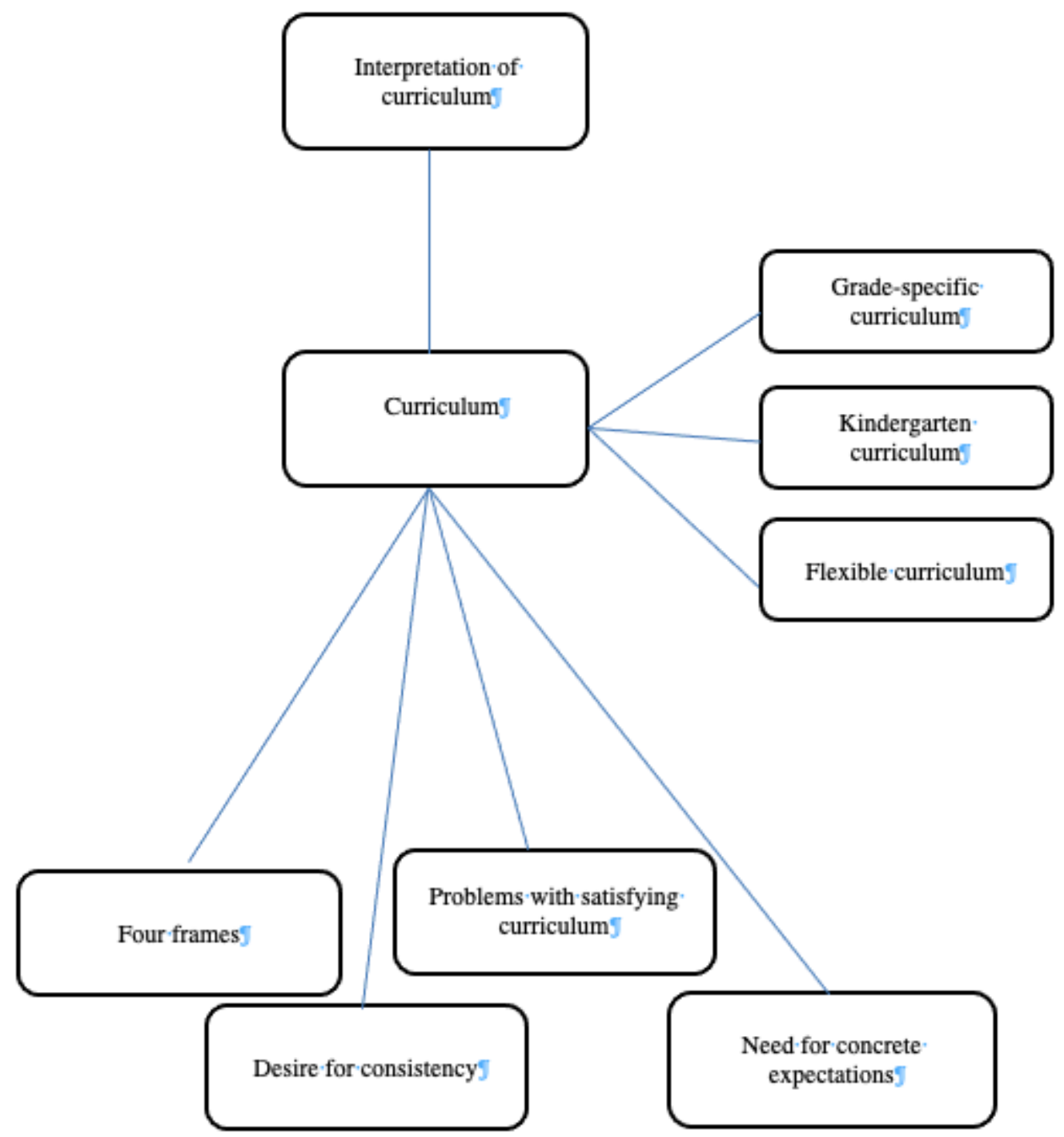




\section{Appendix D - Intercoder reliability}

Participant \#4

So far I've assessed on... for when it comes to listening and speaking for French, I use my calendar and Assess strategres my daily questions as one of my main ways to track it, so I track it almost daily. And so I'm able to see if there's a progression there, if they're struggling, if we need to work on something. For reading, I'll take some short text, they need to be very basic. Yeah, and we'll work on like a letter sound combination. Like "ou" for example, like $O$ and $U$, and we'll read it, we'll practice it many times, and Activitics once we've practiced it a lot then I sit with each student while my other students are working and we'll do like a reading little assessment where they read to me and I track. You know if they make mistakes, if they correct themselves, how fluent they are, that kind of thing. in terms of writing, I use it mainly in my projects and so they have a very structured way of needing to write sentences.

And do you have a rubric at all?

Yeah, so I use rubrics. I could send you one of my sample rubrics if you're interested. I'll see if I can find Rubrics it on here. It might be a little cramped on here because it's on my phone. But the way I assess, and this was something that was given to me again from an experienced teacher who kind of showed me what Collaboration she's done, my mentor.

Yes, yes, there's lots... it's very wordy, very overwhelming. And for like FSL in particular I mentioned this before but, the expectations are word for word the same from grade 2. And so we were actually discussing... I was at an, oh, I forgot to mention this, I was at an FSL PD day for those PD who voluntarily signed up, like I voluntarily signed up for it, for new teachers. I'm part of a program voluntecr called NTIP. It's the new teacher induction program. And so it was for FSL teachers and we were talking about how it would almost be nicer if the curriculum was laid out like: okay here is the expectation, Improving which is verbatim written the same way, either way, for every age. And then just saying: for grade one Cumiculum here's an example of what you could do. Grade two, an example grade three, an example, instead of using all those pages to write the same thing over and over again.

Yeah, it's really good. I think t's a provincially recognized program, like NTIP, but they send out emails New teacher every month and we'll have a list of PD events that you can attend and so the board covers it, you get a Program supply teacher to come in for you while you go. It's a good program so far from what I've gotten.

Once you get permanent you get a lot more release days. So like I have two release days between me PD $\bar{W}$ mentor and my mentor, so basically like one day each kind of thing. Whereas permanent I think get

five, between the two of them. So, who told you about NTIP? Was it just starting at your job? Well, I knew from my placement at there was a leadership consultant that would come in every once in a while. And so I knew her through that, and I ran into her at the beginning of the year this year and when she saw that I had an LTO she said hey just send me an email and we'll put you into this program. And so that was pretty much how. It's just because of the people I knew and the connections I made beforehand in the board as well. Otherwise, I don't know that I would have actually signed up for it or known about it.

For the curriculum document? So they give... basically the FSL curriculums very similar from grade to Breakdown of grade. The expectations are pretty... like they're basically verbatim word for word the same thing. Like document from grade four to six it's all the same, grade one to three it's pretty much all the same. What does differ is the examples that they give. So they'll give examples of questions that you can ask to back up a Examples specific point in the curriculum. So if it's saying you know, students will write... students will learn to write simple texts in a variety of forms. Then it will give examples of questions or types of text that they 


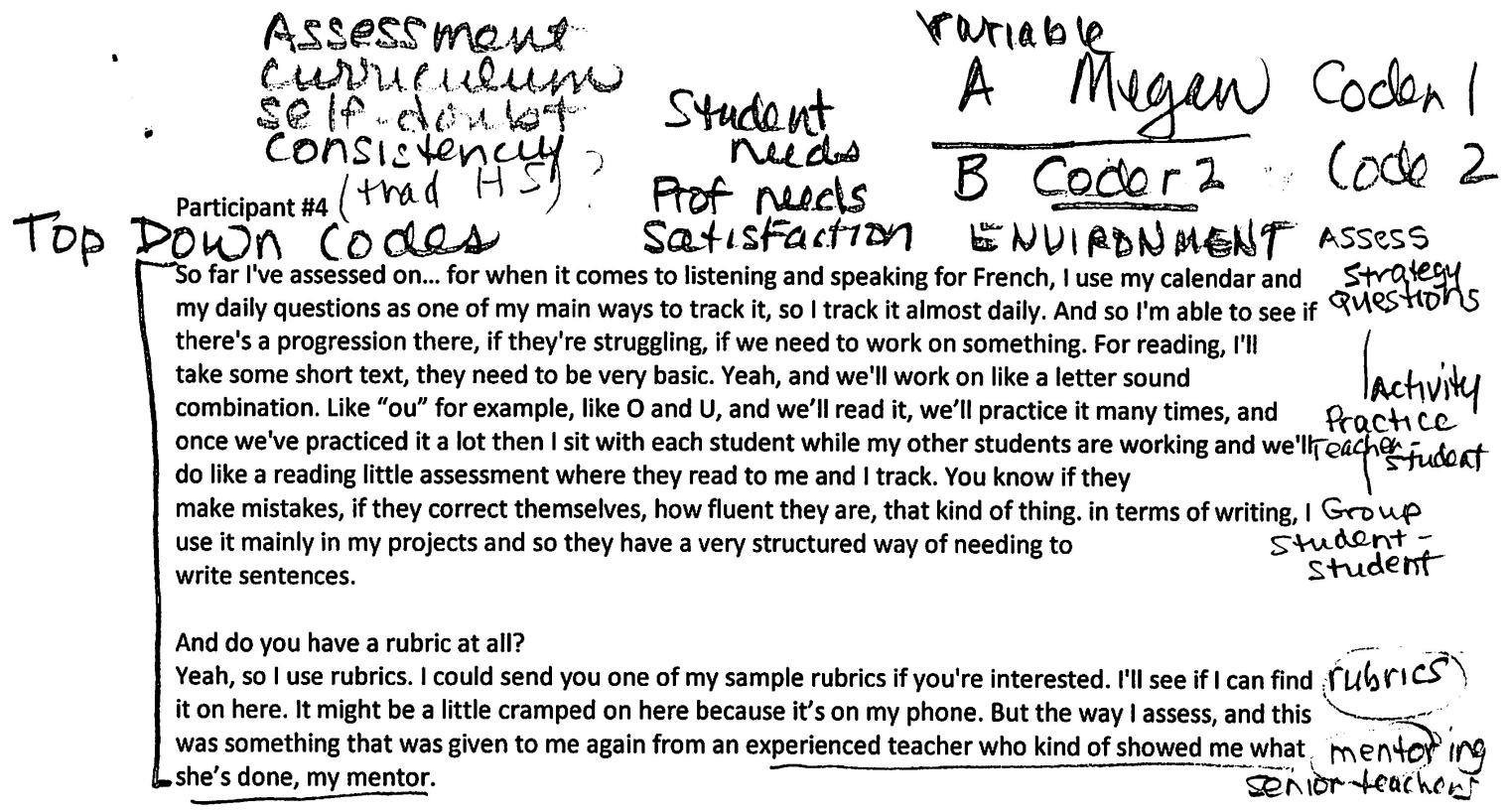

Prof $\bar{Y}$ Yes, yes, there's lots... it's very wordy, very overwhelming. And for like FSL in particular I mentioned this - StafuSNEES before but, the expectations are word for word the same from grade 2. And so NEW Teacler we were actually discussing... I was at an, oh, I forgot to mention this, I was at an FSL PD day for those (PD) who voluntarily signed up, like I voluntarily signed up for it, for new teachers. I'm part of a program Voluntary called NTIP. It's the new teacher induction program. And so it was for FSL teachers and we were talking about how it would almost be nicer if the curriculum was laid out like: okay here is the expectation, which is verbatim written the same way, either way, for every age. And then just saying: for grade one Exampls here's an example of what you could do. Grade two, an example grade three, an example, instead of by grade using all those pages to write the same thing over and over again.

Yeah, it's really good. I think t's a provincially recognized program, like NTIP, but they send out emails Program every month and we'll have a list of PD events that you can attend and so the board covers it, you get a PPO T supply teacher to come in for you while you go. It's a good program so far from what I've gotten. Once you gef permanent you get a lot more release days. So like I have two release days between $\mathrm{m}$ and my mentor, so basically like one day each kind of thing. Whereas permanent I think get five, between the two of them. So, who told you about NTIP? Was it just starting at your job?
Well, I knew from my placement at
come in every once in a while. And so 1 knew her through that, and I ran into her at the beginning of the
year this year and when she saw that I had an LTO she said hey just send me an email and we'll put you
into this program. And so that was pretty much how. It's just because of the people I knew and the
connections I made beforehand in the board as well. Otherwise, I don't know that I would have
actually signed up for it or known about it. emails me $5+a+4 \cdot 3=$

For the curriculum document? So they give... basically the FSL curriculums very similar from grade to Curriculair grade. The expectations are pretty... like they're basically verbatim word for word the same thing. Like out comer from grade four to six it's all the same, grade one to three it's pretty much all the same. What does by grade differ is the examples that they give. So they'll give examples of questions that you can ask to back up a examples specific point in the curriculum. So if it's saying you know, students will write... students will learn to write simple texts in a variety of forms. Then it will give examples of questions or types of text that they 


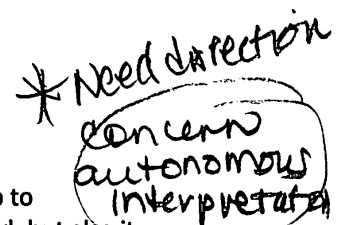

can write, that kind of thing. It's a very broad example, there's no like... It's very much up to

interpuetates interpretation by the teacher, like the teacher can really make it their own. Which is good, but also.it takes away that kind of way to make it uniform, from teacher to teacher, you know, but it is.good because it gives us an ability to be creative with how we want to present it. Participant \#1 ( Kindergarten relies on So in most cases there's a French teacher and an English teacher. And one of the things with the extended day is there's too many points of contact for kids and that leads to behavior because there's always these staff change overs. So that's one of the issues that they have unless... I think part of the reason why they let me do both, even though I'm not super qualified and I refuse to change my contract to 0.5 French because once you're in French, in our board, you'r stuck. Youcan't go back to English because there's a shortage of French teachers. So yeah, so generally speaking they would do one day with the French teacher and one day with their feaching French English teacher, or else half day with their French teacher half day with their English teacher ay aunity but in my class it's always me. I have a prep teacher who teaches in French, and he's slightly prefenence 7 better at teaching French than I am, I would say, but not vastly. But yeah, that's sort of the format.

Well, there's no assessment criteria for French. I can assess anything in the early learning. don't know if you've seen the early learning or the early years that used to be called the kindergarten curriculum, but it's about this thick. It's two years but it's this enormous document with millions of expectations and I can... essentially as far as I can tell I can teach any of them in French, or none of them in French! Well, no, but like $50 \%$ of them but randomly selected I guess so, yeah. It's an interesting situation that I found myself in. Okay. What am I supposed to do?

We had one at the very beginning of this new 50/50 program. I did attend and they showed us a whole bunch of... I think most teachers... it doesn't make sense to me, but most teachers decide they're going to try and do math mostly in French, which is a big disconnect for me because math is now taught in English even in French immersion, it's taught in English. It didn't used to be, it used to be if you're in French immersion, math was in French. If you're going to teach kids to read at our school, our school is a single track school, right so very few of my kids are going on.to.French immersion in grade one. So me teaching them to read in French would not be super productive for them.

The third teacher? Yes, it's huge in kindergarten because everything is play-based now, so really the beginning of the year, we look at the group that we have and you can kind of figure out how your years going to go. And generally at the school that I teach at right now, the kids are not coming from you know, they're not coming from Montessori or Reggio or anything like that the or even preschool or nursery school or daycare. They're just coming from their own family in their own apartment, some of them haven't even really played at the park before.So, basically all $\Gamma$ do is set up play experiences for the first while. So we use the third teacher extensively in my classroom because they just don't have any kind of social skills or self-regulation or prior kng of things like we don't climb on tables like, we don't eat everything, we don't beat concems

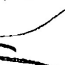
concents struchice iruchice new tenchof - disuplune cusa mavasas Ii,

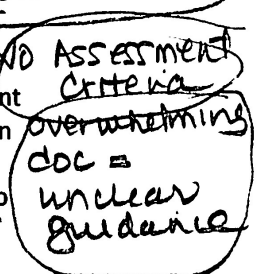
on each other like all of those things are brand new to them. Like that they might have to wait socual $5 \mathrm{~K} / \mathrm{ll}$ for something, like take a turn with something that kind of stuff is all brand new and takes a Self-Megulatich while to teach, so we just put out basically different centers, but we don't even assign the kids. 